\title{
A Modular, Argon-Driven Flow Platform for Natural Product Synthesis and Late-Stage Transformations
}

Merlin Kleoff, Johannes Schwan, Mathias Christmann,* and Philipp Heretsch*

Freie Universität Berlin, Institut für Chemie und Biochemie, Takustraße 3, 14195 Berlin, Germany

\section{Supporting Information}

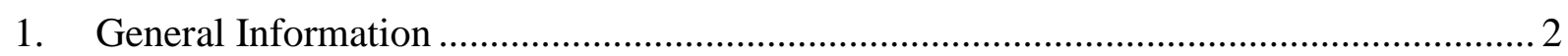

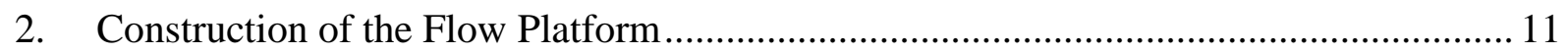

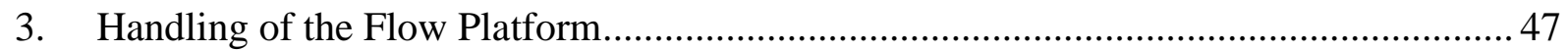

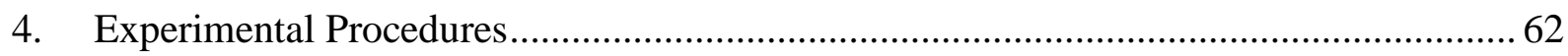

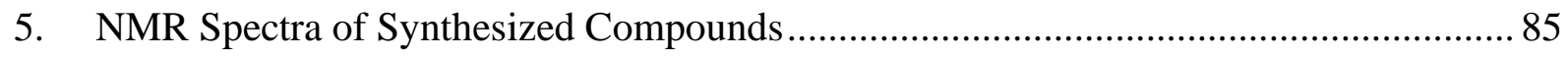

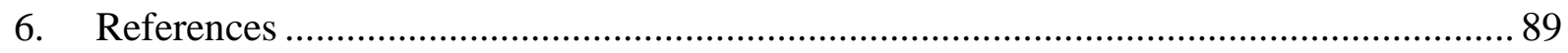




\section{General Information}

\subsection{Materials and Methods}

Unless otherwise noted, all reactions and workups were performed open to air. All compounds sensitive to water and oxygen were handled under an argon atmosphere using standard Schlenk techniques and oil pump vacuum. Room temperature (rt) refers to $23{ }^{\circ} \mathrm{C}$.

Anhydrous THF was distilled under an atmosphere of argon over sodium/benzophenone and stored over activated $3 \AA$ mol sieves. Anhydrous MeCN was obtained from ACROS and stored over $3 \AA$ mol sieves.

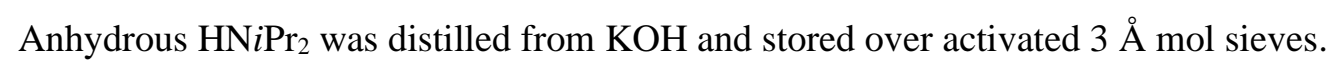

EtOAc, $\mathrm{Et}_{2} \mathrm{O}, n$-pentane, and $n$-hexane were purified by distillation on a rotary evaporator. All other solvents and commercially available reagents were used without further purification unless otherwise stated.

$3 \AA$ mol sieves were activated by drying in an oven at $250^{\circ} \mathrm{C}$ and $10^{-3} \mathrm{mbar}$ for $2-3 \mathrm{~h}$.

Medium pressure liquid chromatography (MPLC) was performed with a TELEDYNE ISCO CombiFlash Rf or a TELEDYNE ISCO Combi-Flash Rf200 using prepacked $\mathrm{SiO}_{2}$ columns and cartridges from TELEDYNE. UV response was monitored at $254 \mathrm{~nm}$ and $280 \mathrm{~nm}$. As eluents, cyclohexane $(99.5 \%+$ quality) and EtOAc (HPLC grade) were used.

For column chromatography, silica $60 \mathrm{M}(0.040-0.063 \mathrm{~mm})$ from MACHERY-NAGEL was used. Concentration under reduced pressure was performed by rotary evaporation at $40{ }^{\circ} \mathrm{C}$ and the appropriate pressure.

The following compounds were prepared according to the literature: $\mathbf{4},{ }^{[1]} \mathbf{5},{ }^{[1]} \mathbf{7},{ }^{[2]}\left[\mathrm{nBu}_{4} \mathrm{~N}\right]_{4}\left[\mathrm{~W}_{10} \mathrm{O}_{32}\right],{ }^{[3]}$ S5, ${ }^{[4]} \mathbf{1 1}{ }^{[4]}$

A zip file including 3D-printing files (.stl files, necessary to print the 3D-printed parts), LabVIEW software (.vi file) and Arduino code (.ino file, both necessary to control the flow platform) can be obtained from the corresponding author (philipp.heretsch@fu-berlin.de) upon request. 


\subsection{Analysis}

Reaction monitoring: Reactions were monitored by TLC carried out on Merck Silica Gel $50 \mathrm{~F}_{254}$ plates and visualized by fluorescence quenching under UV light $(\lambda=254 \mathrm{~nm})$ or by using a stain of vanillin (6 g vanillin, $1.5 \mathrm{~mL} 96 \%$ aq. $\mathrm{H}_{2} \mathrm{SO}_{4}, 100 \mathrm{~mL} \mathrm{EtOH}$ ) and heat as developing agent.

NMR spectroscopy: All NMR spectra were acquired on a JEOL ECP 500 (500 MHz), a Bruker Avance $500(500 \mathrm{MHz})$, a Varian INOVA $600(600 \mathrm{MHz})$, or a Bruker Avance $700(700 \mathrm{MHz})$ in the reported deuterated solvents. Chemical shifts are reported in parts per million (ppm) with reference to the residual solvent peaks. The given multiplicities are phenomenological, thus, the actual appearance of the signals is stated and not the theoretically expected one. The following abbreviations were used to designate multiplicities: $\mathrm{s}=$ singlet, $\mathrm{d}=$ doublet, $\mathrm{t}=$ triplet, $\mathrm{q}=$ quartet, quint $=$ quintet. In case no multiplicity could be identified, the chemical shift range of the signal is given $(\mathrm{m}=$ multiplet $)$.

Karl-Fischer titration: Karl-Fischer titrations were performed using a METLER TOLEDO DL312 Karl-Fischer Coulometer. 


\subsection{Flow Equipment and Hardware}

All flow experiments were carried out using the following equipment:

\section{Flow equipment}

\begin{tabular}{|l|l|}
\hline Material & Provider \\
\hline FEP tube (outer diameter 1/16”, inner diameter 1/32”) & BOLA \\
\hline PTFE tube (outer diameter 1/16”, inner diameter 1.0 mm) & BOLA \\
\hline PTFE tube (outer diameter 1/8”, inner diameter 1/16”) & BOLA \\
\hline T-mixers (stainless steel 316L) & VICI \\
\hline Coned 10-32 UNF fittings (stainless steel 316L) & UPCHURCH SCIENTIFIC \\
\hline Flat bottom 1/4-28 UNF gripper fittings (PP) & DIBAFIT \\
\hline Adapters for 1/4-28 UNF (PP or PTFE) & UPCHURCH SCIENTIFIC \\
\hline Manual 6-way-valves (stainless steel 316L) & KNAUER \\
\hline Low pressure valves (4-port T-configuration, PTFE/PCTFE) & OMNIFIT (DIBA) \\
\hline Low pressure valves (5-port 5 positions, PTFE/PCTFE) & OMNIFIT (DIBA) \\
\hline Gastight glass syringe & VWR \\
\hline Adjustable back pressure regulator & ZAIPUT \\
\hline
\end{tabular}

\section{Electronics}

All kind of tools (pliers, screwdrivers, soldering bolts, saw, etc.) were obtained from BAUHAUS.

\begin{tabular}{|c|c|}
\hline Material & Provider \\
\hline $\begin{array}{l}\text { Pressure sensor Walfront3crb1gv75x, 0-12 bar, 0.5-4.5 V VDC, } \\
\text { G1 }\end{array}$ & WALFRONT \\
\hline Shrinking tube in different sizes & CHILITEC \\
\hline Threading tap for $1 / 4-28 \mathrm{UNF}$ & GSR PROFI \\
\hline M2-M5 Screws, flat washers, and nuts (stainless steel) & BAUHAUS \\
\hline $60 \mathrm{~mm} P C$ fan & NOISEBLOCKER \\
\hline 140 mm PC fan Arctic F14 & ARCTIC \\
\hline Linear guide $8 \mathrm{~mm} \times 500 \mathrm{~mm}$ & ROBOMALL \\
\hline Linear bearing LM8UU & UEETEK \\
\hline M8 threaded bolt & BAUHAUS \\
\hline Perforated plate $500 \times 250 \times 1.5 \mathrm{~mm}$ (anodized aluminum) & BAUHAUS \\
\hline Aluminum rod (outer diameter $=6 \mathrm{~mm}$, inner diameter $=4 \mathrm{~mm})$ & BAUHAUS \\
\hline Flexible shaft coupling ( $5 \mathrm{~mm}$ to $8 \mathrm{~mm}$ ) & UEETEK \\
\hline
\end{tabular}




\begin{tabular}{|l|l|}
\hline Luster terminal & KOPP \\
\hline Circuit board $40 x 60 \mathrm{~mm}$ & VKTECH \\
\hline 4-Pin wire & FOXNOVO \\
\hline 1-Pin wires & CONRAD ELECTRONICS \\
\hline Resistors & CONRAD ELECTRONICS \\
\hline 4 channel fan controller $12 \mathrm{~V}$ & RICHER-R \\
\hline Coaxial power supply & WENTRONIC \\
\hline Power adapter $1000 \mathrm{~mA}$ Goobay 59031 & GOOBAY \\
\hline Nema stepper motors $(12 \mathrm{~V}, 1.7 \mathrm{~A}, 40 \mathrm{Ncm})$ & TOPDIRECT \\
\hline $\begin{array}{l}\text { Arduino Uno R3 }+\mathrm{CNC} \text { engraver shield }+4 \text { A4988 stepper } \\
\text { drivers }\end{array}$ & KUMAN \\
\hline Cable Conduit $5 \mathrm{~m}$ & CALLSTEL \\
\hline $140 \mathrm{~mm}$ Fan Grill & AAB Cooling \\
\hline LED stripe (12 V, LED $2835,385-400 \mathrm{~nm})$ & DEEPDREAM \\
\hline LED stripe (24 V, LED 2835, 365 nm) & LUXALIGHT \\
\hline
\end{tabular}

\section{D-Printing}

In general, 3D-printing was performed with a Creality CR-10 Prusa using PLA as filament at $200{ }^{\circ} \mathrm{C} / 65^{\circ} \mathrm{C}$ (extruder/heat bed) on a glass bed sprayed with a fine layer of hair spray. PLA filament was stored in a "dry box" containing silica gel orange as desiccant. A zip file including 3D-printing files (.stl files) can be obtained from the corresponding author (philipp.heretsch@fu-berlin.de) upon request.

\begin{tabular}{|l|l|}
\hline Material & Provider \\
\hline 3D-printer Creality CR10-S & CREALITY \\
\hline Hair spray today Glanz\&Halt & PENNY MARKT \\
\hline PLA filament & AMZ3D \\
\hline
\end{tabular}

\section{D-printed files}

A list of the 3D printed files and the respective infill used.

\begin{tabular}{|l|l|}
\hline 3D-file (.stl) & Infill \\
\hline ArduinoCase_Backplate & $25 \%$ \\
\hline ArduinoCase_Case & $25 \%$ \\
\hline ArduinoCase_CoverTop & $25 \%$ \\
\hline Connector_tube_to_UNF14-28 & $100 \%$ \\
\hline
\end{tabular}




\begin{tabular}{|l|l|}
\hline FlexValves_Mounts & $50 \%$ \\
\hline FlexValves_Clips & $100 \%$ \\
\hline FlexValves_Sledge_HPLC_valves & $25 \%$ \\
\hline FlexValves_Sledge_LP_valves & $25 \%$ \\
\hline MFC_Mount & $40 \%$ \\
\hline Photoreactor_Body & $50 \%$ \\
\hline Photoreactor_Body2 & $50 \%$ \\
\hline Photoreactor_Ground & $50 \%$ \\
\hline Photoreactor_TubeReactor & $50 \%$ \\
\hline Photoreactor_Curve & $50 \%$ \\
\hline SyringePump_Body & $50 \%$ \\
\hline SyringePump_Sledge & $50 \%$ \\
\hline
\end{tabular}

(Selected) Specifications of the used mass flow controllers (MFCs)

Bronkhorst EL-FLOW Prestige

$\mathrm{V}_{\text {flow }}={ }^{\circ} 0.076 \ldots 10 \mathrm{~mL} / \mathrm{min}( \pm 0.5 \%$ onset scale, $\pm 0.1 \%$ full scale $)$

Medium: Argon

Operating temperature: $20^{\circ} \mathrm{C}$

Operating pressure (in): $30 \mathrm{bar}$

Operating pressure (out): 0 bar

Sealing: Viton 51415

Plunger: FFKM

Process fittings: G1/8 female 


\subsection{General Remarks and Advices for Performing Experiments}

\section{Tubes}

Tubes for flow chemistry are typically made from PTFE, PFA, or FEP. All polymers show excellent chemical resistance. In fact, there are slight differences (PTFE is chemically more resistant than FEP or PFA), however, these differences are not significant for most reactions in flow. Typically, $1 / 16$ " tubes of PTFE have an inner diameter of $1.0 \mathrm{~mm}$; tubes of FEP have an inner diameter of $0.8 \mathrm{~mm}$, PFA have an inner diameter of $0.75 \mathrm{~mm}$. In order to reduce dead volume between wetted parts, tubes with smaller inner diameter are preferable.

PTFE is a relatively stiff polymer that is easy to cut. FEP and PFA are more flexible making it more difficult to equip them with ferrules. On the other hand, they have the large advantage to be more permeable to light. Therefore, impurities (primarily solids!) are easier to detect. Because of their superior translucence and their smaller inner diameter, we use typically FEP tubes.

For additional tips about assembling a flow system, see the literature. ${ }^{[5]}$

\section{Blockages}

Blockages are a big problem when performing flow chemistry. In general, the undesired formation of solids in tubes, valves, and connectors should be avoided. Especially, when moisture-sensitive organometallics are used, problems can arise. After passing a solution of organolithiums or organomagnesiums through a flow system, it is problematic to wash the system with water afterwards. In our experience, it is better to wash the system first one time (= volume of the sample loop; otherwise 1-2 mL) with iso-propanol, then with deionized water and finally two more times with iso-propanol to remove the water.

A good way to remove blockages is to wash the system with a solution of $\mathrm{AcOH} / \mathrm{MeOH} / \mathrm{H}_{2} \mathrm{O}(0.1: 1: 1)$ as recommended by Williams et al. ${ }^{[6]}$ If this does not work, tubes and connectors can be sonicated in a bath of deionized water, iso-propanol for some minutes removing most of the solids.

To prevent blockages, only clear solutions of the reagents should be pumped in flow. Even small particles can lead to blockages. When possible, reagent solutions should be filtered through a plug of glass wool or using syringe filters.

\section{Treatment of parts made from stainless steel 316L}

Many parts that are used in HPLC and flow chemistry are made from stainless steel 316L. Although this steel shows broad chemical resistance, it is relatively sensitive against acids and, especially, chlorides. In general, components made from stainless steel $316 \mathrm{~L}$ should never be treated with hydrochloric acid. If diluted solutions of chloride in organic solvents (such as magnesium chloride, when Grignard reactions are performed), or of compounds that can generate hydrochloric acid (such as titanium 
tetrachloride) come in contact with components made from stainless steel $316 \mathrm{~L}$, it is recommended to wash these components as soon as possible with iso-propanol, deionized water and one more time with iso-propanol in order to prevent salt formation and corrosion.

\section{Keeping the flow system in "stand-by" for longer times}

After each flow experiment, all wetted parts should be washed thoroughly with an appropriate solvent. In most cases, iso-propanol can be used, as it dissolves both organic and inorganic residues and most polymers (even PLA) are chemically resistant against iso-propanol.

In the case, the flow platform is not used for several weeks, all wetted parts should be flushed with isopropanol and stored with iso-propanol for the "stand-by" time. Equally recommendable are ethanol or acetonitrile instead of iso-propanol. However, prolonged contact of wetted parts with solvents such as tetrahydrofuran or dichloromethane should be avoided.

When tubes, mixers, or other wetted components are not used for a foreseeable time, they should be thoroughly flushed with iso-propanol. In order to dry these components, they can be stored in a drying cabinet at $50-90{ }^{\circ} \mathrm{C}$ also for longer time.

\section{D-Printing of wetted parts from polypropylene}

3D-Printed components for chemical reactions are typically printed from polypropylene. Polypropylene shows a higher chemical resistance than PLA (polylactic acid) or PETG (polyethylene terephthalate, glycol-modified), but cannot compete with fluorinated polymers such as PTFE, FEP, or PFA. Hence, it has to be noted that these printed components are not suitable for a broad range of chemical reactions. Due to good, but still limited chemical resistance of polypropylene, typical solvents such as diethyl ether, tetrahydrofuran, dichloromethane, or 1,2-dichloroethane are not recommended. ${ }^{[7]}$

We performed a test concerning the chemical resistance of a polypropylene filament (3dkTop kindly provided by $3 \mathrm{dk}$. berlin):

The filament $(10.0 \mathrm{~g})$ was cut in $2-5 \mathrm{~mm}$ parts. The parts were transferred in a flask equipped with a reflux condenser and treated with $\mathrm{THF}(50 \mathrm{~mL})$ at $65^{\circ} \mathrm{C}$ for $3 \mathrm{~h}$. After some minutes, the polymer started to swell. After $1 \mathrm{~h}$, most of the THF was absorbed by the filament. On the walls of the flask, colorless gel deposited. 


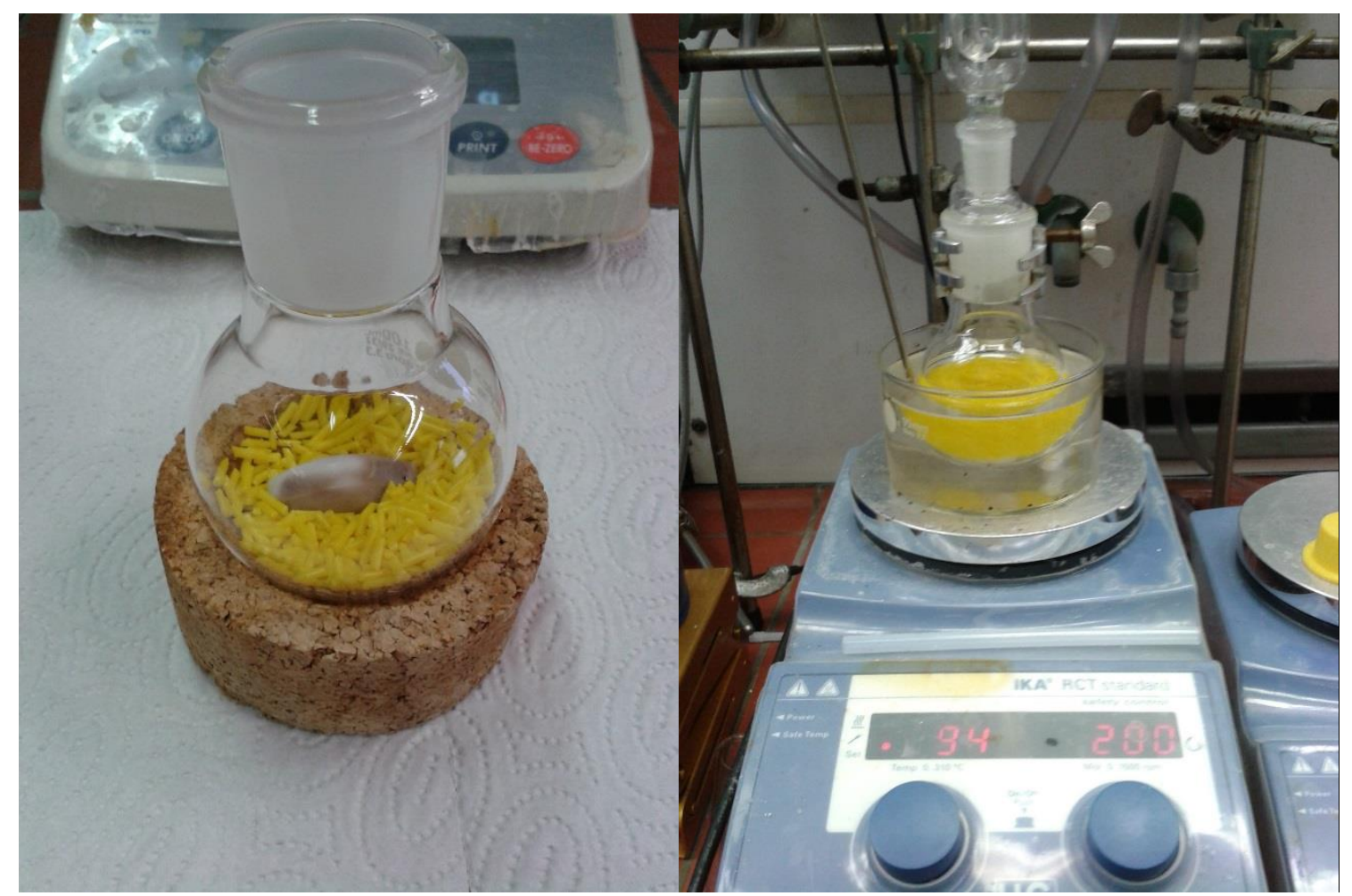

Left: The cut filament before treatment with THF. Right: Boiling the filament in THF.

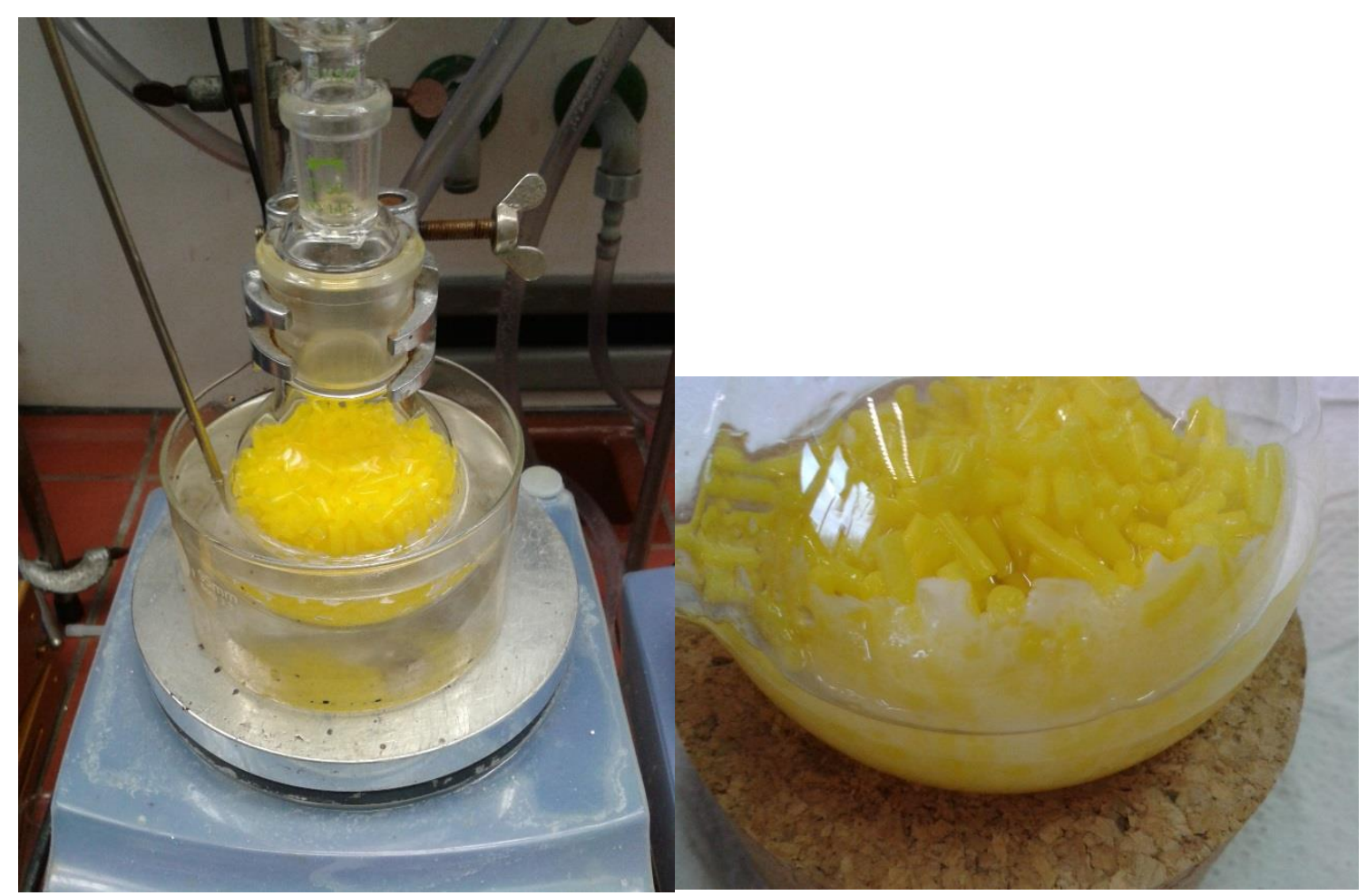

Left: After $1 \mathrm{~h}$, swelling of the filament was observed. Right: Colorless gel deposited on the walls of the flask after cooling to room temperature.

After these experiments, we stopped our efforts to employ 3D-printed components as reactors. 
Unfortunately, printing of chemically more resistant polymers (PEEK, FEP, PFA) is challenging (for PTFE, it is not possible) ${ }^{[8]}$ In the case that specially designed components offering a high chemical resistance are required, we recommend to order these components from professional 3D-printers, either made from stainless steel 316L, or titanium (both metals can be printed). 


\section{Construction of the Flow Platform}

\subsection{Hardware}

For a list of used materials, see 1.3.

\section{Cutting of tubes and equipping tubes with ferrules and connectors}

Introduction of tubes (1/16“ outer diameter) through a septum.

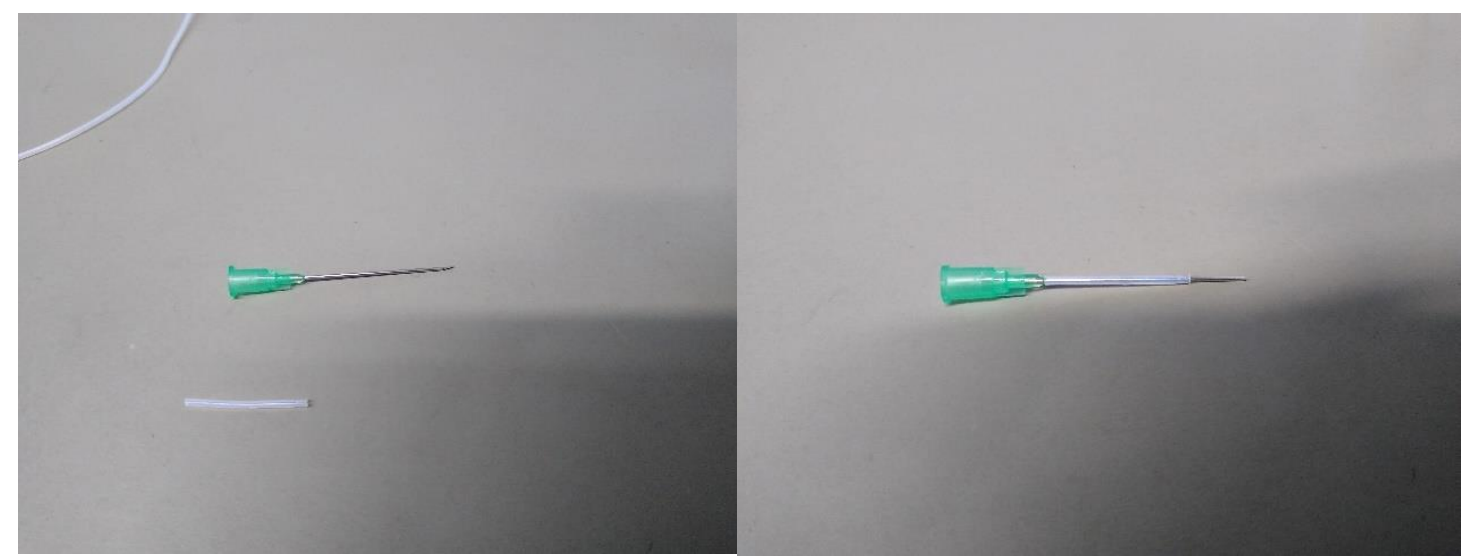

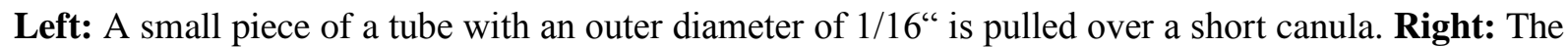
canula equipped with the tube.

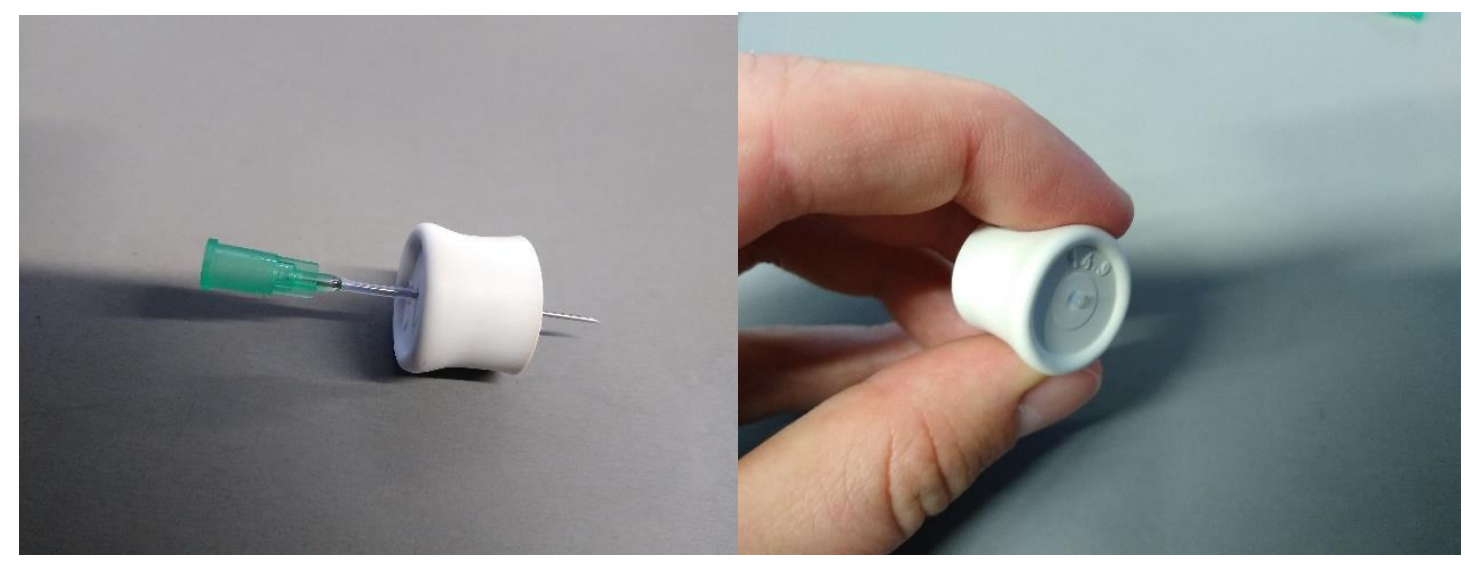

Left: The equipped canula is pierced through the septum. Right: The canula is removed, while the tube remains in the septum. 


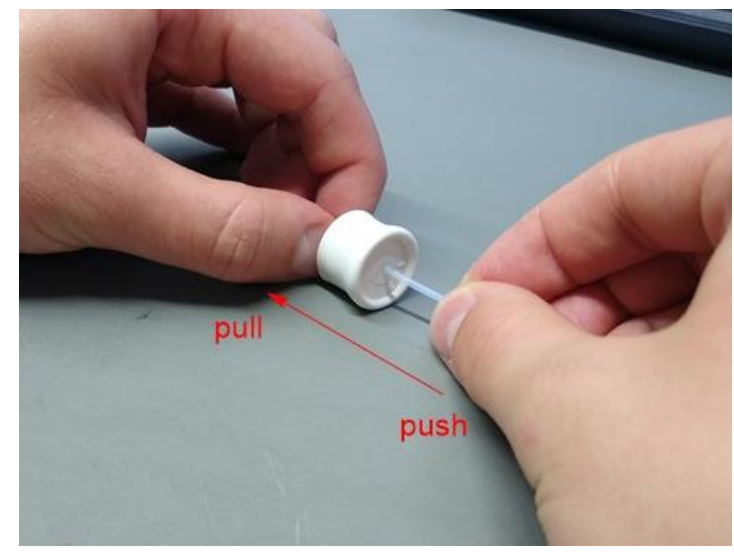

The tube to be introduced to the septum is pushed directly on the end of the pulled tube piece.

Fittings and ferrules:

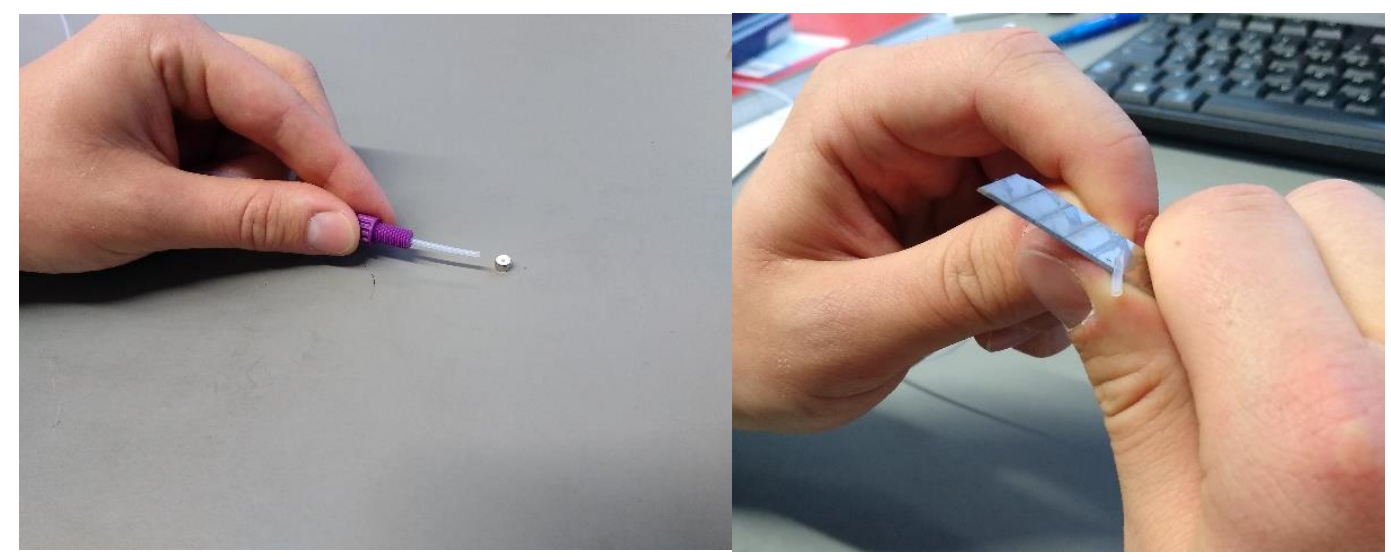

Left: The tube (outer diameter 1/16") is equipped with a fitting (flat bottom $1 / 4-28$ UNF gripper fitting).

Right: The end of the tube is carefully cut in a slight angle.

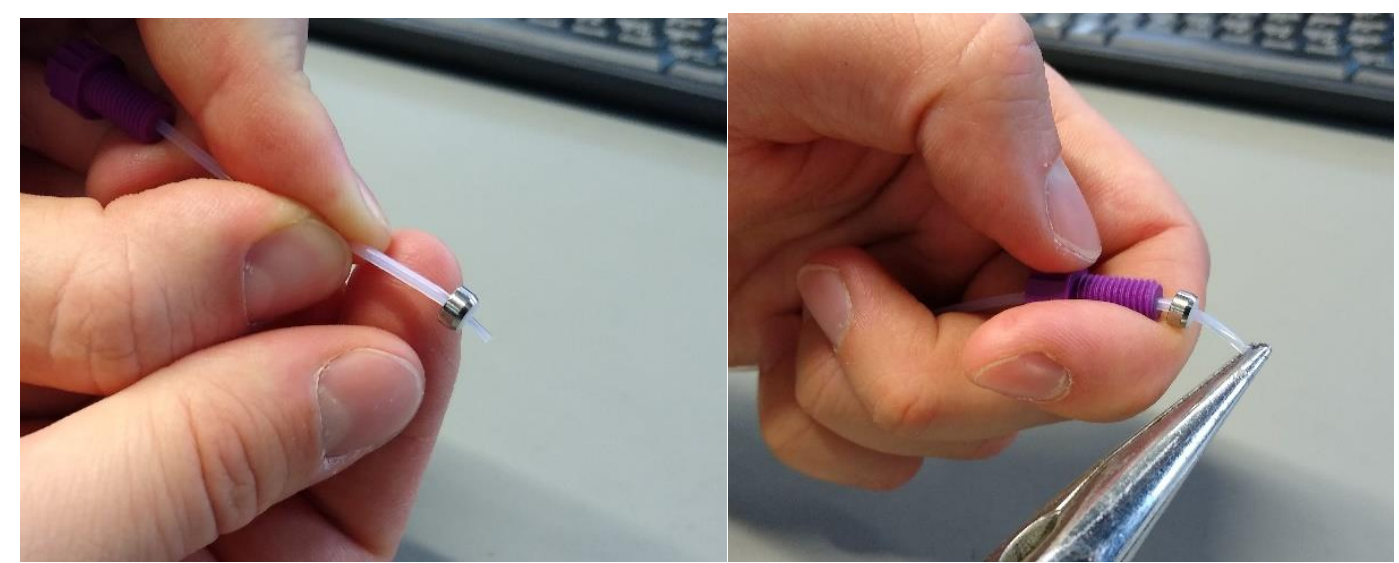

Left: The ferrule is pulled on the tube. Right: The ferrule is further pulled on the tube by using a longnose pliers. 


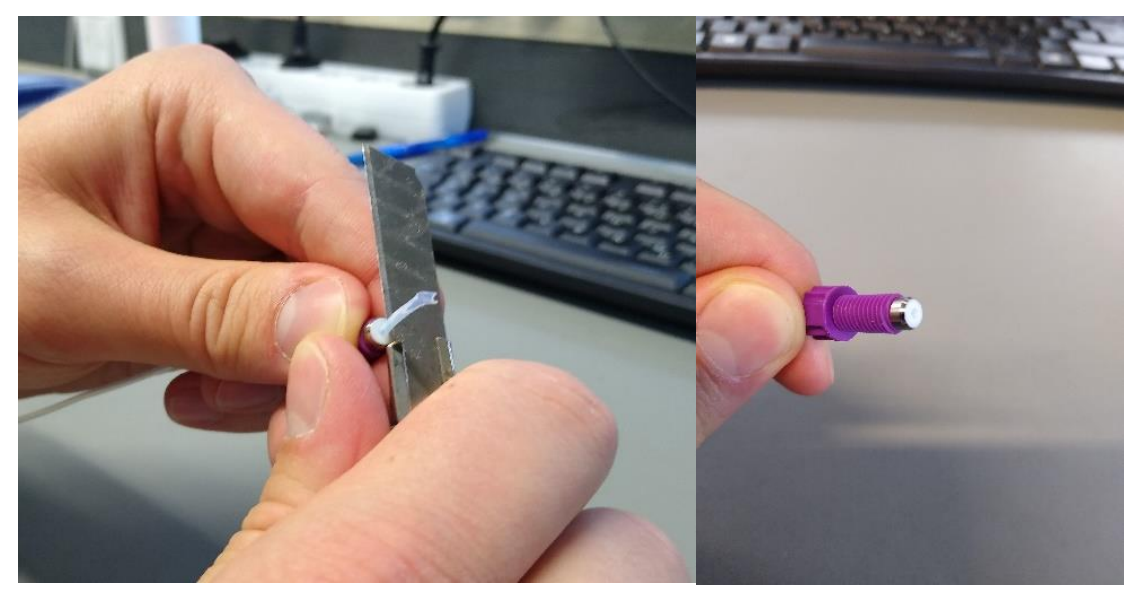

Left: The overhanging tube is cut to provide a plane surface on the end of the ferrule. Right: The tube equipped with fitting and ferrule.

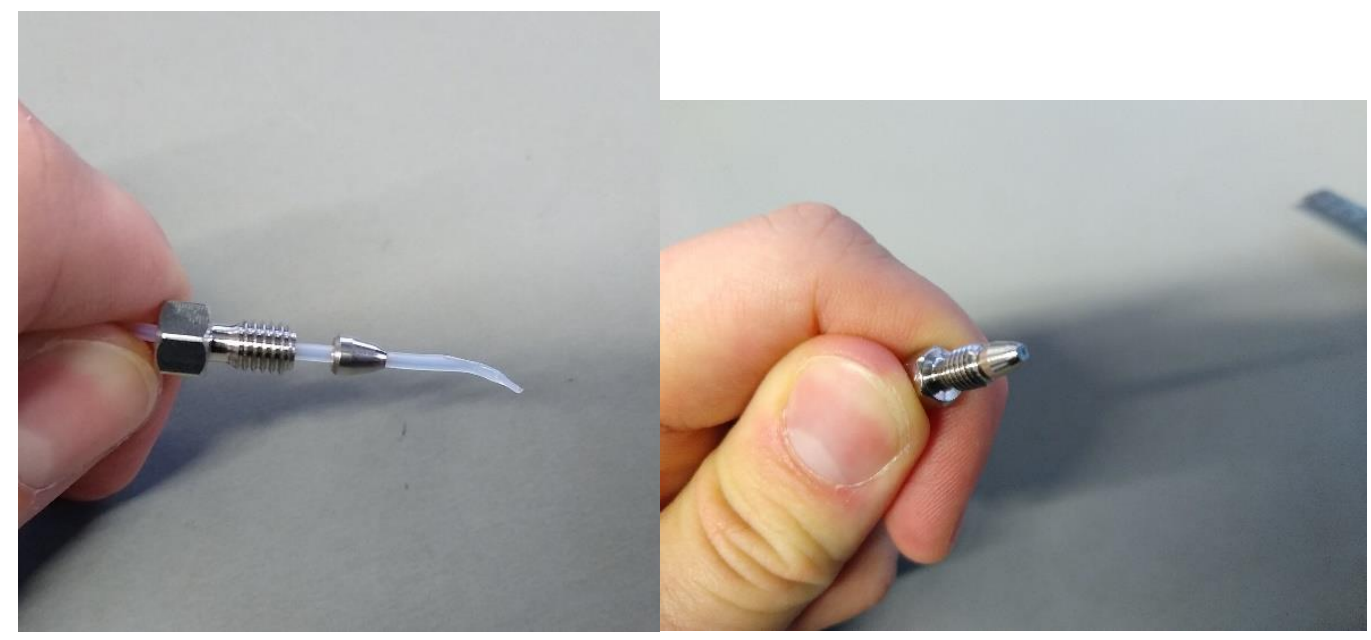

Left: In the same way, tubes (outer diameter 1/16") are equipped with HPLC fittings (10-32 UNF fitting) and conical ferrules Right: A tube equipped with fitting and ferrule. 


\section{Assembly of the controller board}

The controller board consists of valves arranged on a commercially available perforated plate made from anodized aluminum. The plate has a size of 500x250x1.5 mm and screwing holes with an inner diameter of $4 \mathrm{~mm}$ suitable for M4 screws and are assembled in a distance of $15 \mathrm{~mm}$ from center to center.

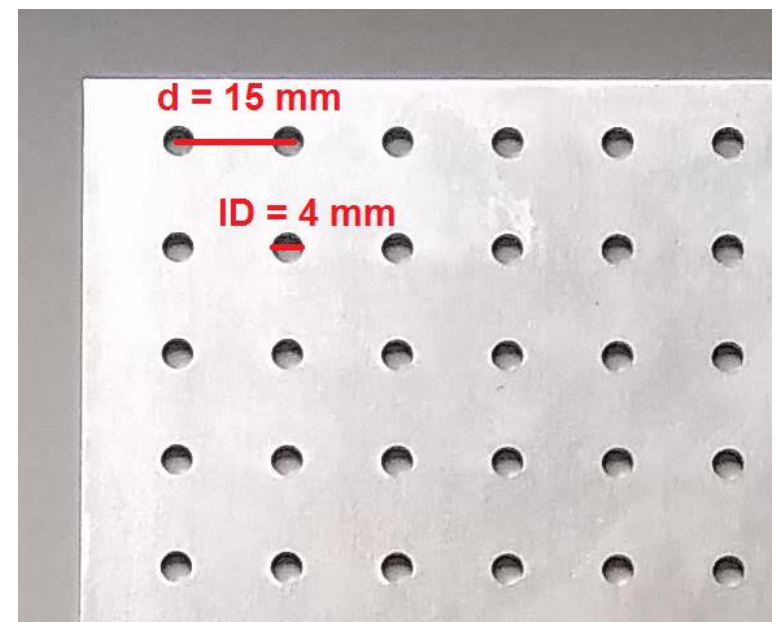

The perforated plate with an internal distance between each screwing hole of $15 \mathrm{~mm}$ and holes with an internal diameter of $4 \mathrm{~mm}$ for M4 screws. 


\section{Mounting of the controller board in a fume hood}

The controller board can be mounted in a fume hood using stands and cross sleeves. To do so, four holders were installed on the edges of each perforated plate. A holder consists of a M4x80 countersunk screw made from nickel plated brass, three M4 flat washers made from stainless steel, one M4 nut and a rod (outer diameter $=6 \mathrm{~mm}$, inner diameter $=4 \mathrm{~mm}$ ) made from anodized aluminum to armor the screw of the countersunk screw.

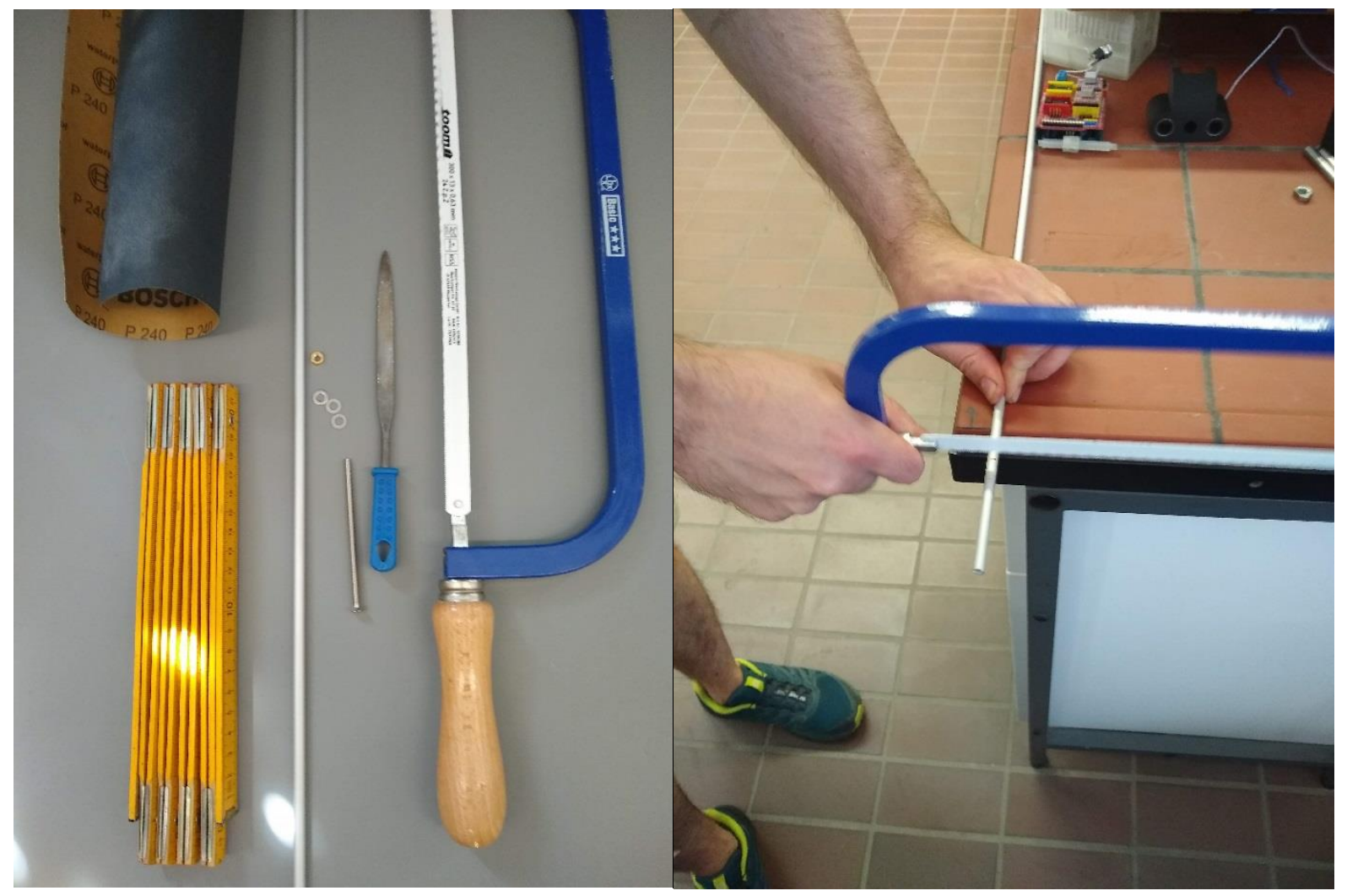

Left: Assembly of all material and tools used for the holders of the controller board. Right: Shortening of the aluminum rod with a jab saw.

The aluminum rod was shortened to four small rods with a length of approximately $65 \mathrm{~mm}$ using a jab saw. Afterwards, the ends of each rod were filed with a metal file and polished using sand paper. The ends of the rod should have a plane and smooth surface. This is important to allow direct contact between the rod and the flat washers. 


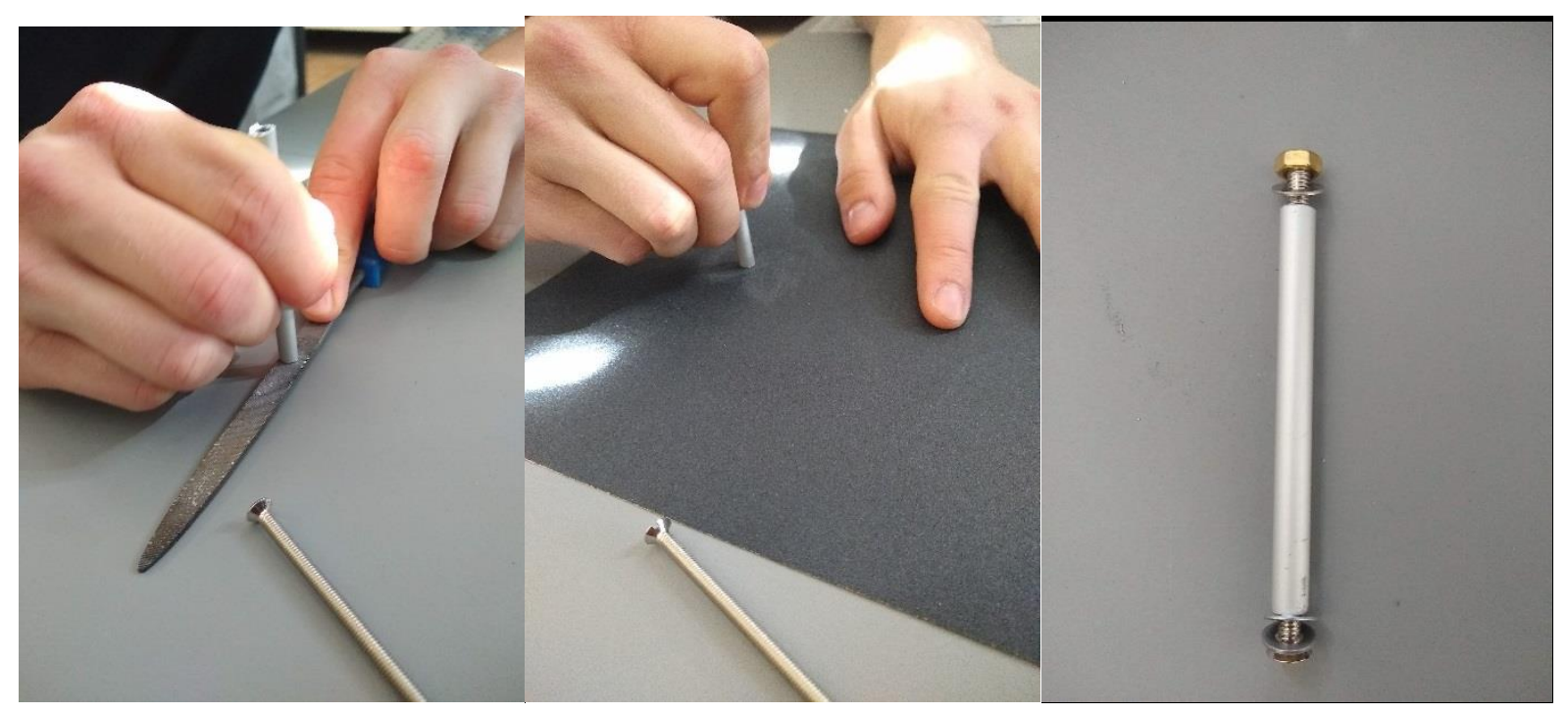

Left: Each aluminum rod was filed... Center: ....and subsequently polished. Right: Assembly of the countersunk screw, the rod, the flat washers, and the nut. The perforated plate will be mounted between the two flat washers (bottom).

Then, the holder is mounted on the perforated plate. First, the countersunk screw is equipped with one flat washer. Then, the countersunk screw is introduced through the perforated plat and the second flat washer is put on the other side to hold the perforated plate between the flat washers. The screw of the countersunk screw is covered with the aluminum rod. On the end of the screw, the third flat washer is placed, followed by the M4 brass nut to tighten the holder on the board.

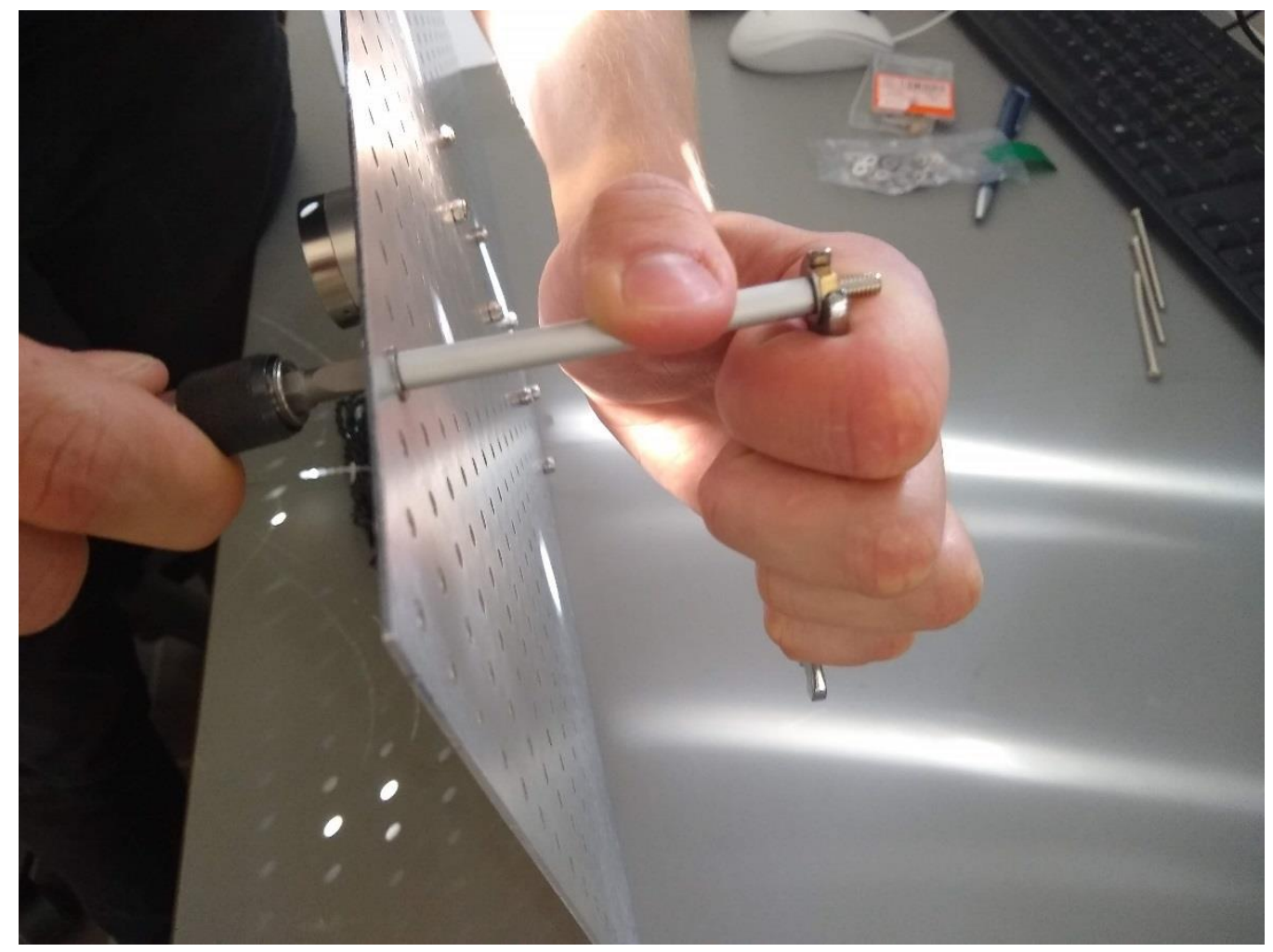

Tightening of the holders on the perforated plate. 
The board equipped with the four holders is then placed in a fume hood using cross sleeves. It is important to apply mechanical pressure only on the part of the holders that are covered by the aluminum rod.

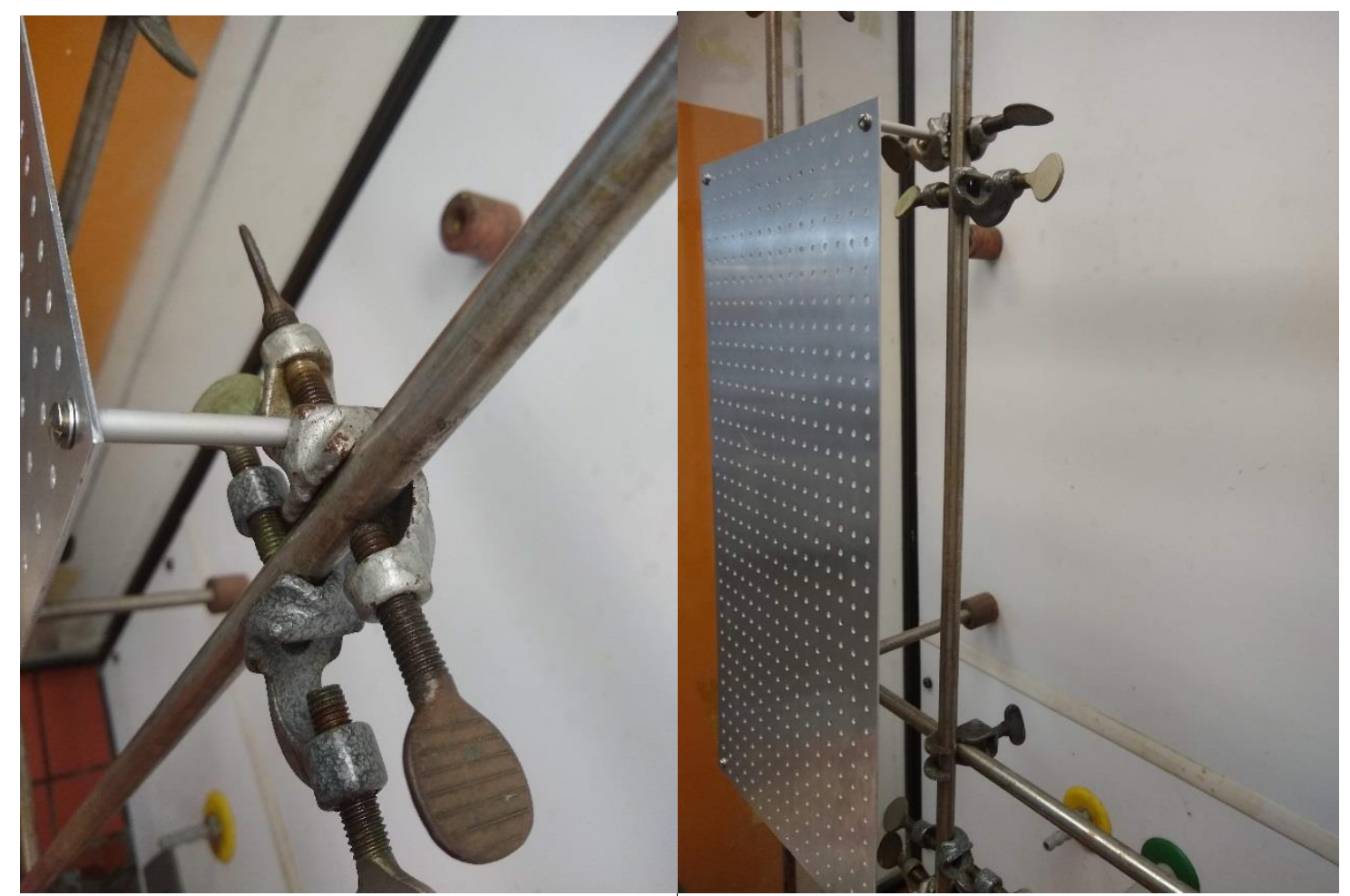

Left: Mounting of the controller board in a fume hood using cross sleeves to secure the holders. Right: The controller board connected on four points to the stand of a fume hood. 


\section{Assembly of the photoreactor}

A self-made photoreactor was constructed from 3D-printed parts (white PLA, 25\% infill), a $140 \mathrm{~mm}$ computer fan, a LED stripe (12 V, LED 2835, 385-400 nm) and FEP tube (outer diameter 1/16", inner diameter 1/32"). The $140 \mathrm{~mm}$ fan is used to cool both the LEDs and the reaction mixture in the FEP tube and is powered by a universal power supply.

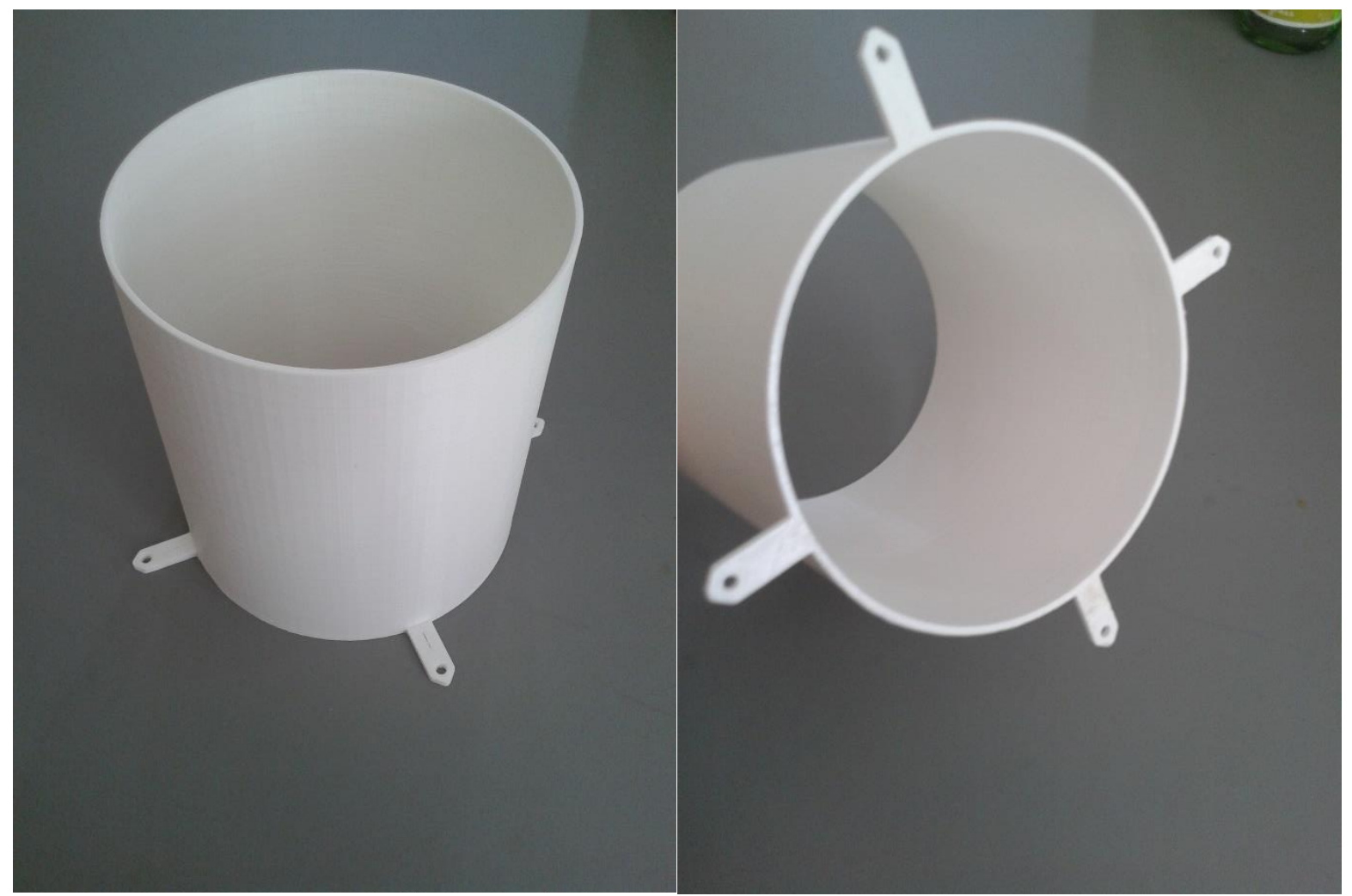

Left: The body of the photoreactor printed from white PLA. Right: The bottom of the body.

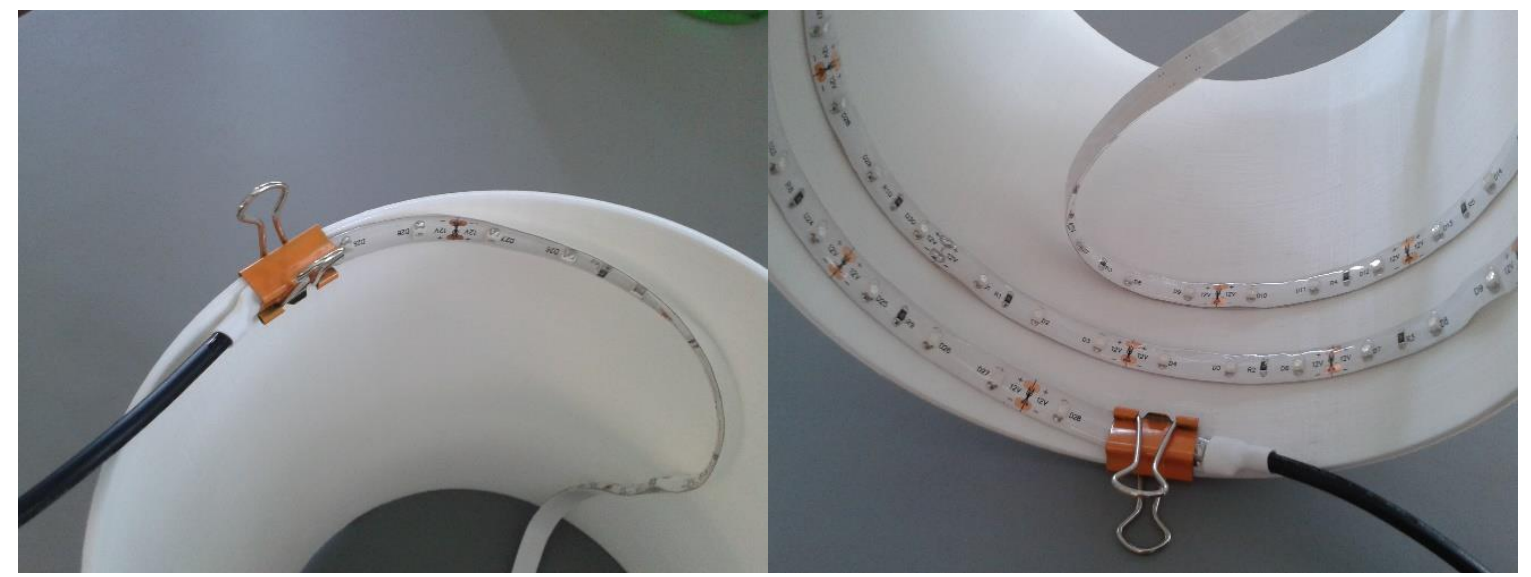

Left: The LED stripe is secured with a clip on the top of the body of the photoreactor. Right: The LED stripe is coiled inside of the body. 


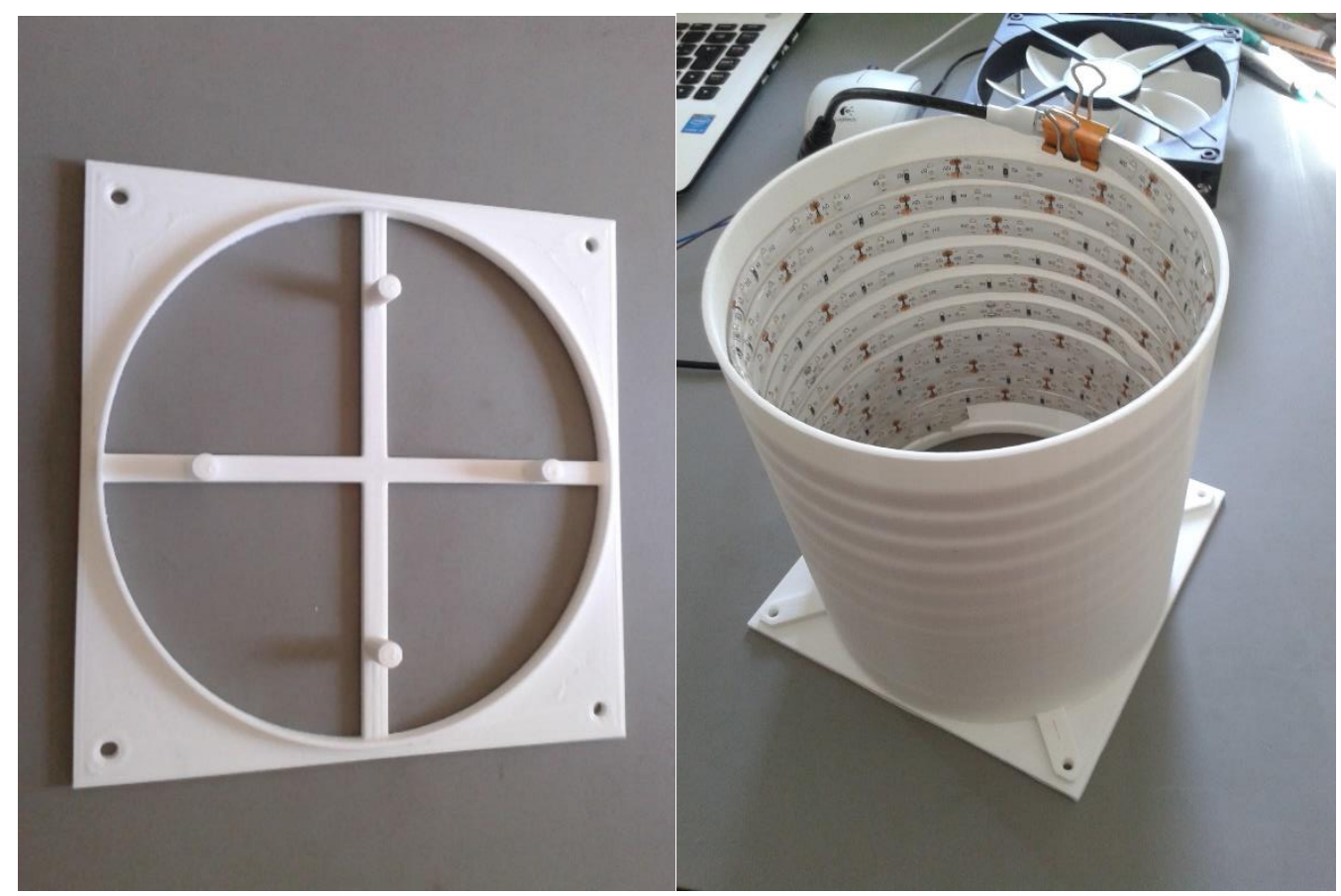

Left: The bottom plate of the photoreactor printed from white PLA. Right: The body of the photoreactor is placed on the bottom plate.

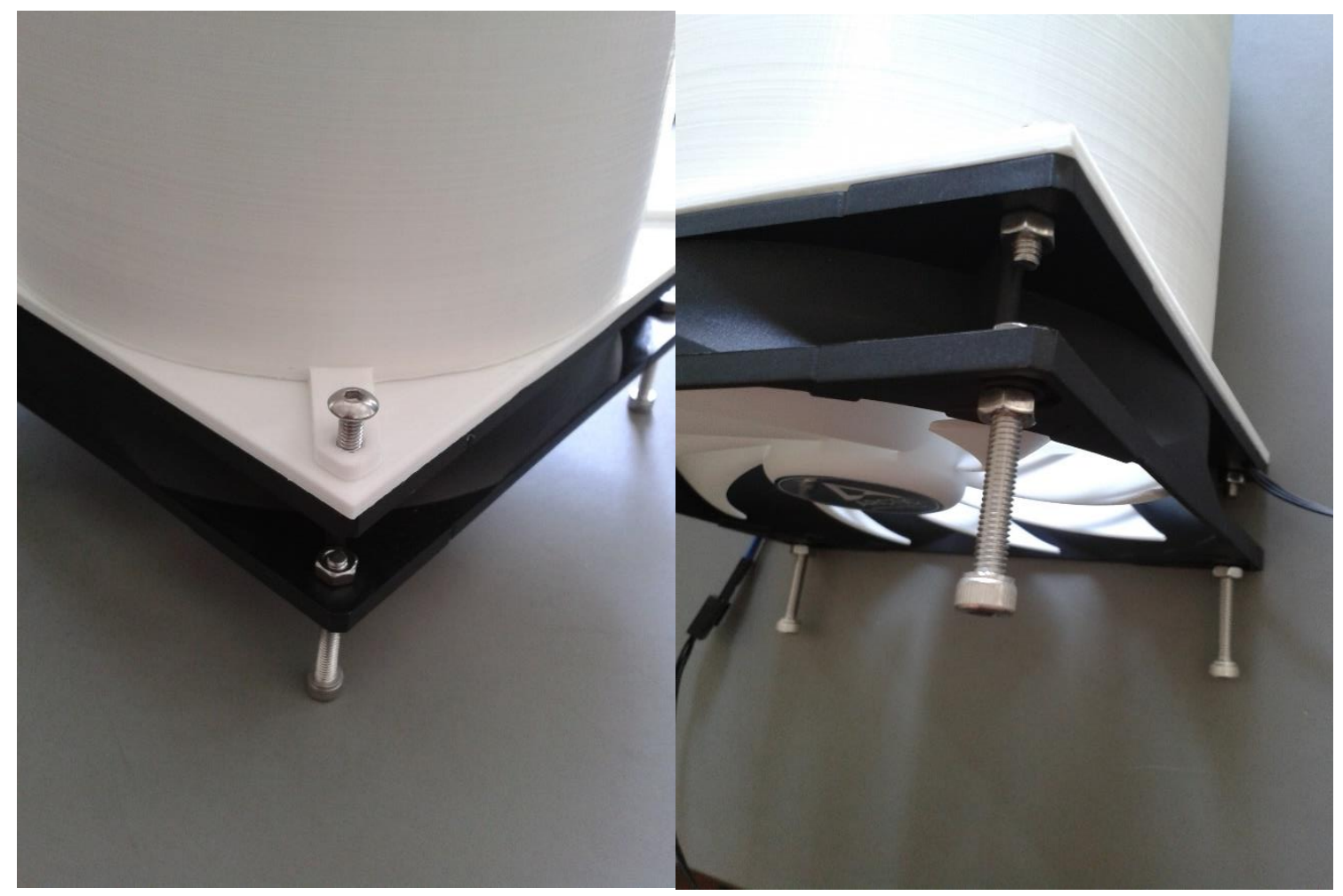

Left: The bottom plate and the fan are connected with a M4x16 screw. Right: The fan is equipped with a M4x30 screw. These screws serve as "foots" for the photoreactor to allow a proper air stream for the fan. 


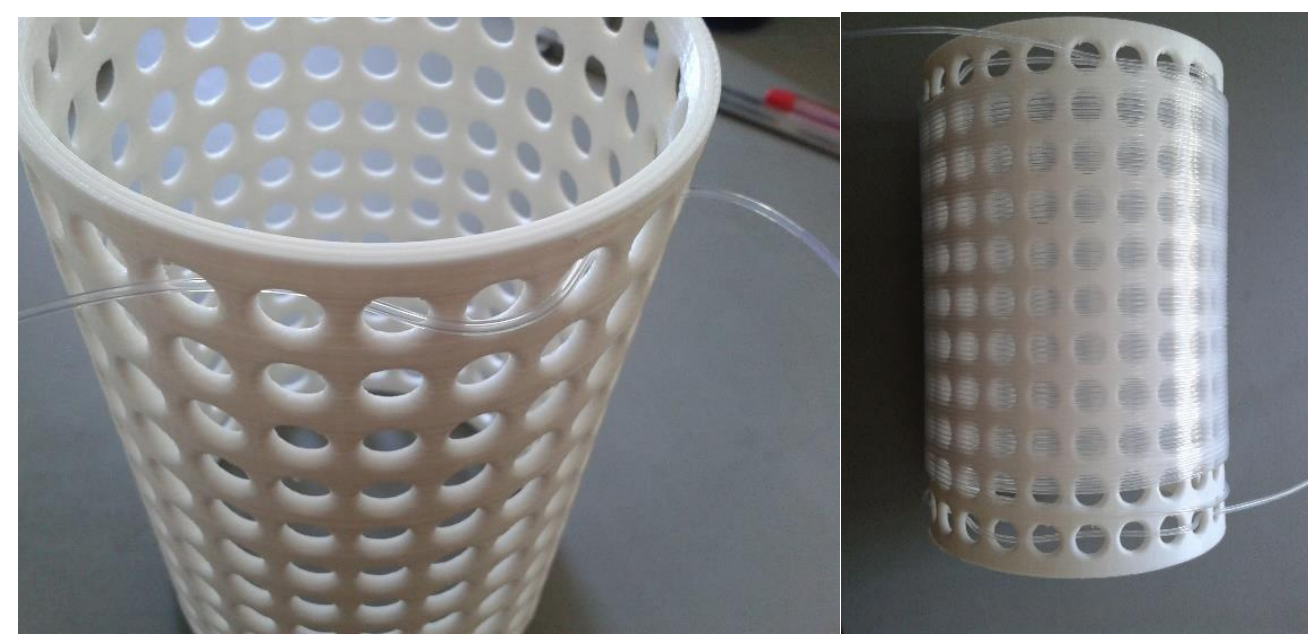

Left: The tube cage is equipped with FEP tube of the appropriate length. To secure the tube, it is threaded through some holes of the tube cage. When the tube is secured, the remaining tube is winded up on the tube cage. Right: The tube-cage equipped with $24 \mathrm{~m}(\mathrm{~V}=12 \mathrm{~mL})$ FEP tube.

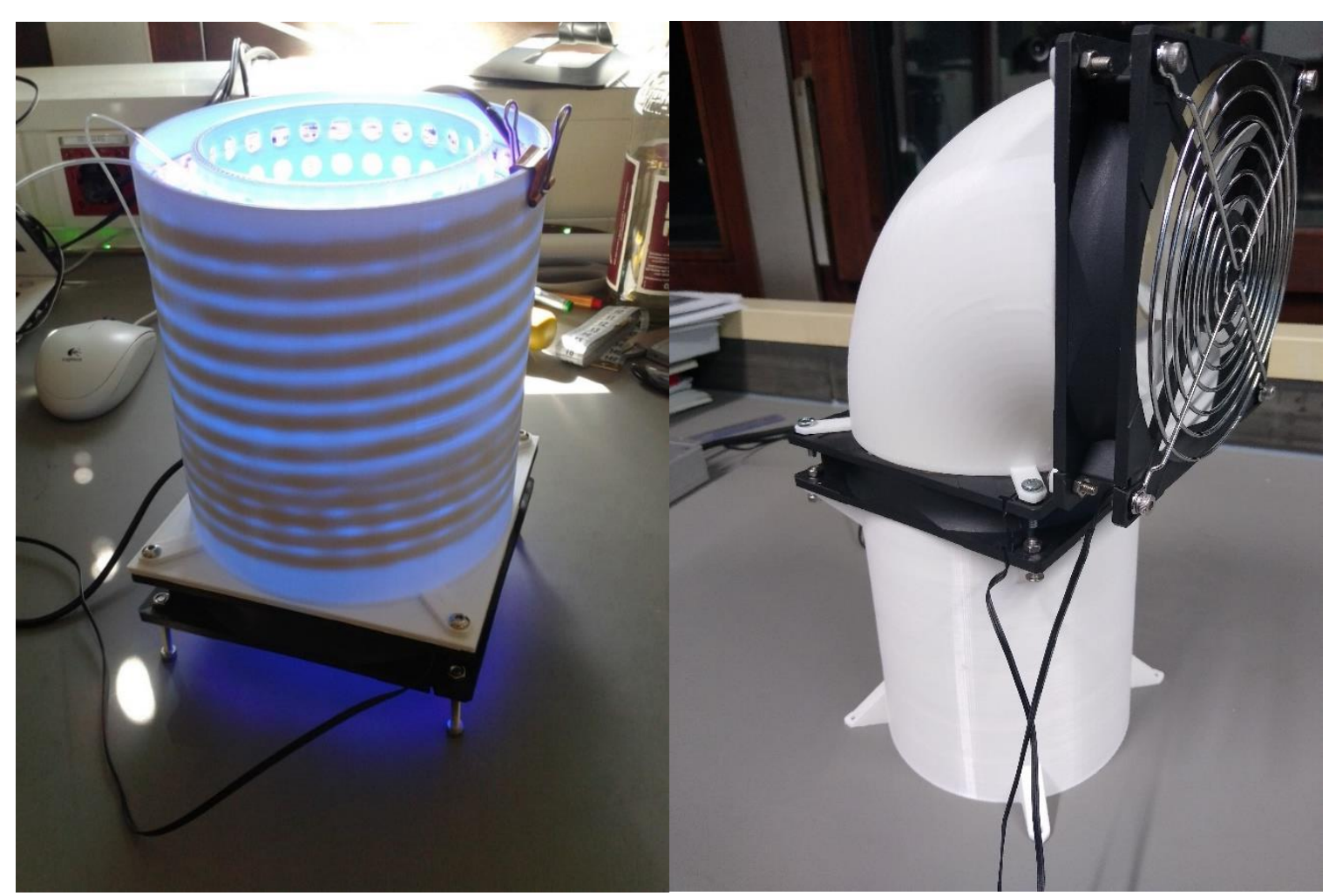

Left: The complete photoreactor. Right: Alternatively, the air is sucked from the ground through the photoreactor using a curved tube equipped with two $140 \mathrm{~mm}$ computer fans (analogously constructed as described above). 


\section{Assembly of the syringe pumps}

The syringe pumps consist of 3D-printed parts (PLA, 50\% infill), threaded bolt, rods, linear bearings, and Nema 17 stepper motors $(1.7 \mathrm{~A}, 40 \mathrm{Ncm})$ that are typically used for 3D-printers. The syringe pumps are specifically designed for $10 \mathrm{~mL}$ gastight glass syringes from VWR.
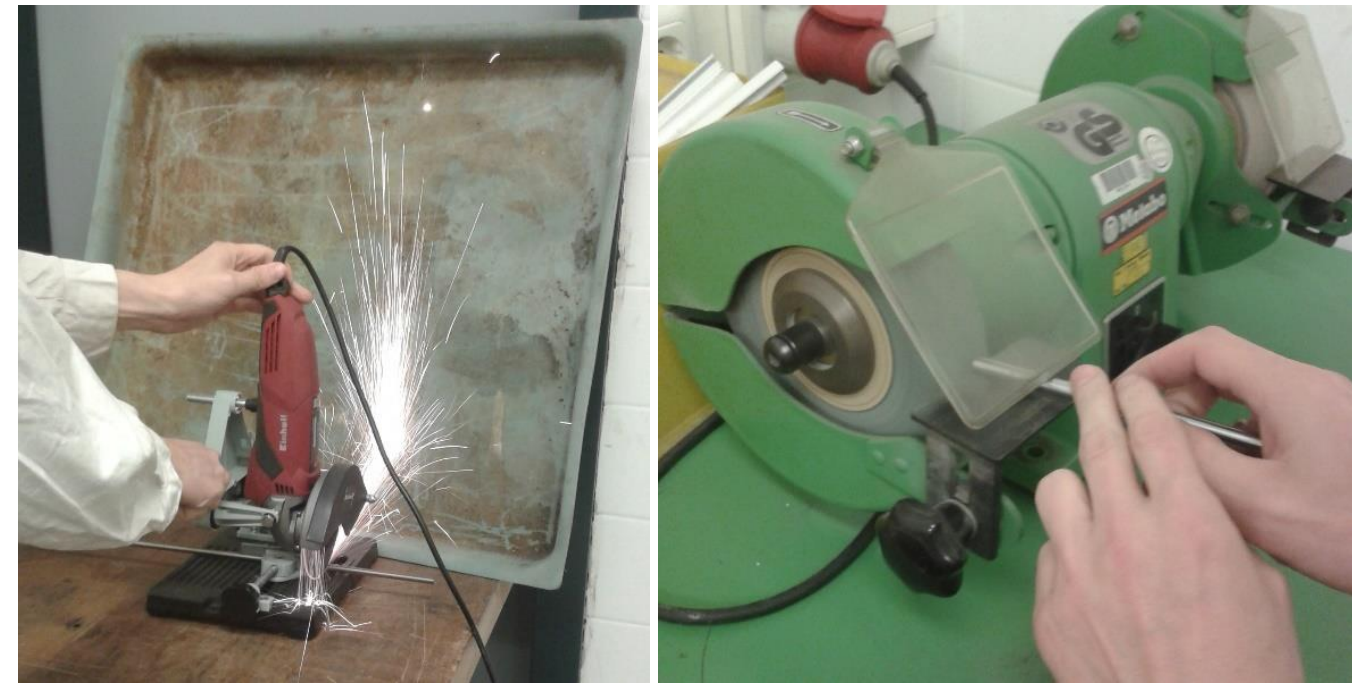

Left: Shortening of the linear rods and the threaded bolt using an angle grinder. Right: The ends of the linear rods and the threaded bolt are grinded using an electronic grindstone.
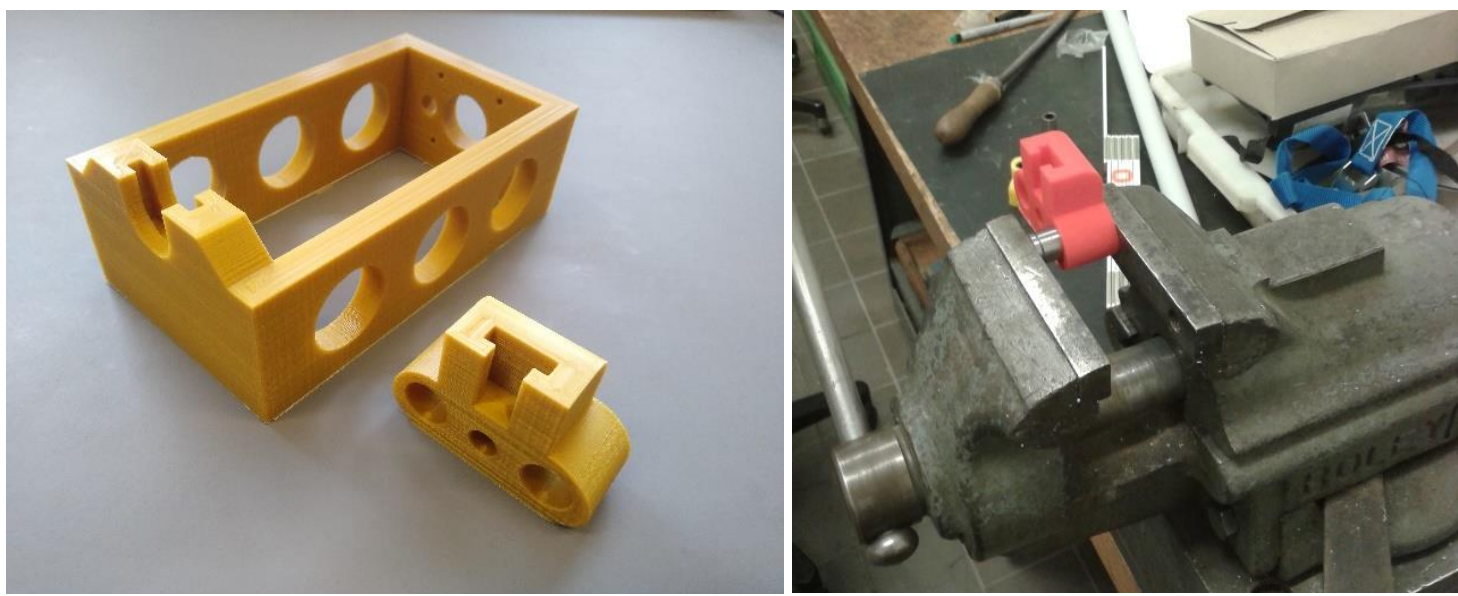

Left: The body (left) and the sledge (right) of a syringe pump. Right: The linear bearings are pressed in the sledge using a parallel vise. It is important, that the linear bearings are fixed precisely in the sledge. However, if the holes of the sledge are too tight and the linear bearings are pressed with too much pressure, the sledge can break. In this case, the holes of the sledge should be polished with a file or sandpaper before introducing the linear bearings. 


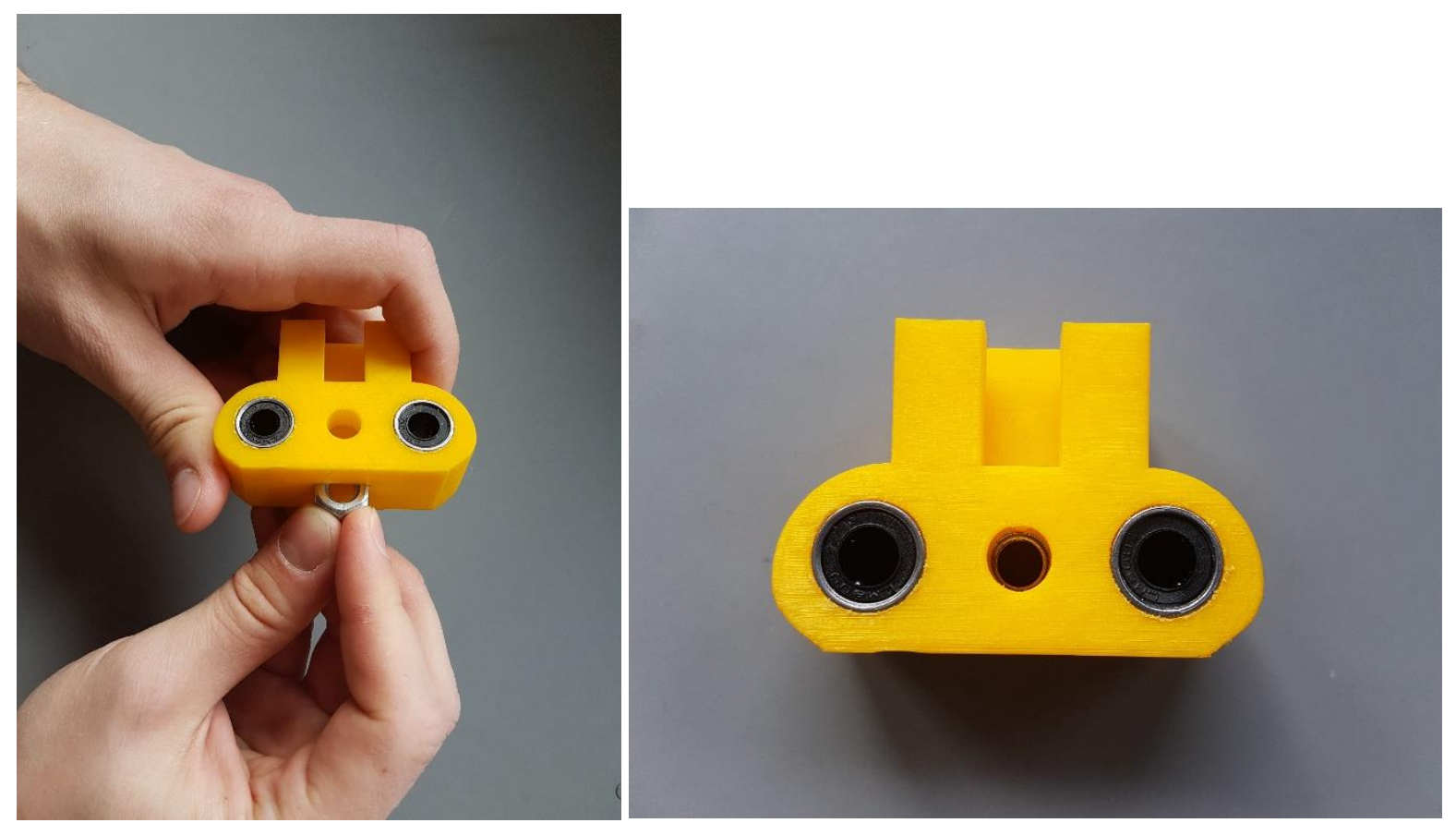

Left: The sledge is equipped with a M8 hexagonal nut. Right: The sledge with the linear guides and the hexagonal nut in the middle.
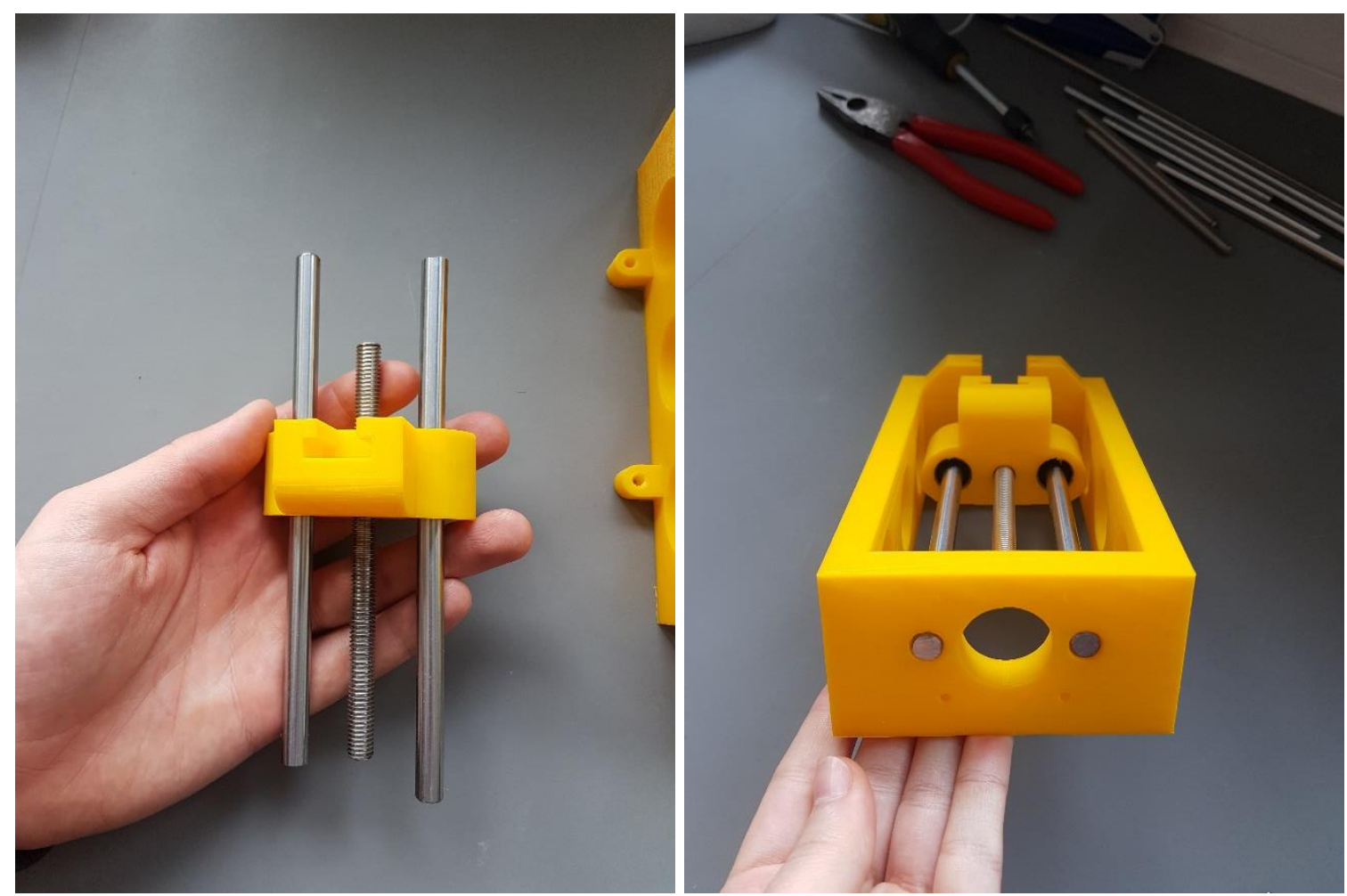

Left: The sledge with the linear rods and a M8 threaded bolt in the middle. Both the threaded bolt and the linear rods were shortened by a jab saw. Right: The sledge placed in the body of the syringe pump. 

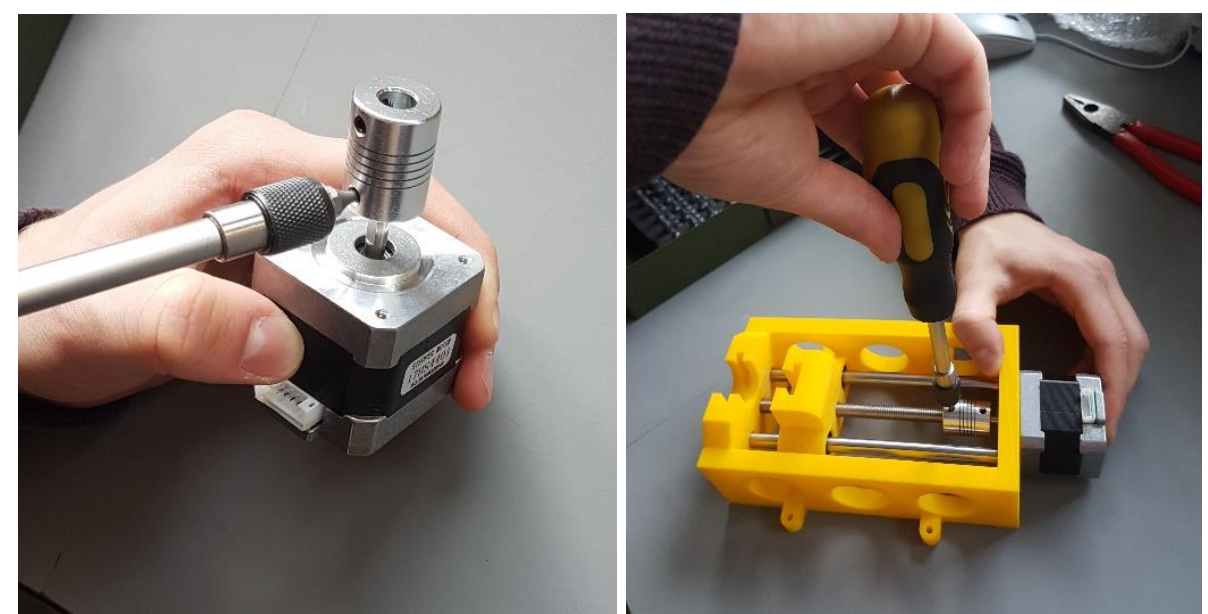

Left: The stepper motor is equipped with a flexible shaft coupling. Right: The threaded bolt and the stepper motor are connected using the flexible shaft coupling.
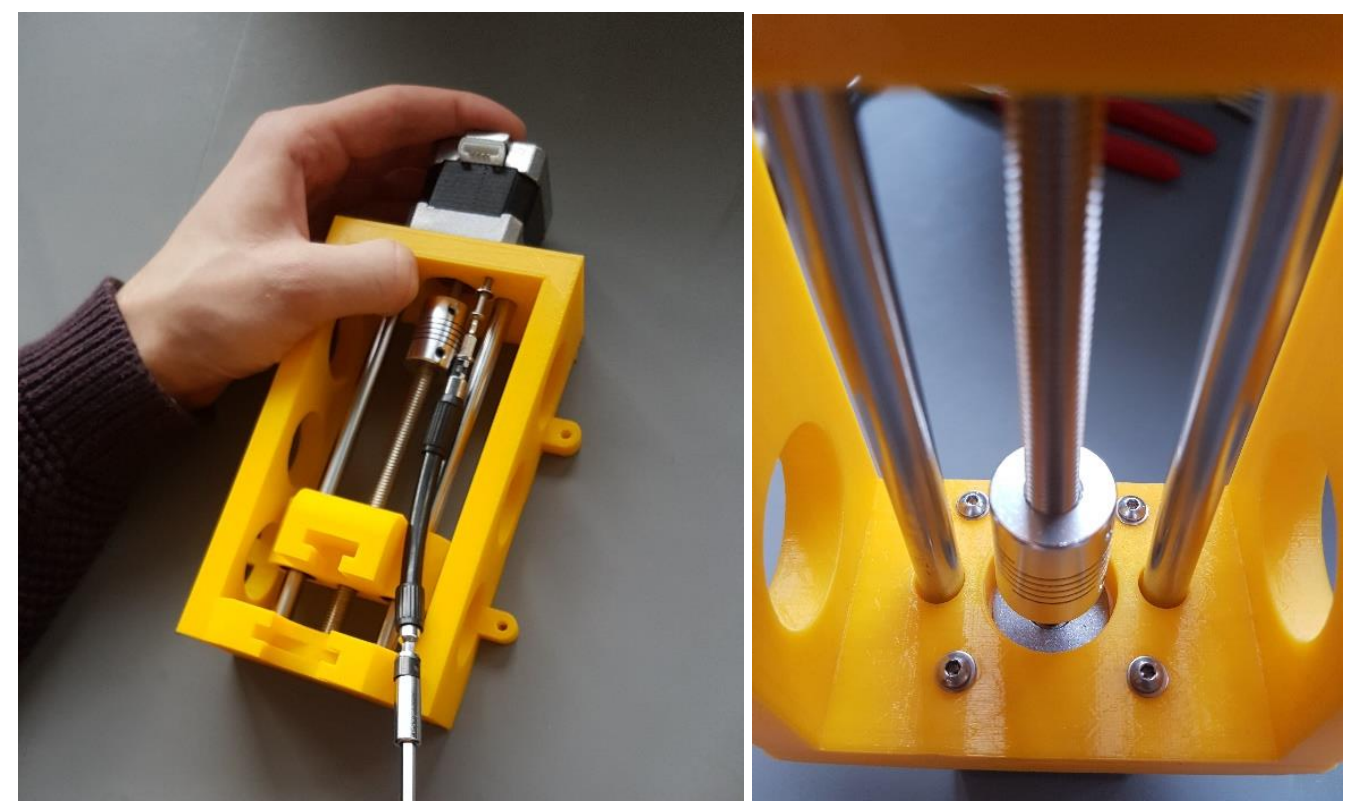

Left: The stepper motor is mounted with a M3x12 screw and a M3 washer. Right: The stepper motor mounted with four screws. 


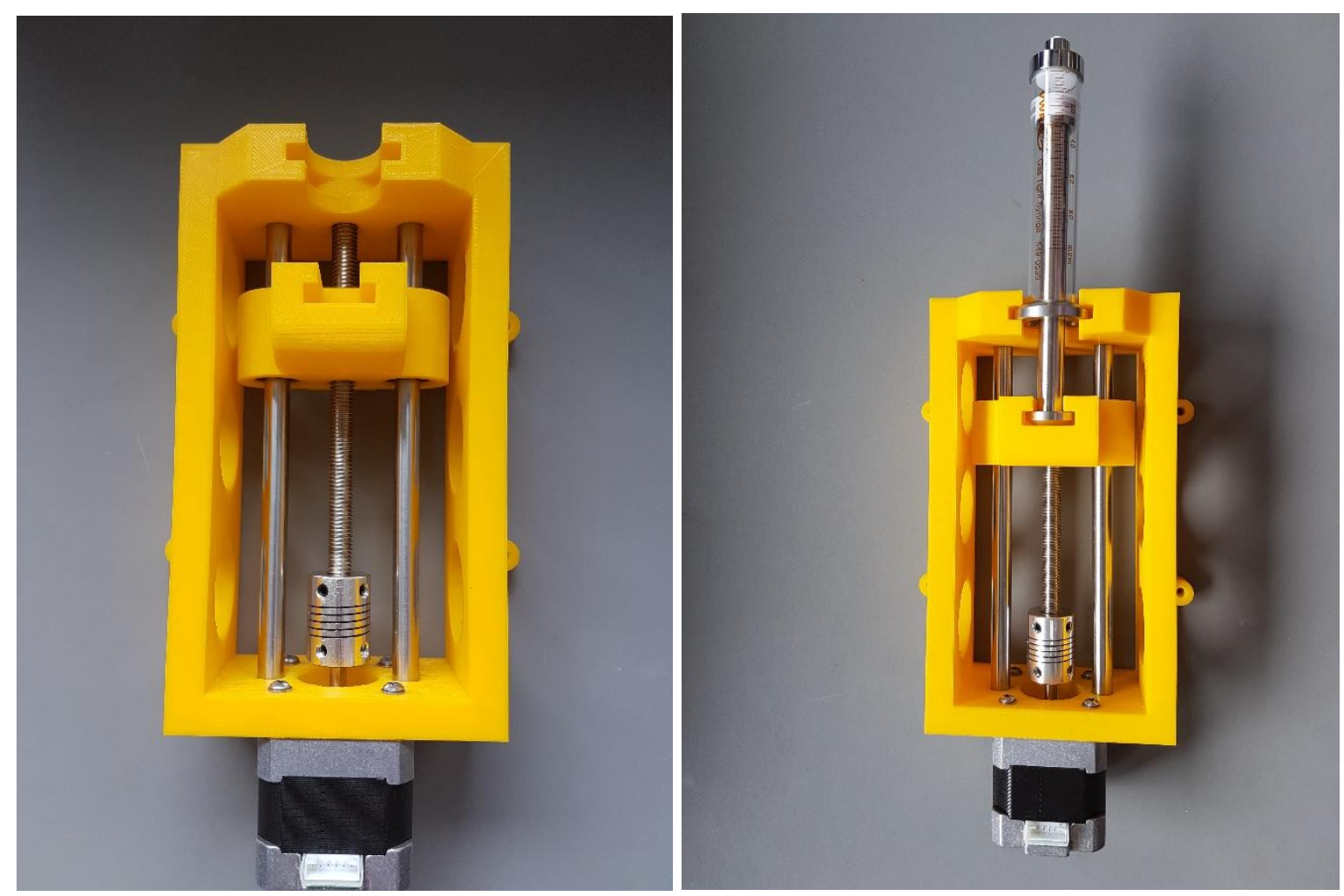

Left: The complete syringe pump. Right: The syringe pump equipped with a gastight glass syringe. 


\section{Electronic configuration of the Arduino}

The MFC's and the Arduino Uno are connected to a computer via serial ports. For time reading, a circuit board was manufactured. Resistors with $10 \mathrm{k} \Omega$ or more are used.

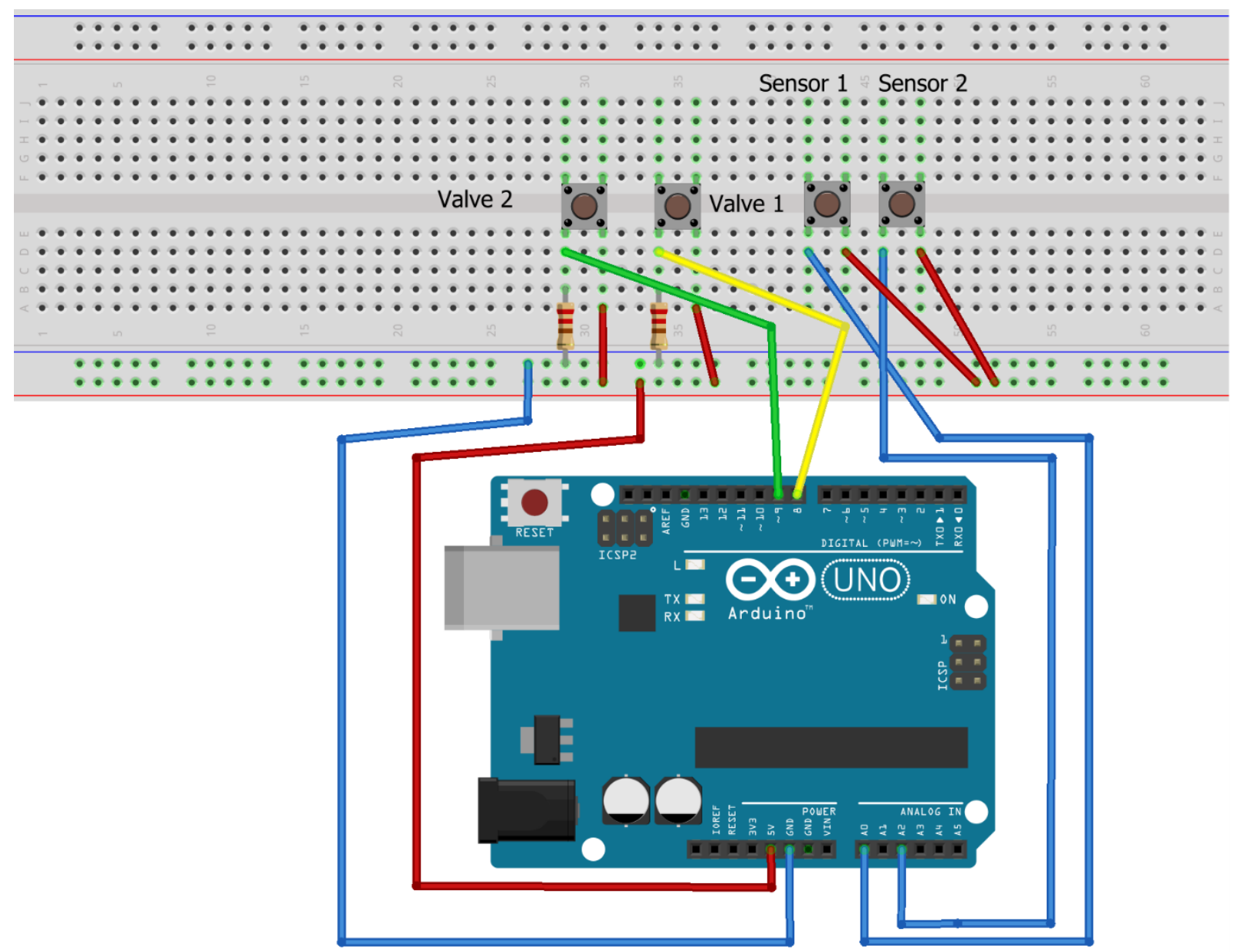

fritzing 


\section{Assembly of the controller box}

The microcontrollers are assembled in a 3D-printed controller box (PLA, 50\% infill) to protect the electronics. One microcontroller is connected to a CNC shield with three stepper drivers that controls up to three syringe pumps. Since the stepper drivers heat up, they are cooled with a $60 \mathrm{~mm}$ computer fan from the side.
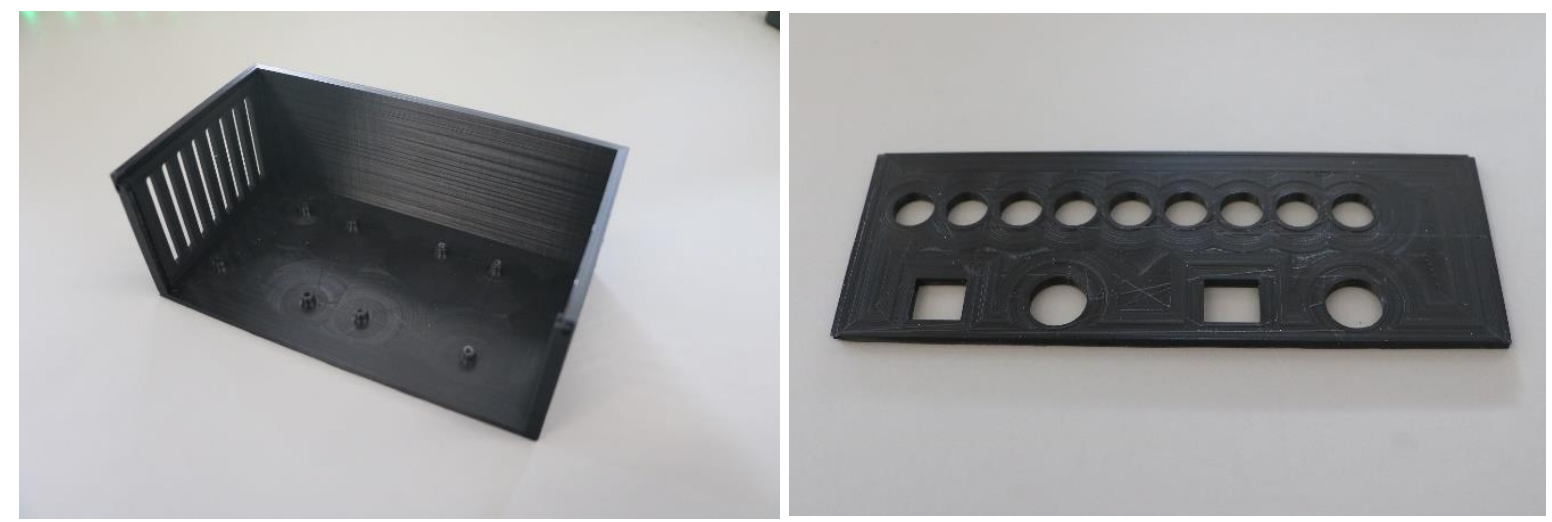

Left: The 3D-printed case of the controller box. Right: The 3D-printed side cover.
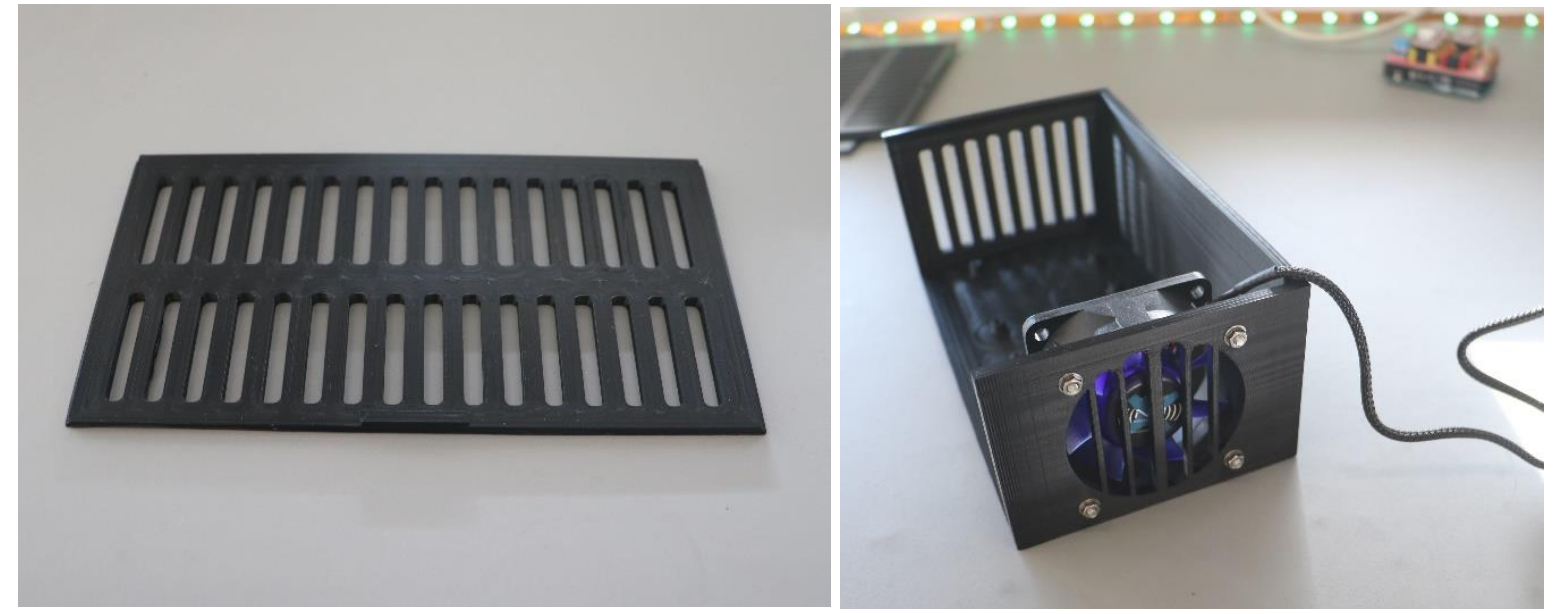

Left: The 3D-printed top cover. Right: The case is equipped with the $60 \mathrm{~mm}$ fan using M3x12 screws with washers. 

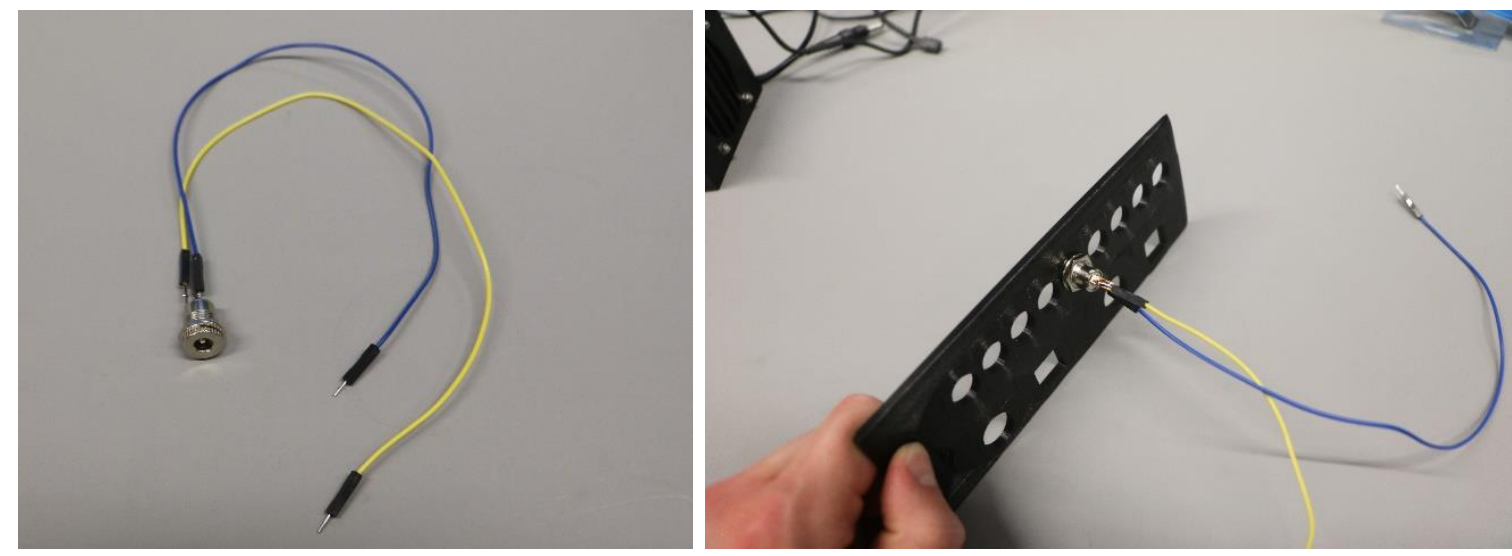

Left: A coaxial power supply is equipped with two wires. Right: The coaxial power supply is mounted on the side cover.
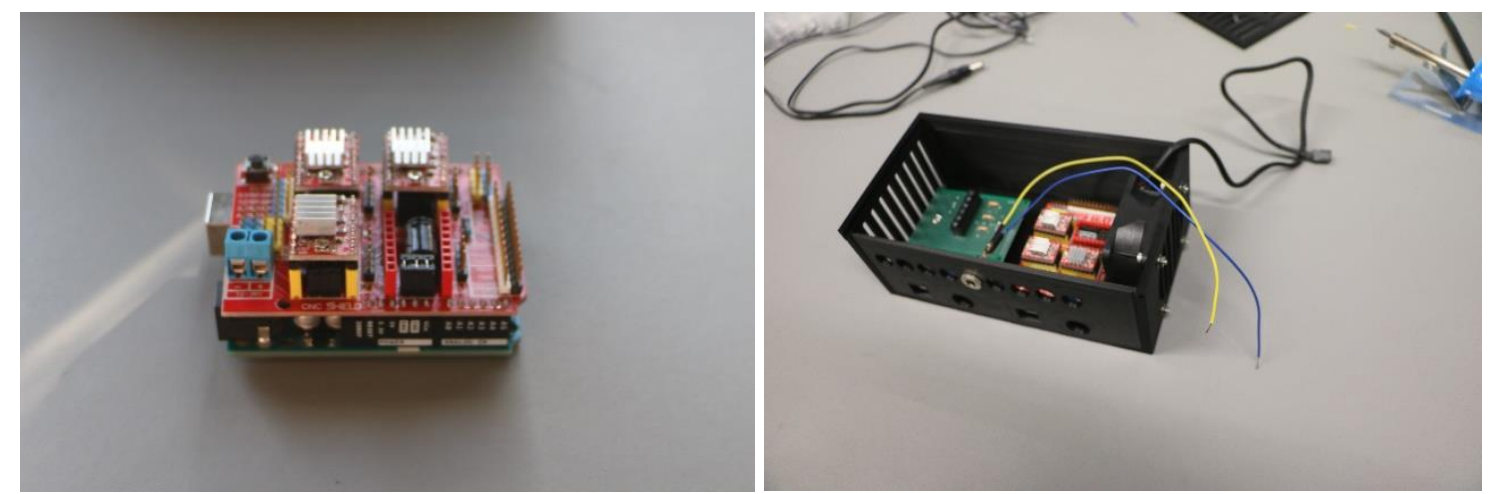

Left: An Arduino Uno equipped with CNC shield and three stepper drivers (positioned at X,Y,Z; A is free). Right: Both Arduinos are mounted in the case using M3x6 screws. The side cover is attached. Typically, Arduinos are connected with wires using crimp connections. Therefore, wires need to be terminated with crimp connectors. Detailed instructions can be found online.

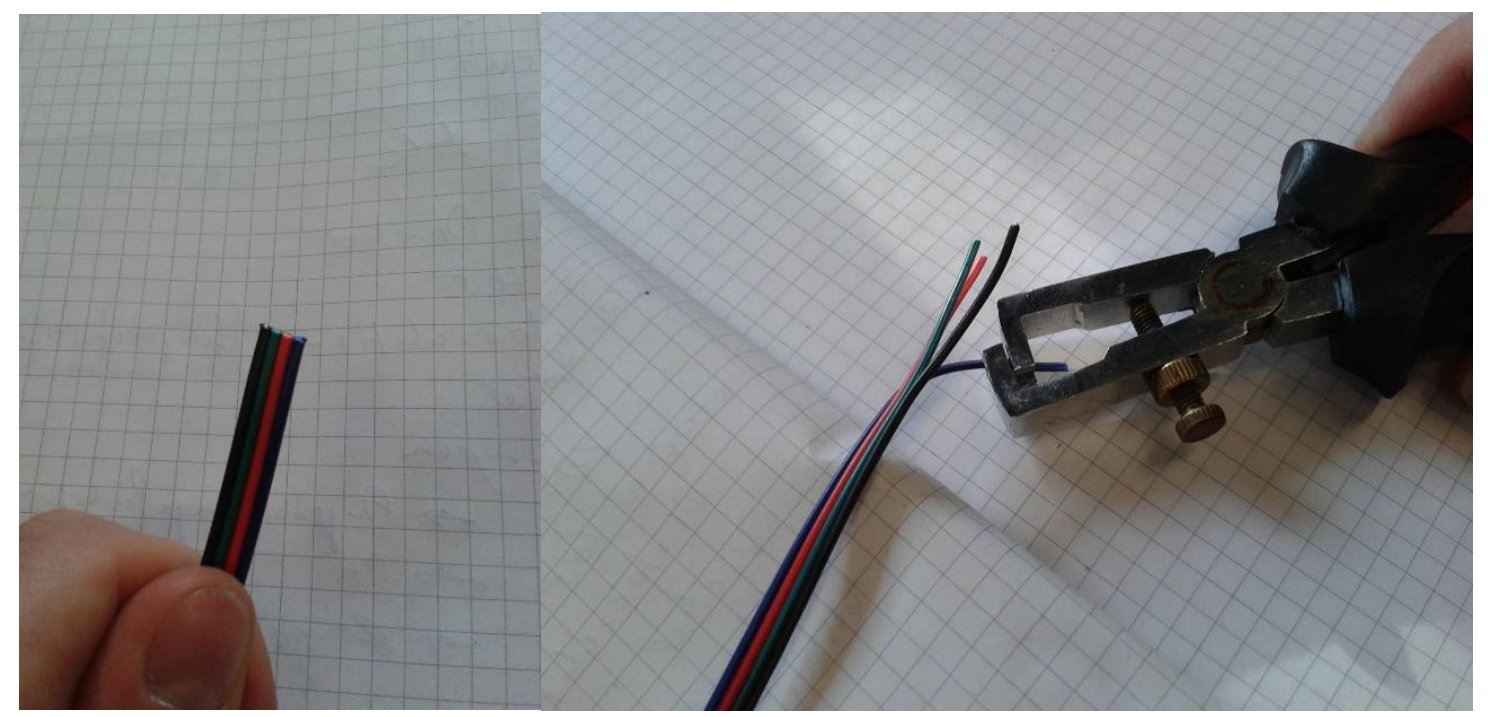

Left: A 4-conductor cable. Right: The wires are skinned using a wire stripper. 


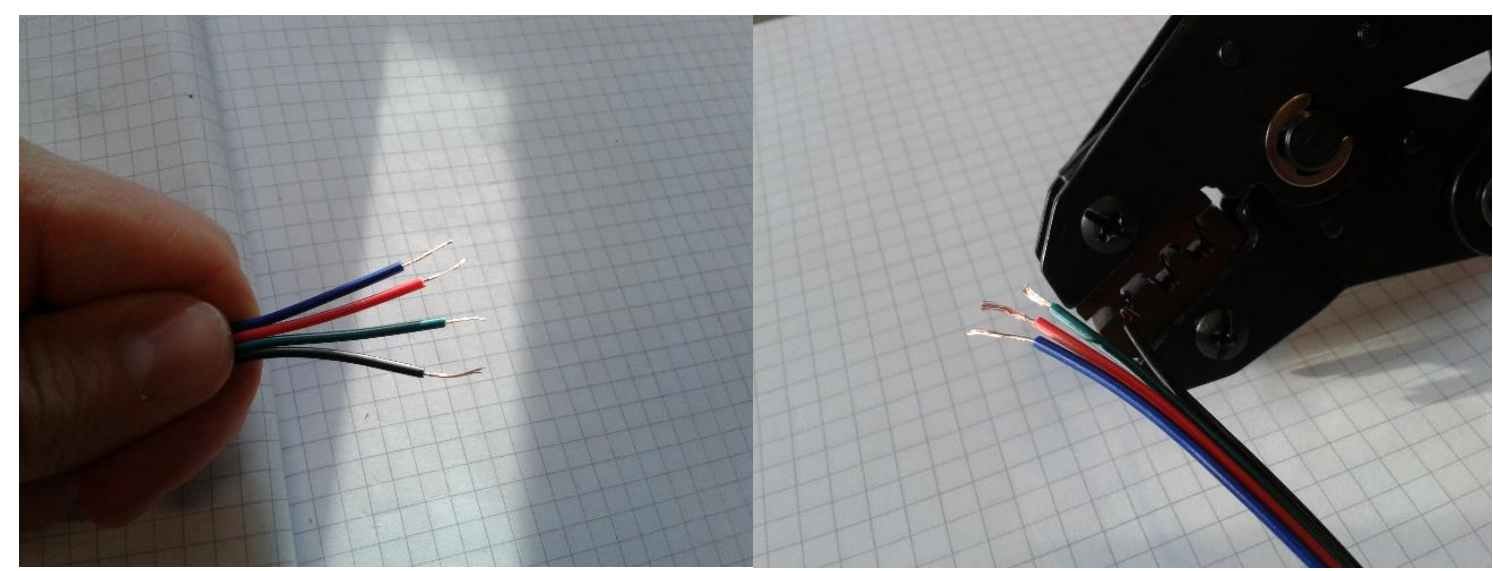

Left: The stripped 4-conductor cable. Right: The ends of the stranded wires are terminated with crimp connections using a crimp clamp.

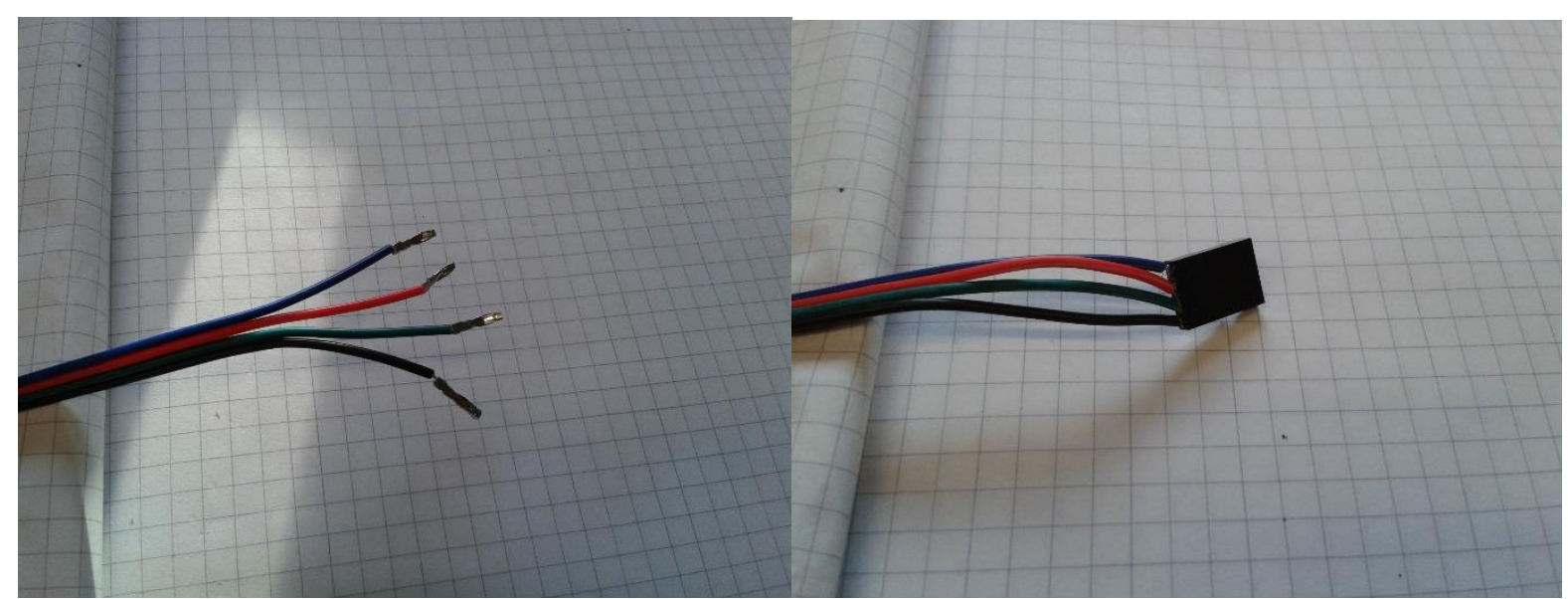

Left: The wires terminated with crimp connectors. Right: The crimp connectors are introduced in a Dupont connector.

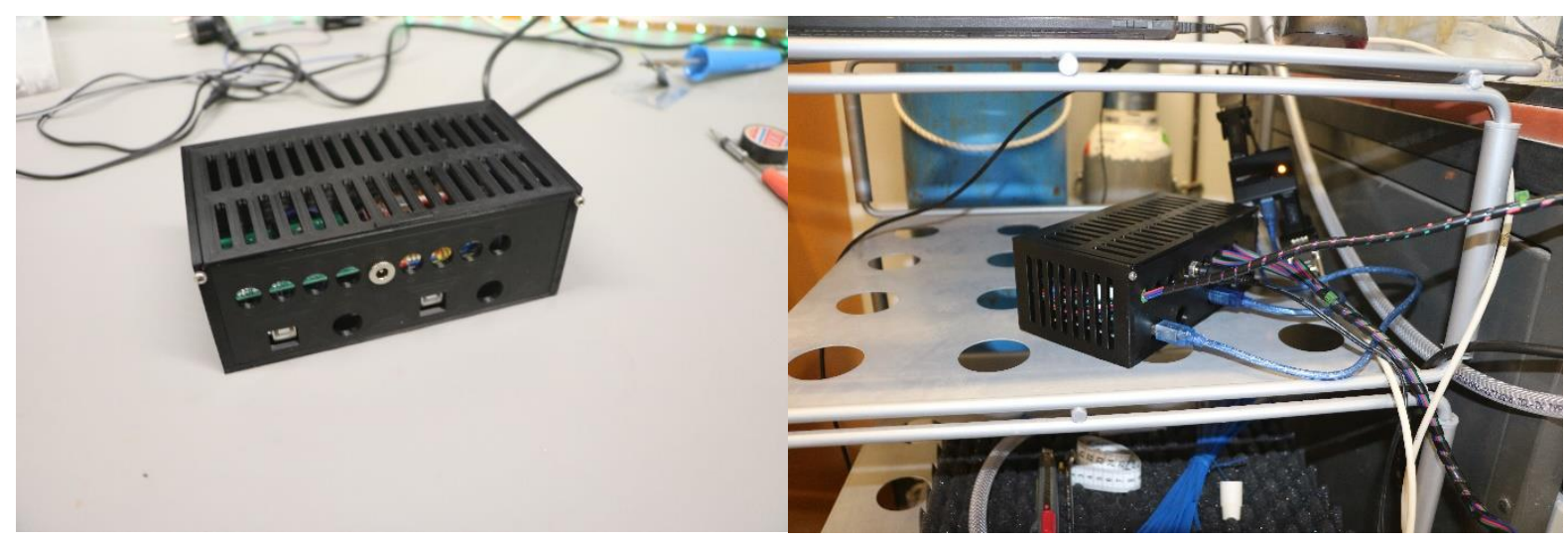

Left: The complete controller box. Right: The controller box equipped with cables. 


\section{Assembly of the modular valve system}

It is practical, when all valves can be easily disconnected from the controller board. In this way, cleaning of the valves or changing tubes becomes much easier. To allow as much flexibility as possible, we designed a modular valve system. Thus, the low pressure valves and the HPLC injection valves are mounted on 3D-printed mounts having a unified size. On the controller board, 3D-printed sockets are secured. The mounts of the valves can be placed in the sockets and further secured by using two 3Dprinted clamps on the top of each socket.

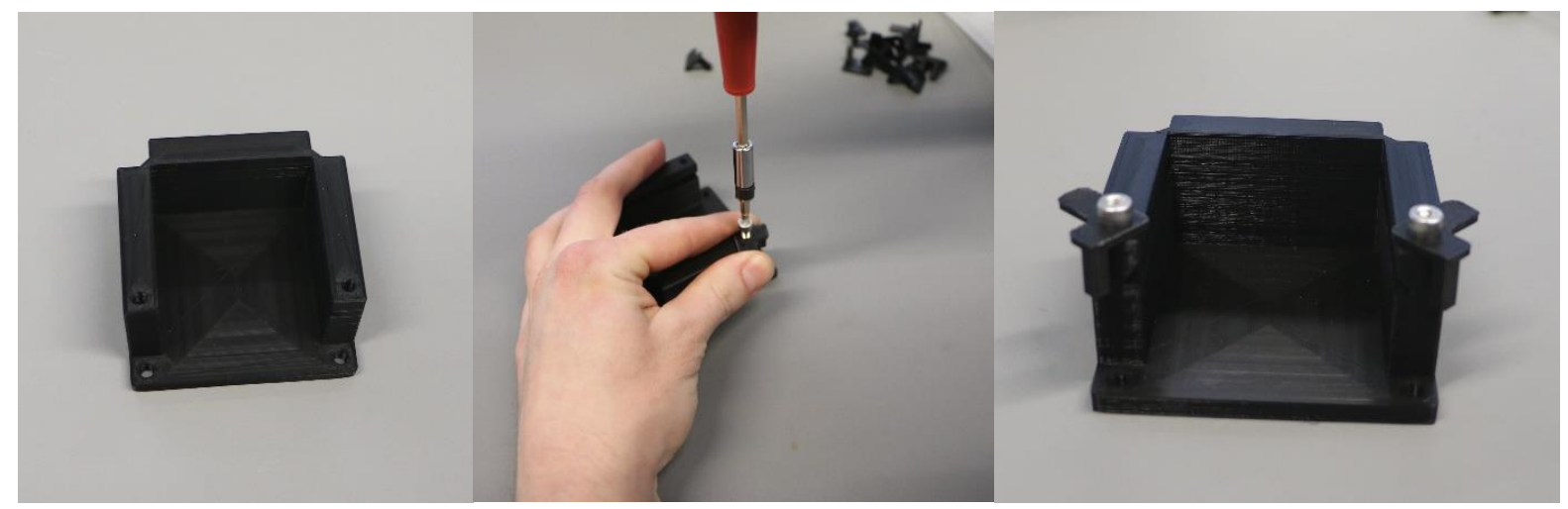

Left: The 3D-printed socket. Center: The 3D-printed hooks are secured using M4 screws. Right: The socket equipped with two hooks.

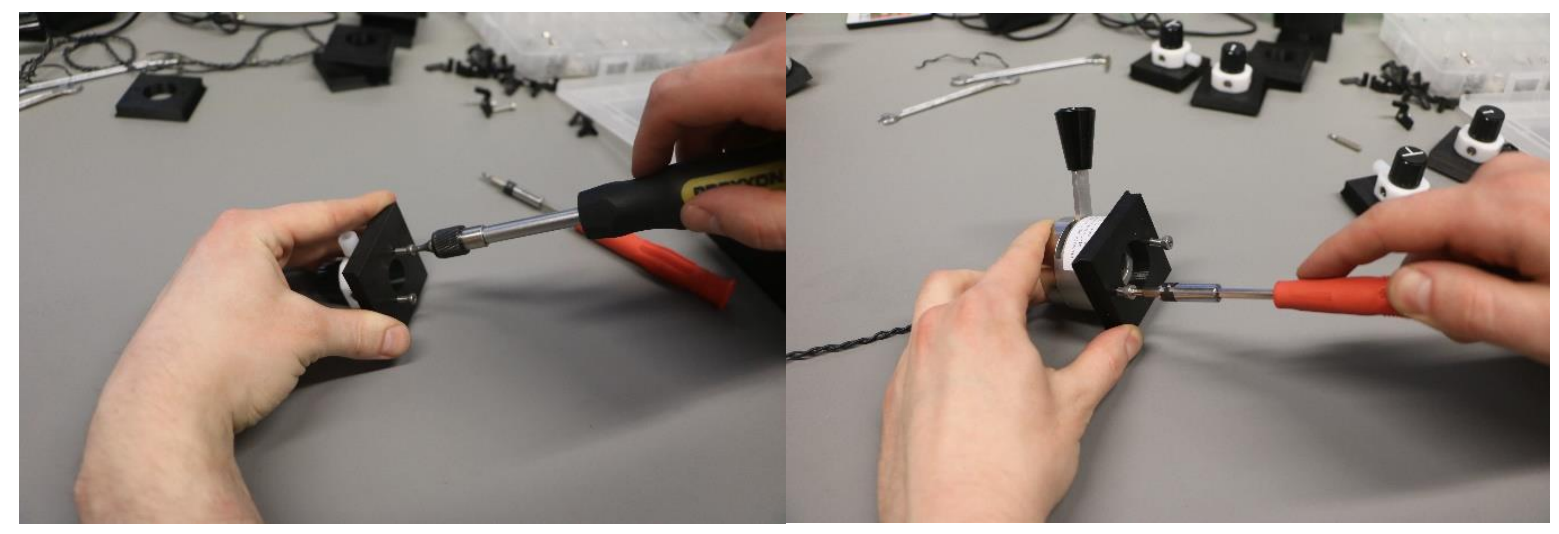

Left: The low-pressure valves are secured on the low-pressure valve mounts using M3 screws. Right: The HPLC injection valves are secured on the corresponding mounts using M4 screws. 


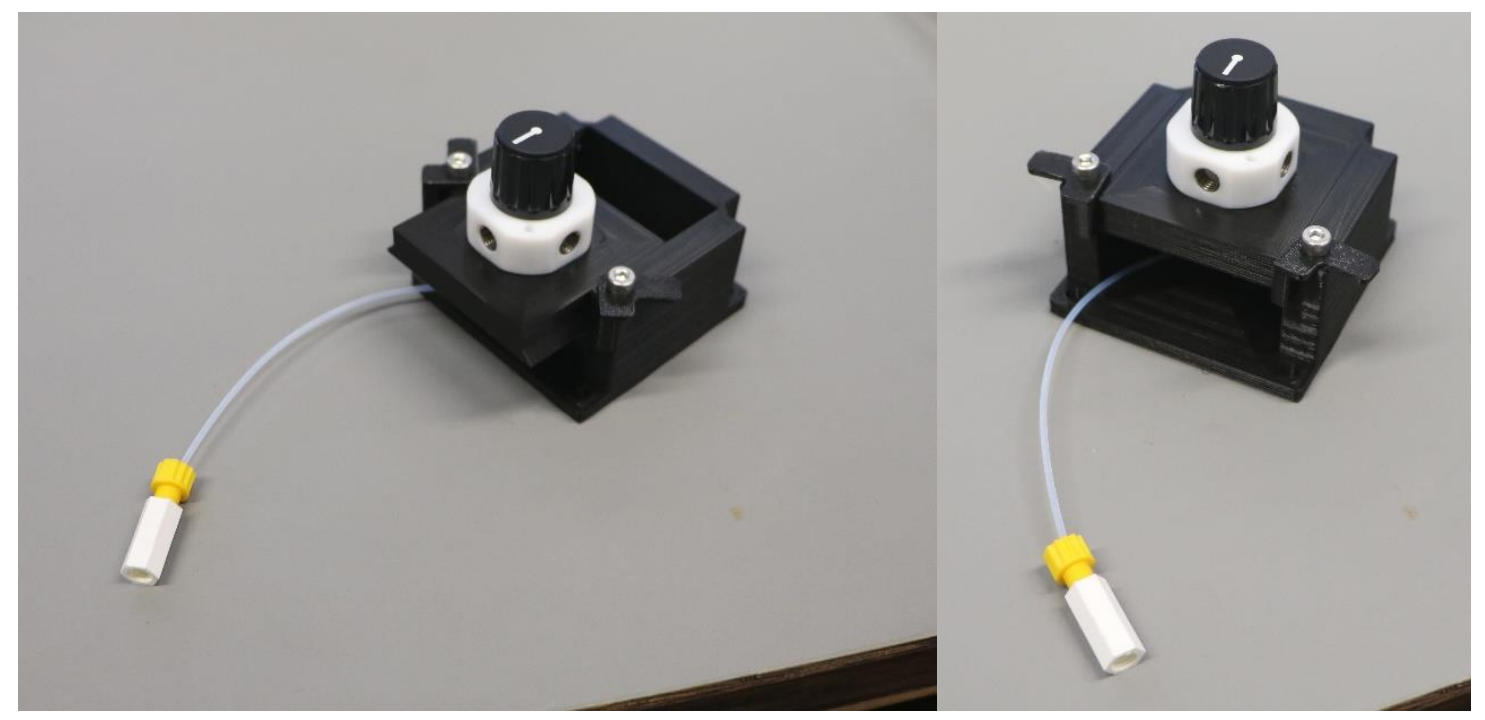

Left: A mount equipped with a low pressure valve is introduced to the socket. Right: The mount is secured using the hooks.

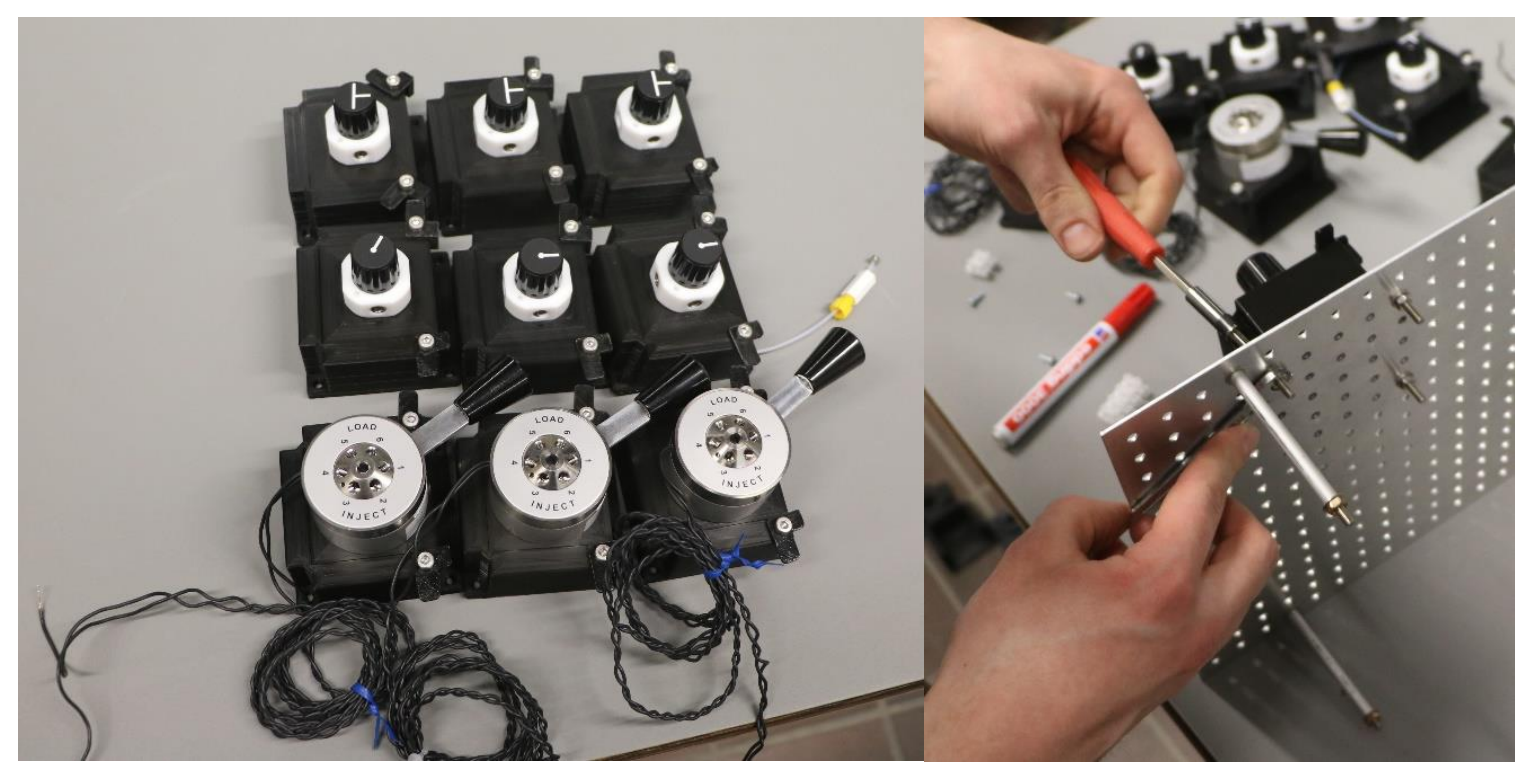

Left: A small collection of the three different valves placed in the valve sockets. Right: The sockets are mounted on the controller board using M4 screws. 


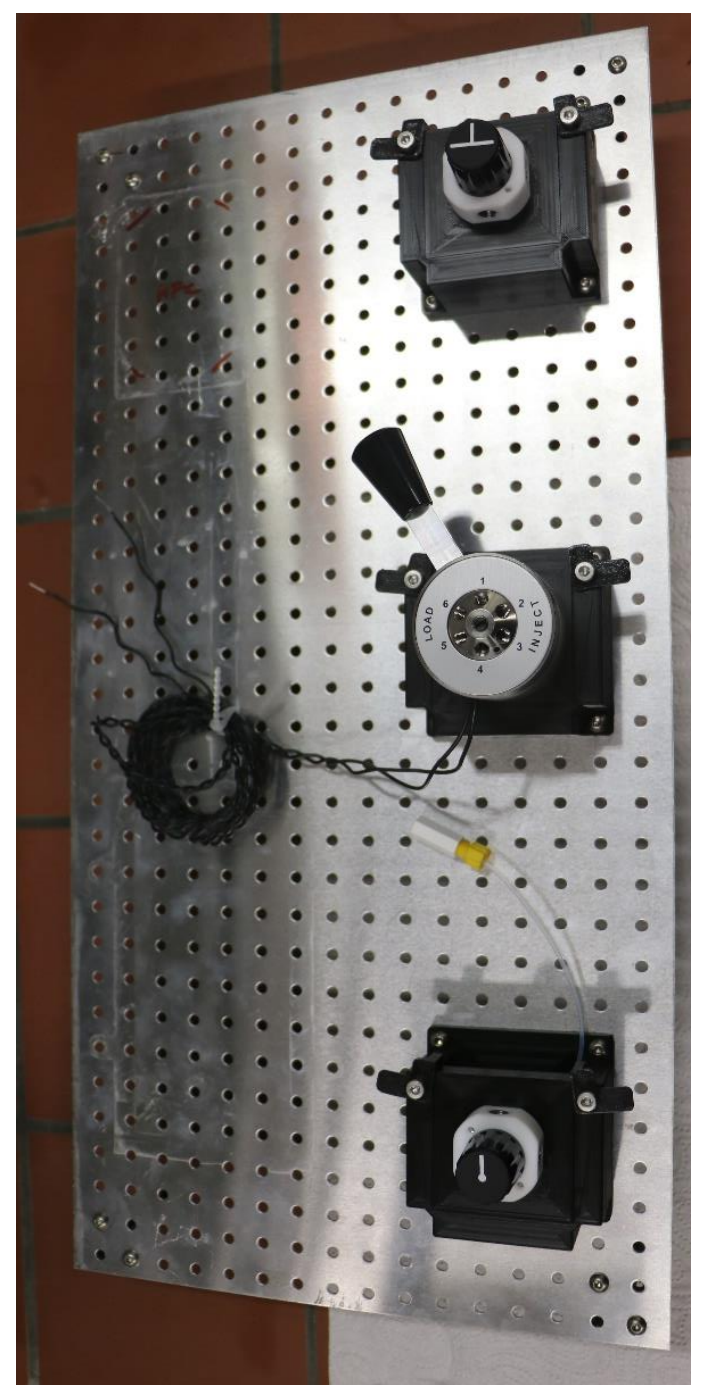

The controller board equipped with three sockets and valves. 


\section{Mounting of the MFCs}

3D-printed mounts for the MFCs were designed to attach the MFCs to the controller board.
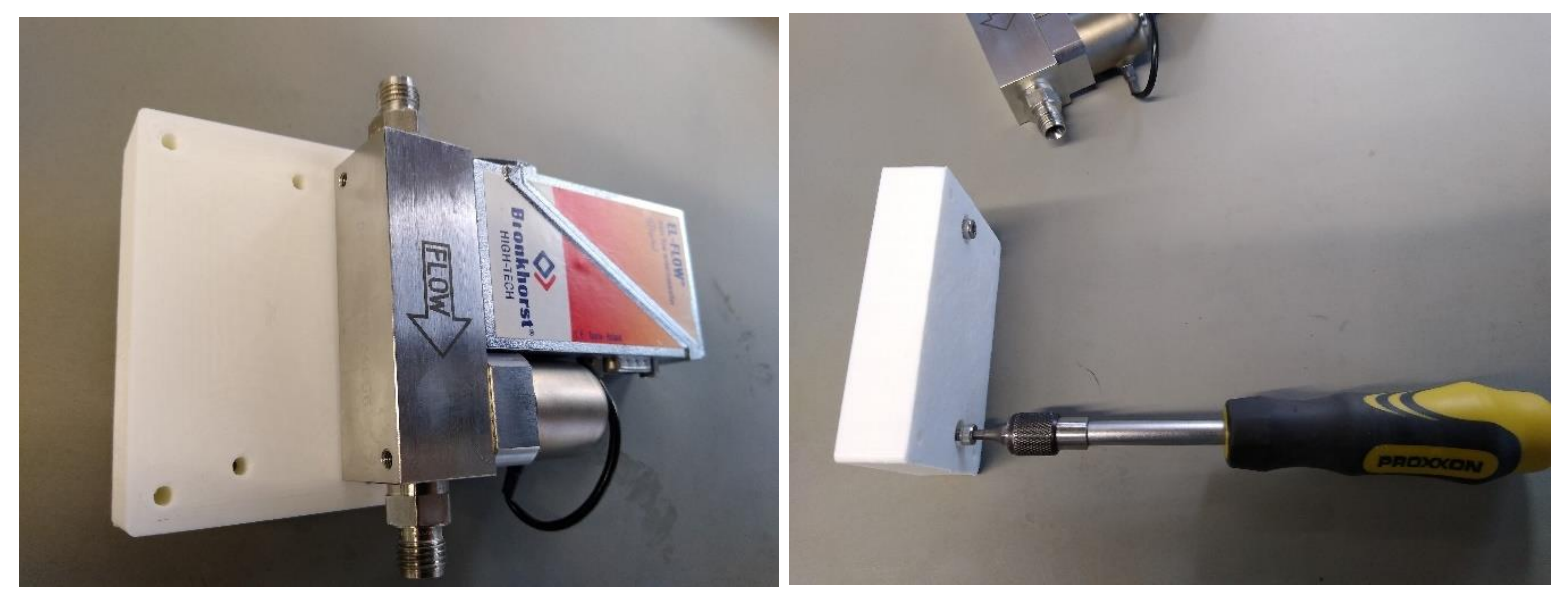

Left: The mount is designed to be connected with the MFC from the one and with the controller board from the other side. Right: M4x14 screws are screwed in the mount.
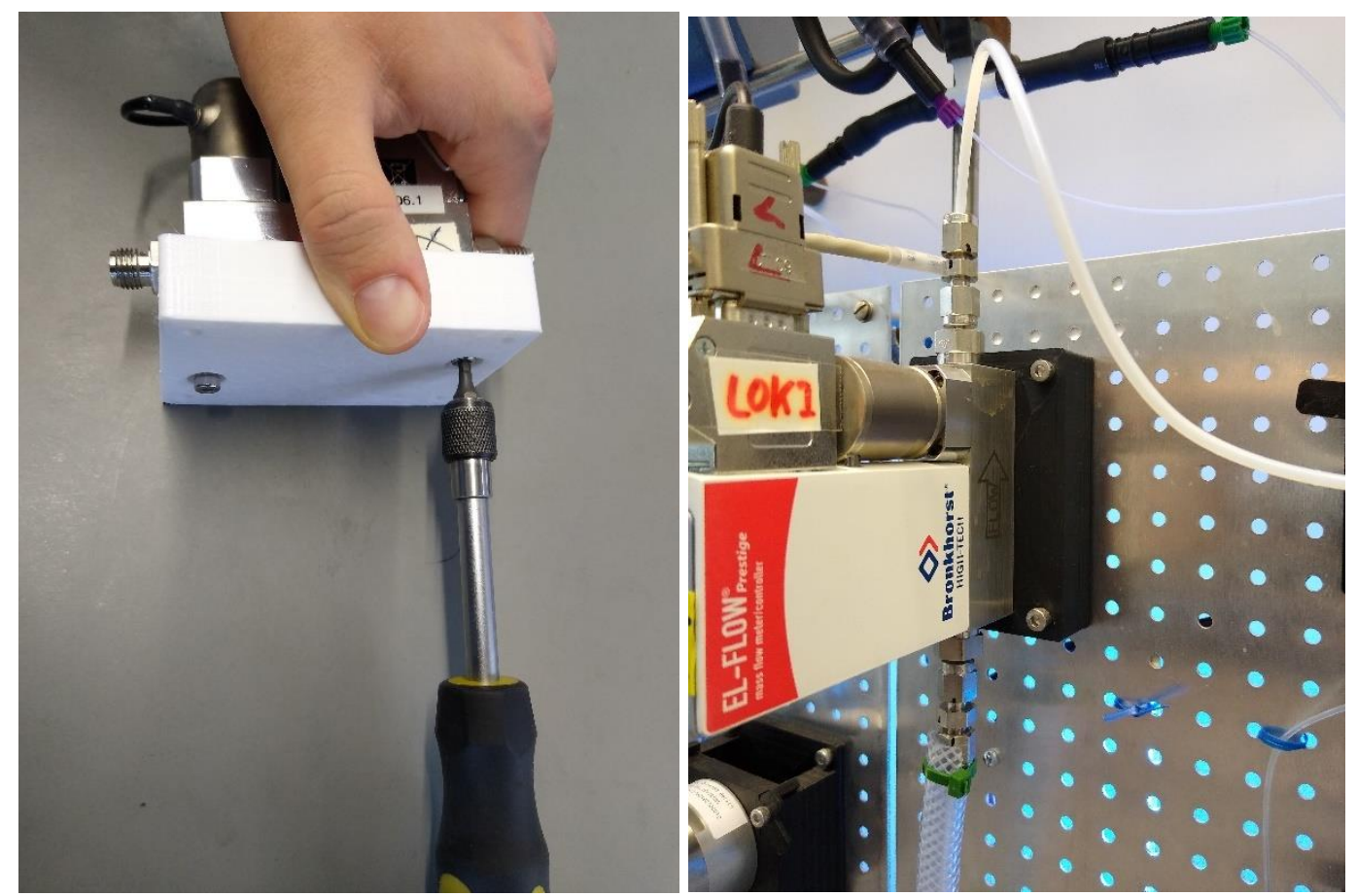

Left: A MFC is secured to the mount. Right: A fully equipped MFC secured via the mount to the controller board. 


\section{D-printed connectors between the flow platform and a Schlenk line}

To connect the flow platform with a standard laboratory Schlenk line, 3D-printed connectors (PLA, $100 \%$ infill) were designed connecting a pipe nozzle (10 mm diameter) on one side and a 1/4-28 UNF thread on the other side. To enable tight contact between the connector and a 1/4-28 UNF fitting, a small piece of shrink tube is employed as seal.

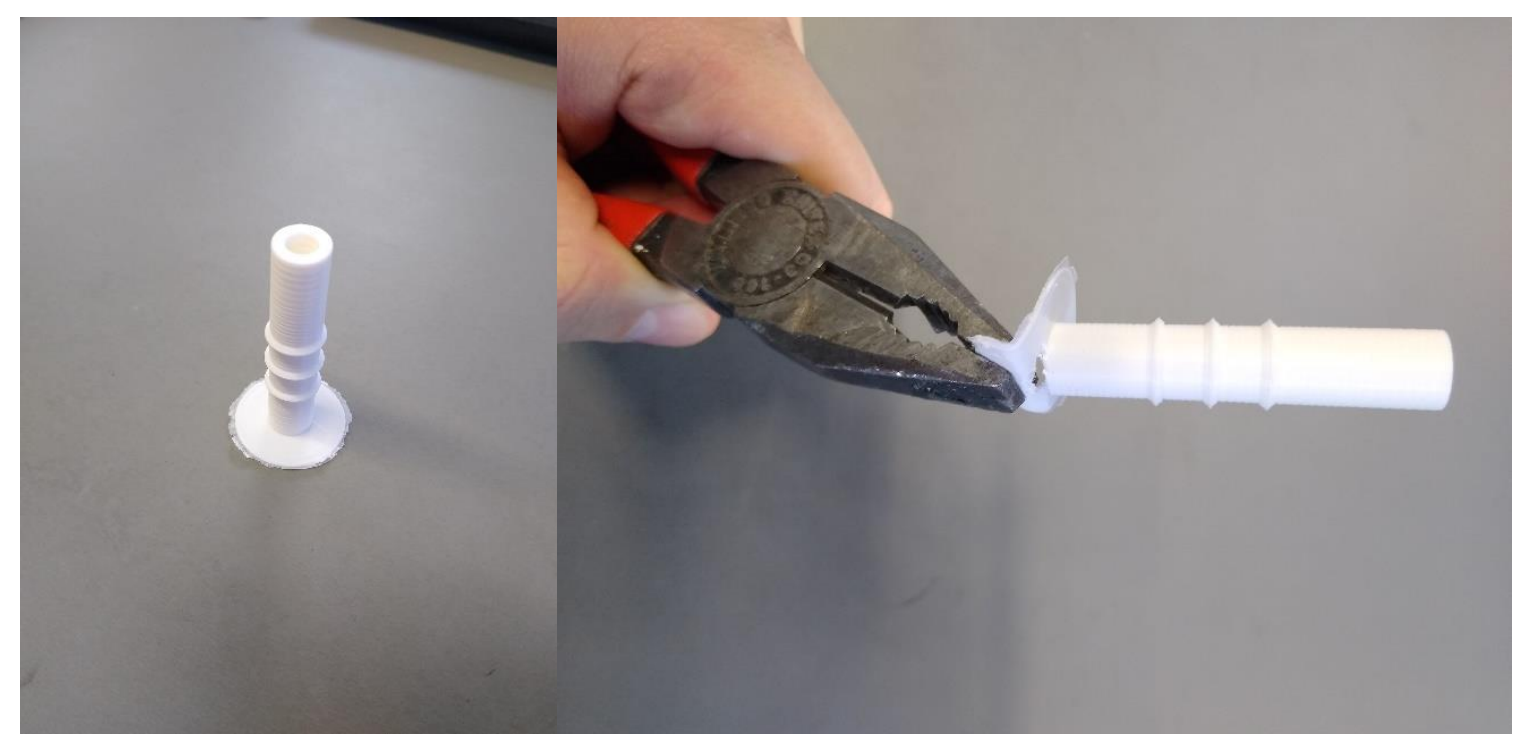

Left: A connector printed on a small raft. Right: The raft is removed using pliers.

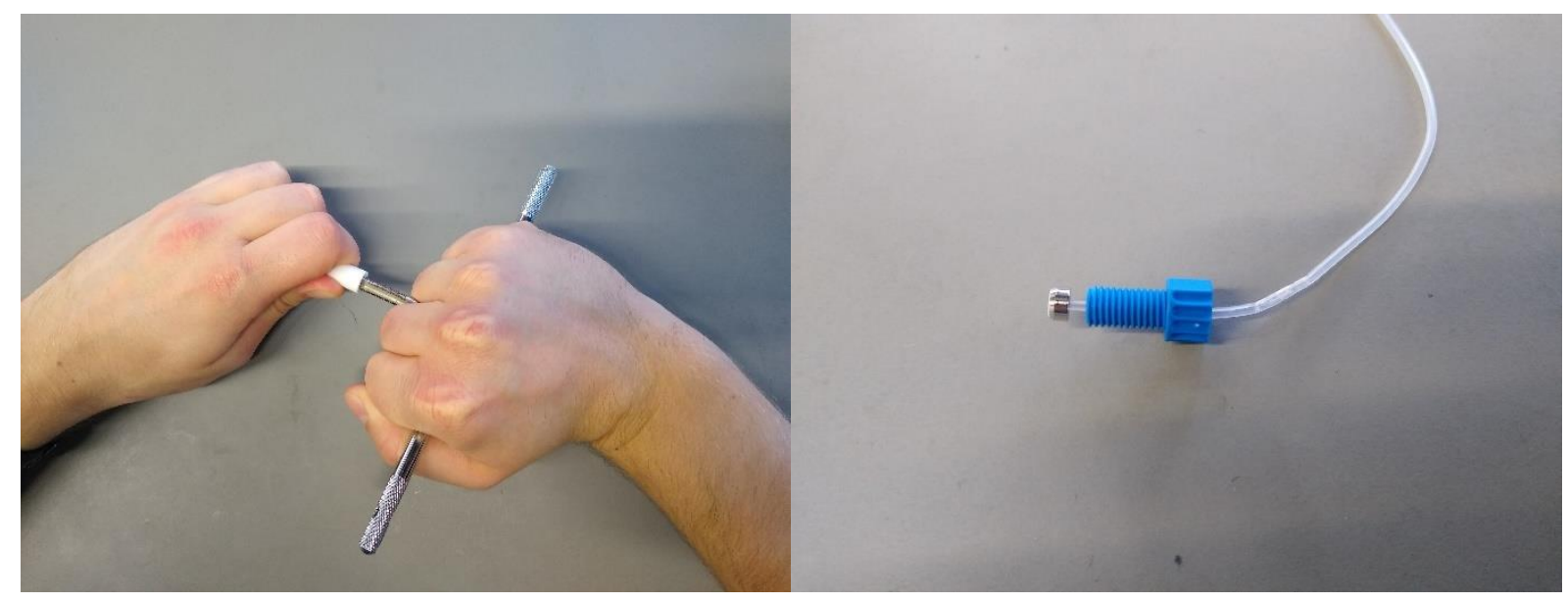

Left: Using a 1/4-28 UNF screw tap, a thread is drilled. Right: A tube equipped with a 1/4-28 UNF fitting. 


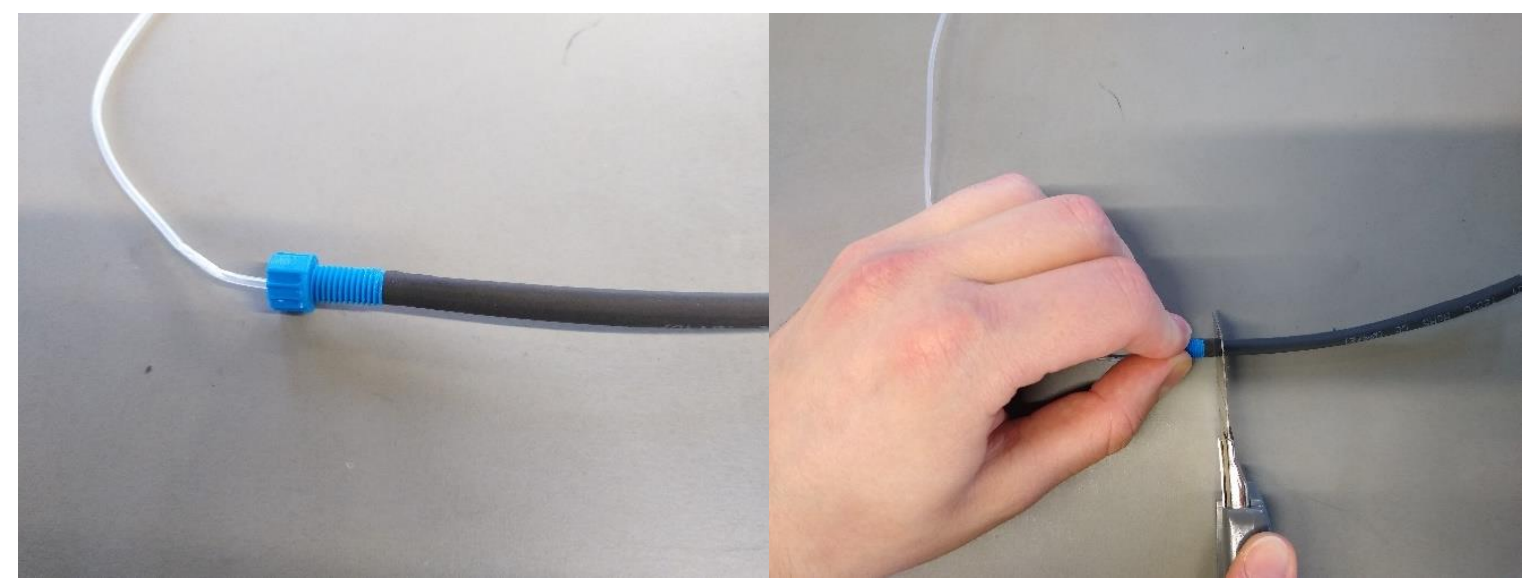

Left: The ferrule is covered with a shrink tube of appropriate size. Right: The shrink tube is shortened using a cutter and shrunk employing a heat gun.

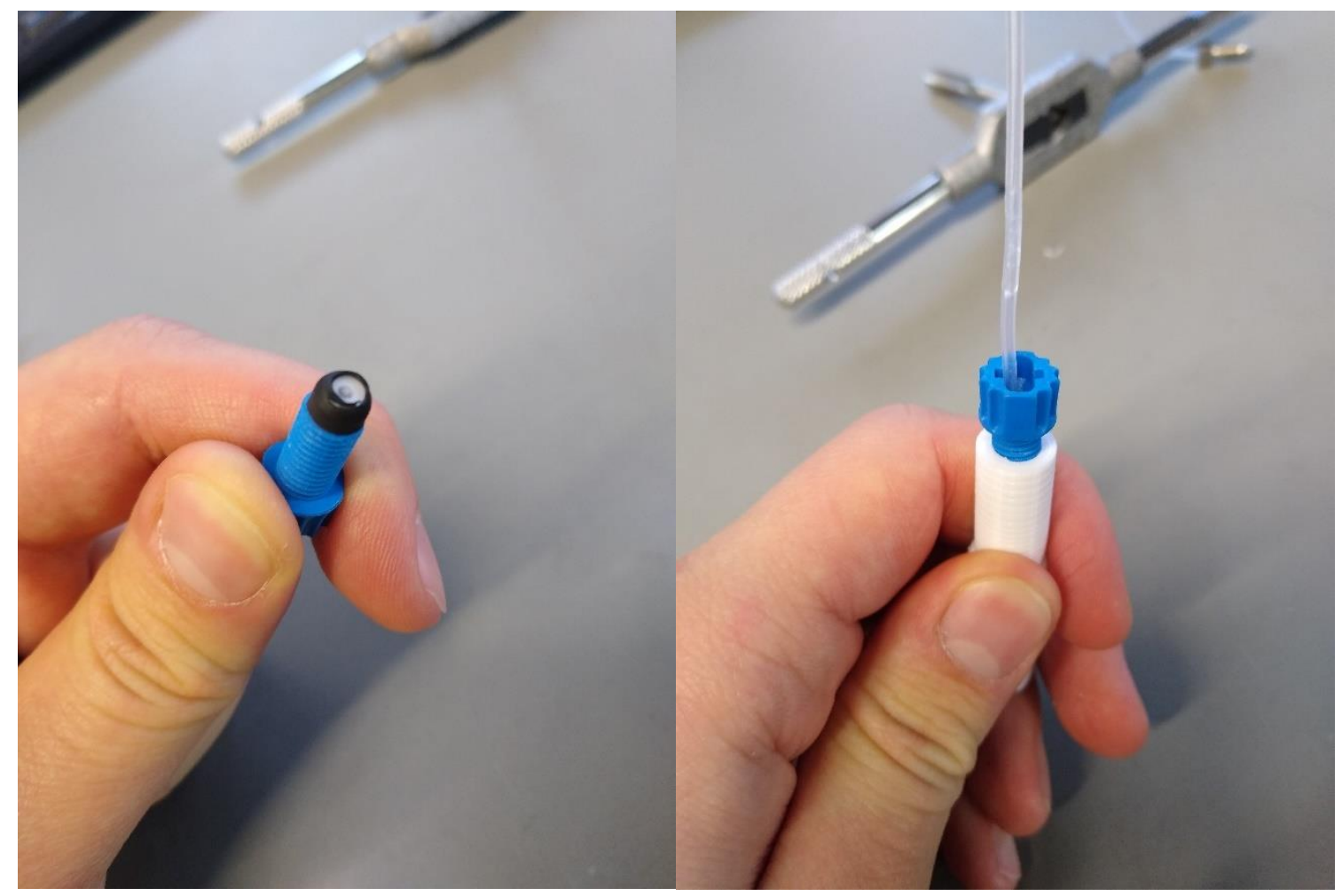

Left: The ferrule equipped with a small piece of shrink tube that serves a seal between the connector and the fitting. Right: The connector equipped with the fitting providing a vacuum tight connection between a Schlenk line and typical flow tubes. 


\section{The complete flow platform:}

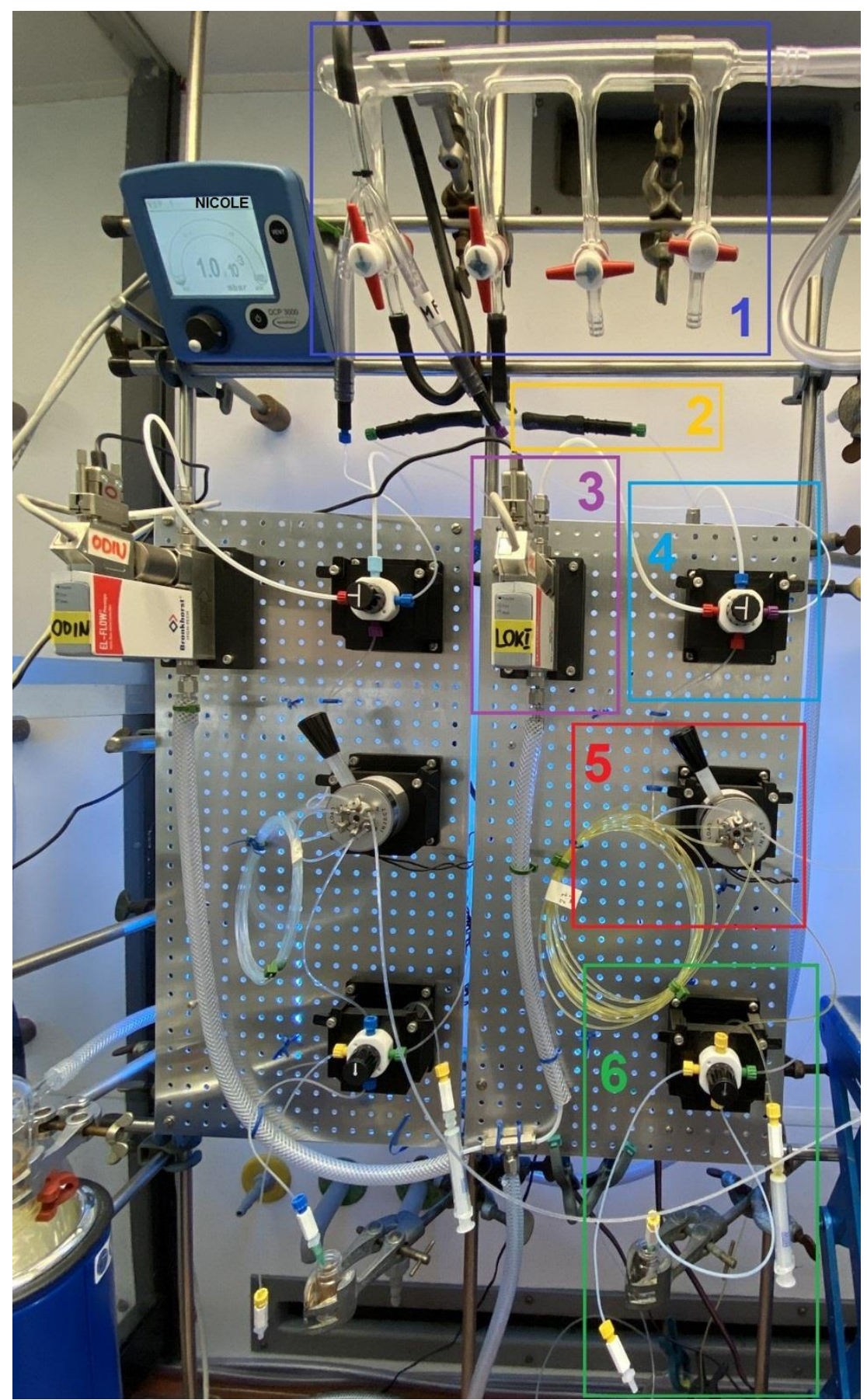

The complete flow platform consisting of two setups. 1: Schlenk line. 2: Connector between Schlenk line and flow platform. 3: MFC. 4: Vacuum/argon module. 5: Reagent module. 6: Inert sample loading module. 


\section{Detailed pictures}

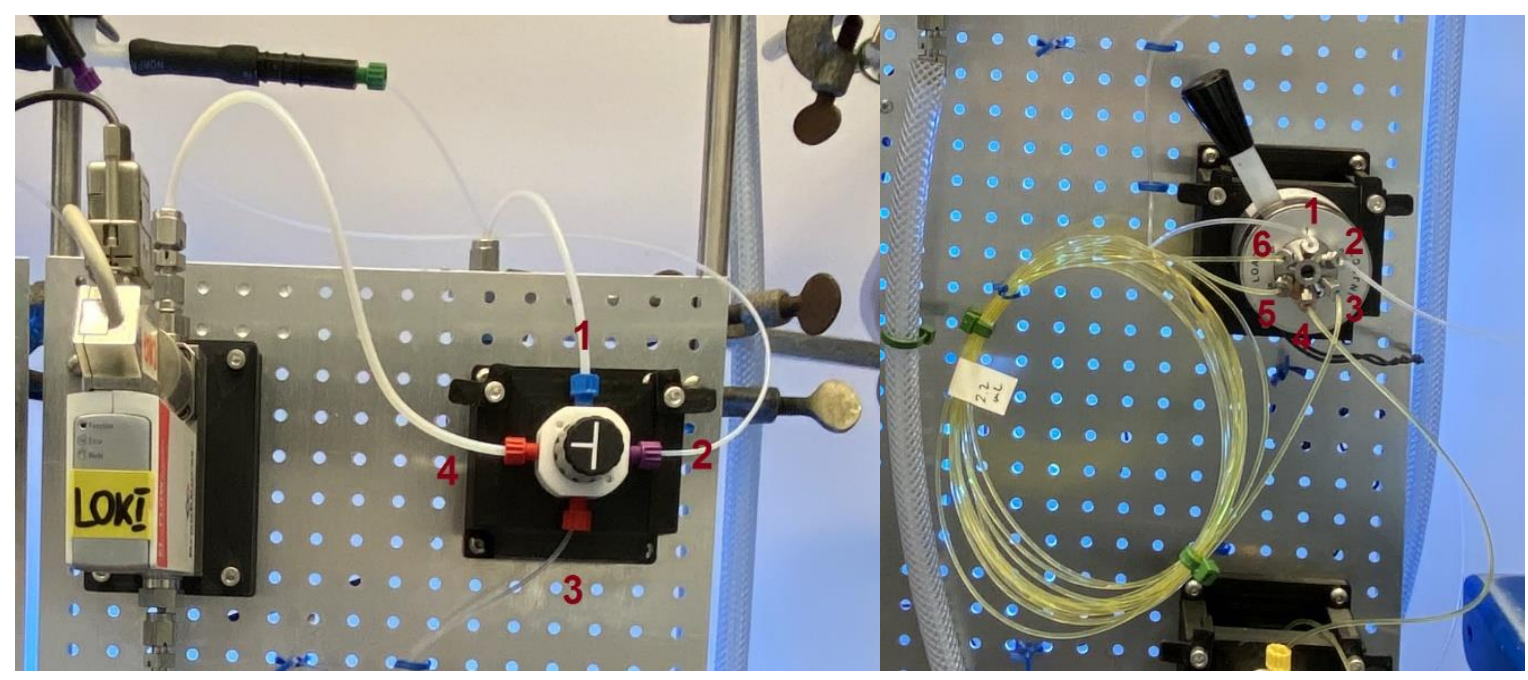

Left: The vacuum/argon module. 1: To pressure sensor. 2: To Schlenk line. 3: To HPLC injection valve. 4: To MFC. Right: The reagent module. 1: To the vacuum/argon module. 2: To reactor. 3: To sample loop I. 4: To the inert sample loading module. 5: To waste. 6: To sample loop II.

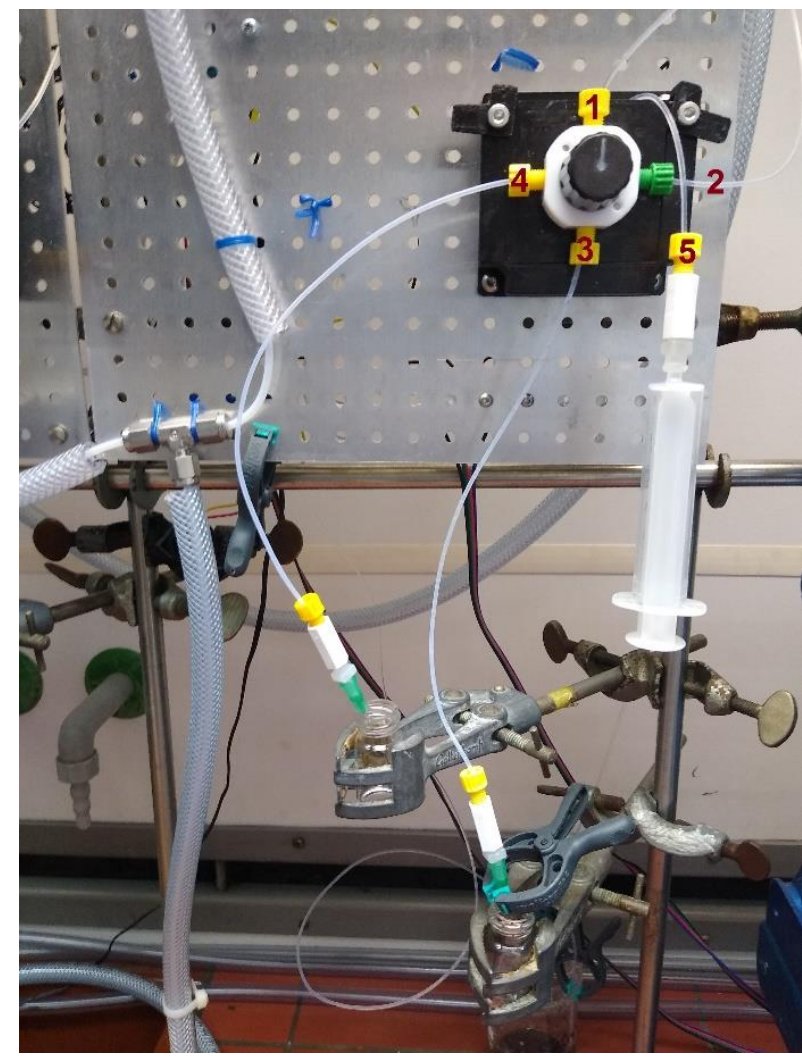

The inert sample load module. 1: To HPLC injection valve. 2: To Schlenk line. 3: To solution I. 4: To solution II. 5. To syringe (the tube is connected on the backside of the 5-port 5 positions valve). 


\subsection{Software}

\subsubsection{LabVIEW Software}

In order to establish a defined flow rate, the MFCs are adjusted by a LabVIEW-based software. The mass flow rate of the MFC must also be correlated with the measured pressure in order to yield the desired volumetric flow rate. Thus, the software also reads the pressure at each individual MFC via analog pressure sensors that are connected to an Arduino Uno unit. Furthermore, the HPLC injection valves are also connected to the Arduino and act as a trigger to start a stopwatch. The Arduino® is implemented into the LabVIEW software by using the graphical LabVIEW interface for Arduinos.

The Bronkhorst MFC's are implemented into the software by using the Flow-BUS VI's developed by Bronkhorst. The program is depicted below and is available for download at https://www.ni.com. 


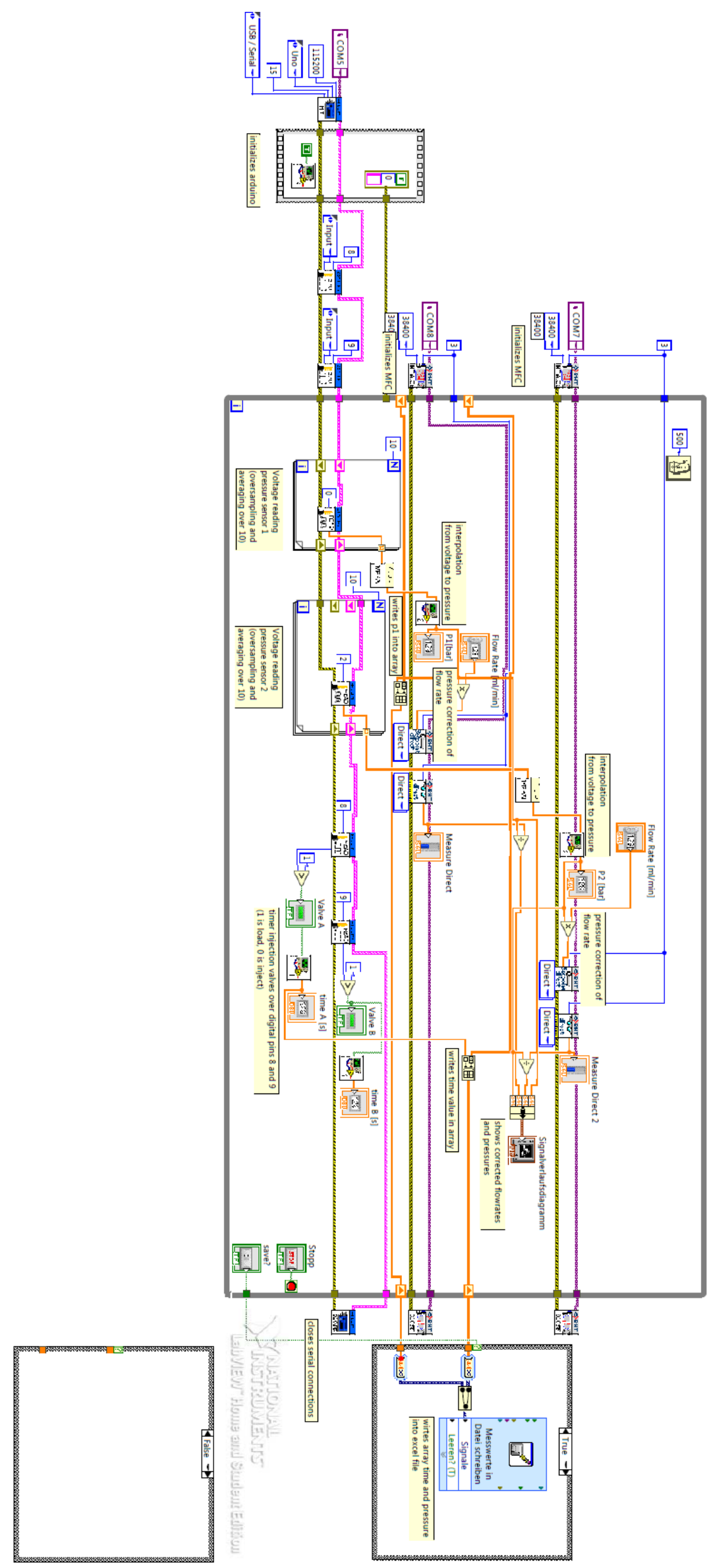




\subsubsection{Arduino Script for Controlling the Syringe Pumps}

The following script is a modified version of a script provided by Michael B. Spano and can be copied in Arduino IDE (free of charge available at https://www.arduino.cc/). It uses Mike McCauley's AccelStepper library which can be downloaded for free via Arduino IDE.

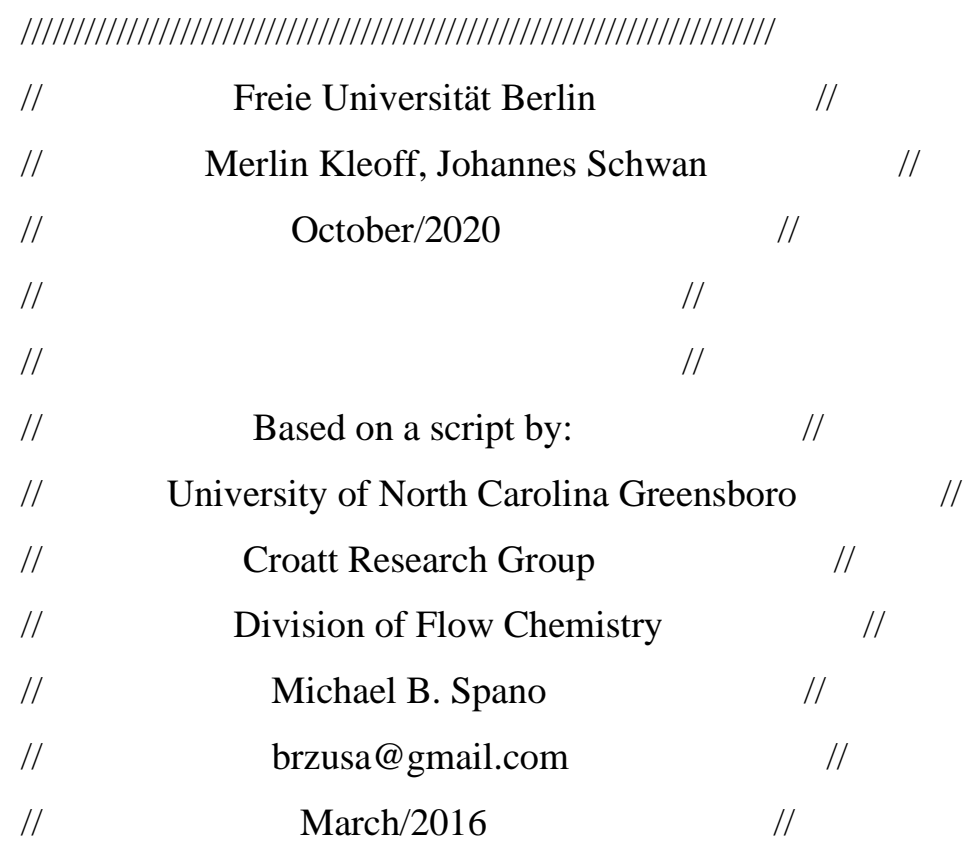

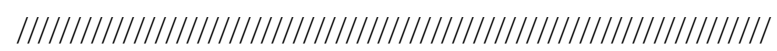

// Go to our homepage for info on how to build your own system //

// https://chem.uncg.edu/croatt/flow-chemistry/ //

// //

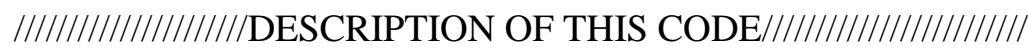

// //

// This program controls 3 syringe pumps simultaneously with the //

// aid of Mike McCauley's AccelStepper library. //

// //

// The pumps can be controlled via a USB connection to the arduino //

$/ /$ and sending commands via the Serial Monitor $(\mathrm{ctr}+\mathrm{shft}+\mathrm{m})$. //

// //

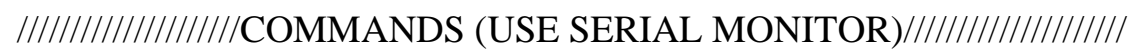

// * The pound symbol (\#) represents an arbitrary number //

// * The percent sign (\%) represents a number from 1 to 6 //

// //

// \#,\#,\#,\#,\#,\# - Sets the flowrate for all 6 pumps. //

// set\%]\#\#] - Sets the current volume that is in stepper[\%] // 
// reset] - Makes the current position correspond to $0 \mathrm{~mL} / /$

// volumes] - Returns how many $\mathrm{mL}$ are in the syringe //

// diamater\%]\#\#] - Changes the internal diamater of syringe \% //

// help] - Displays SPM, Diameters and Volumes //

// //

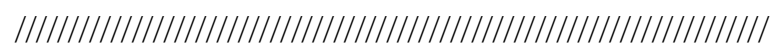

\#include < AccelStepper.h> //Includes the functions found in the AccelStepper library used to control the stepper motors.

AccelStepper stepper[6]; // Six instances of the AccelStepper are instantiated with their default constructors.

String inputString = "", command;

boolean stringComplete $=$ false, protect $=$ false, bounce $=$ false;

boolean rebound $=$ false, sufficientSolvent, sufficientReagents;

|/III||||||||||||||||||||||||||||||||||||||||||||||||||||||||||||||||

int i;

float ThreadDensity $=0.8$; / Thread density of lead screw, Unit: [Revolutions per millimeter]. This can be changed if a different lead screw was used to build the pumps.

float stepAngle $=0.1125$; / This is the stepper motor step angle.

float Position[7];

float position1, position2, position3, rate1, rate2, stoich1 $=1.0$, stoich $2=1.0$;

float Diameter[7] $=\{14.5,14.5,14.5,14.5,14.5,14.5\}$; / The default value for syringe diameter is

$20.0 \mathrm{~mm}$

float commandval;

float Rate[7];

float Limit[7];

int commaIndex[6];

int bracketIndex[3];

unsigned int start T, nowT;

float spm[7]; // spm is a acronym for 'Steps Per Milliliter'

// spm is calculated during void setup() and will differ based on

// Diameter, ThreadDensity and StepAngle

||||||||||||||||||||||||||||||||||||||||||||||||||||||||||||||||||||||| 


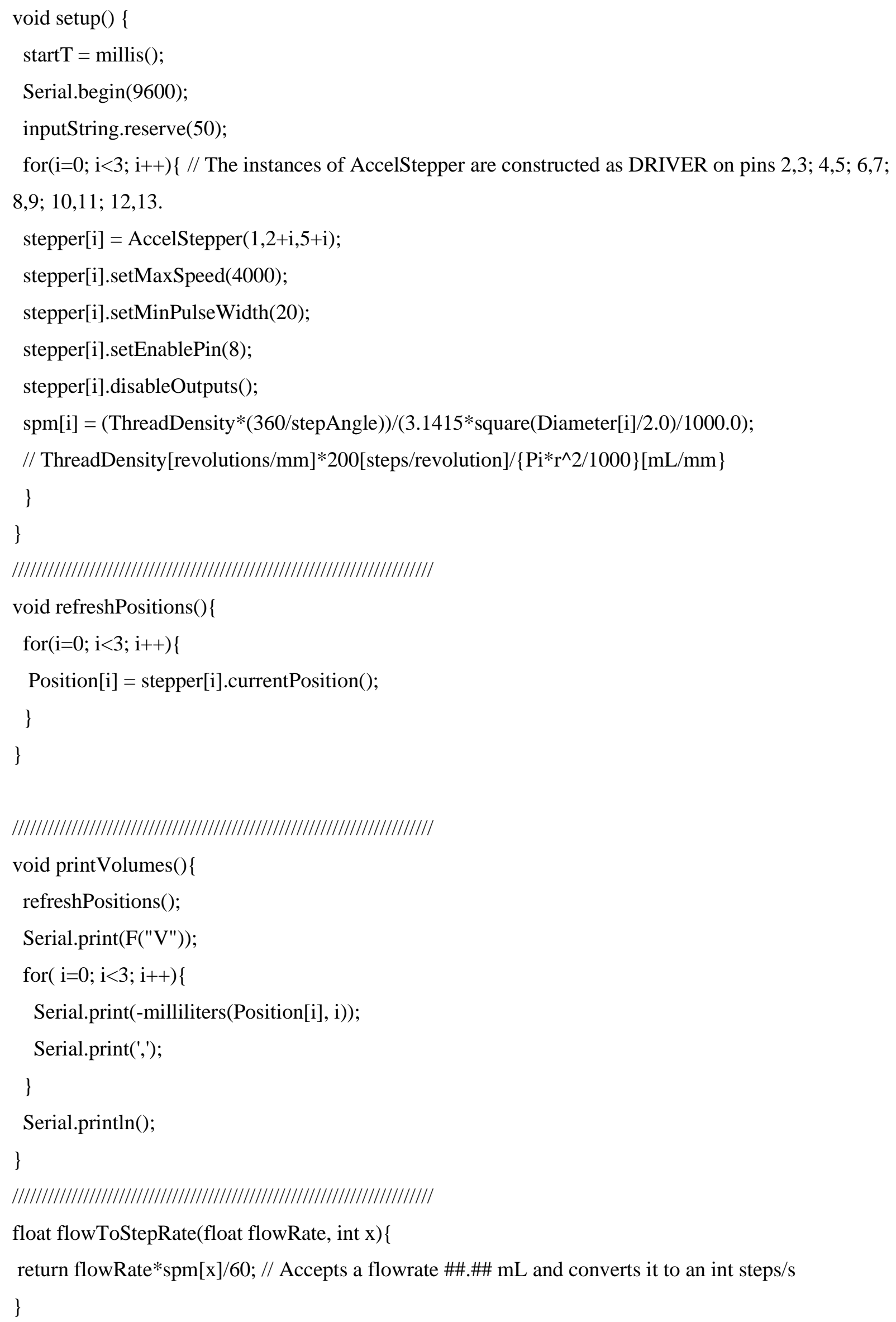




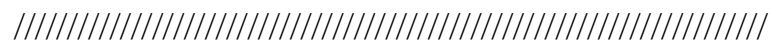

float volumetosteps(float $\mathrm{mL}$, int $\mathrm{x})\{$

//Accepts a volume \#\#.\#\# and returns the corresponding integer of steps //the motor must take make.

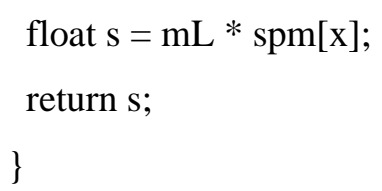

// This function creates a string 'inputString' by compound addition // of the characters stored in the serial buffer. The global boolean // 'stringComplete' is then set to true to tell the main loop that // a new user input is available.

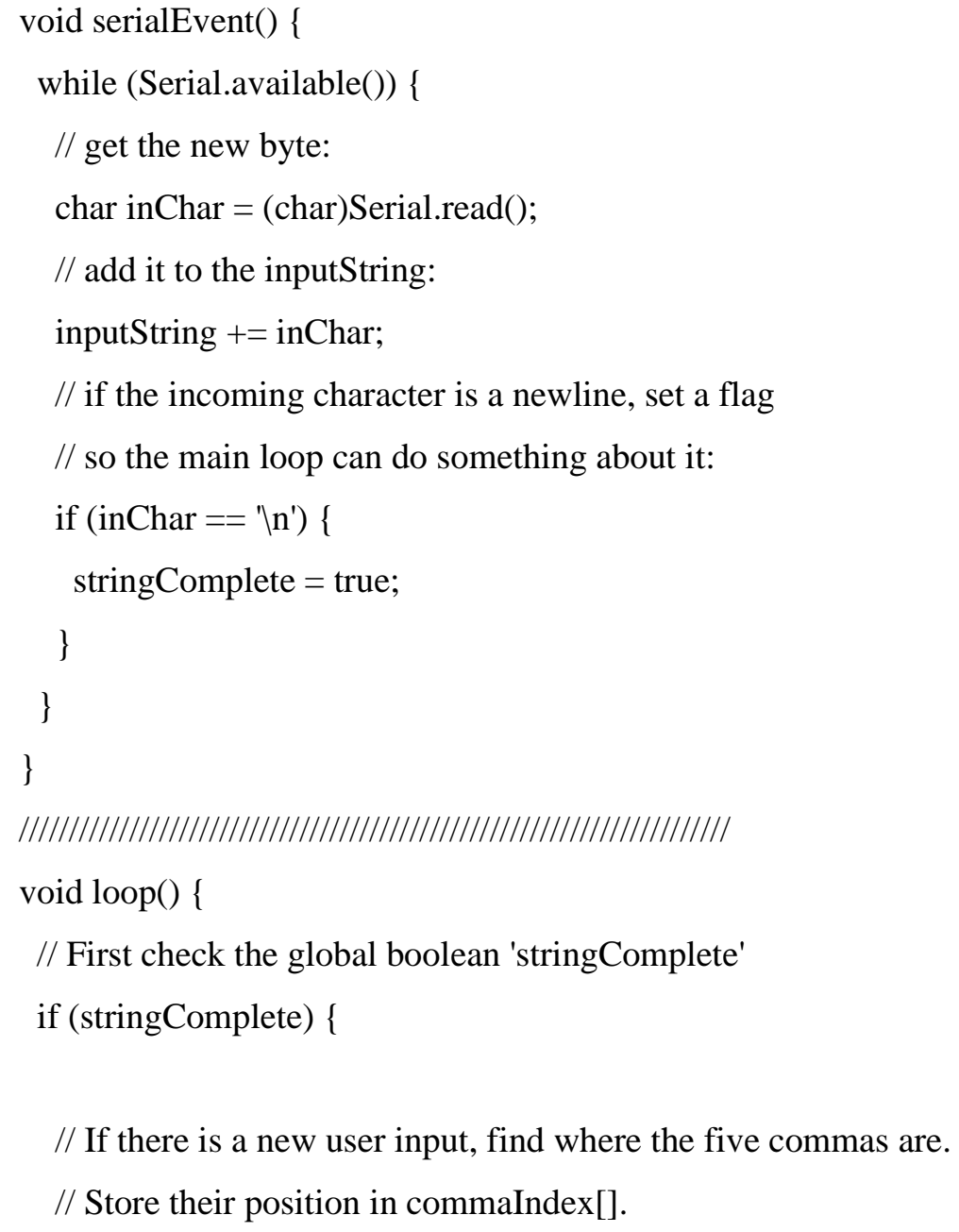




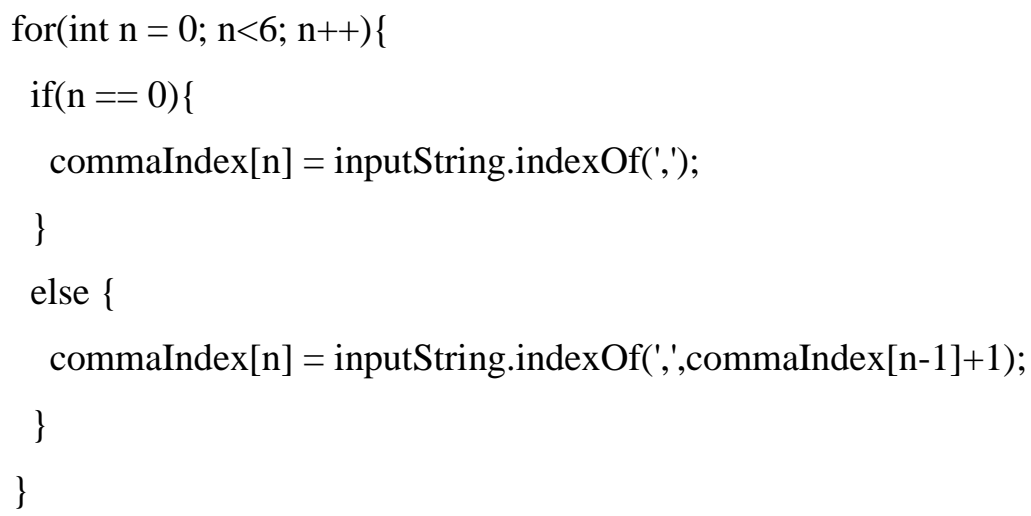

// Now store the position of the brackets in the bracketIndex[].

bracketIndex[0] = inputString.indexOf(']');

bracketIndex[1] = inputString.indexOf(']', bracketIndex[0]+1);

// Now split the inputString at each commaIndex

// Convert the strings to a floats and store them in Rate[]

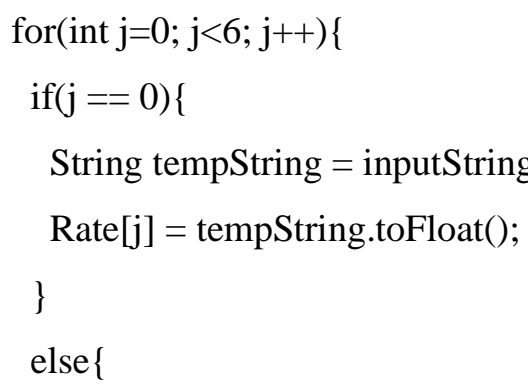

// Do the same for the bracket indexes

// Store the first as a String type variable and the second as a Float type

String command $=$ inputString. $\operatorname{substring}(0$, bracketIndex[0]);

commandval $=$ inputString .substring $($ bracketIndex[0]+1, bracketIndex[1]).toFloat();

// Now the original 'inputString' is cleared

// The global boolean 'stringComplete; is set to false. 
inputString = "";

stringComplete $=$ false;

// Now that the user input has been processed the code

// proceeds to manage the stepper motors. First thing

// is to refresh where each stepper is with respect to

// it's initial position.

refreshPositions();

// Now begins a multitude of 'if' statements to check what

// the program should do with the users input. Most procedures

$/ /$ are evident in their functionality.

if (command == "volumes" )printVolumes();

if $($ command $==$ "reset" $)\{$

for(int $\mathrm{g}=0 ; \mathrm{g}<6 ; \mathrm{g}++)\{$

stepper[g].setCurrentPosition(0);

Diameter $[\mathrm{g}]=20.0$;

\}

refreshPositions();

Serial.println(F("reset"));

\}

// Ceck if the command string contains "set" and change the appropriate volume if so.

// Remember the steppers are zero indexed but the pumps are one indexed.

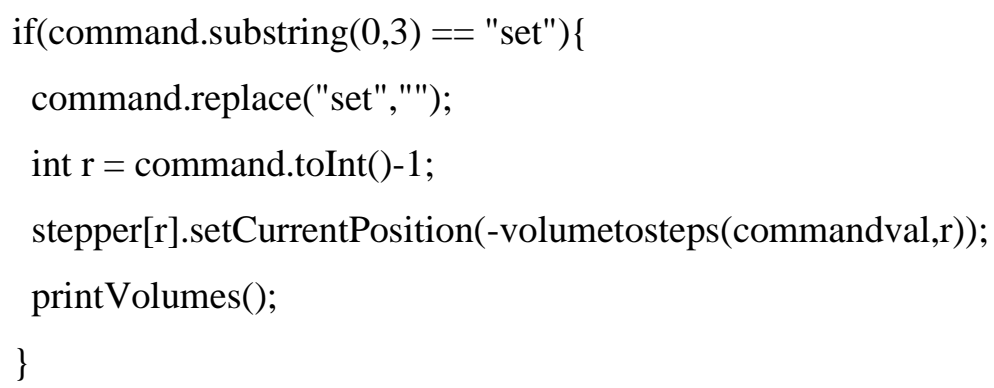

// Ceck if the command string contains "diameter" and change both the appropriate diameter // and the spm[] calculation for that pump. 
// Remember the steppers are zero indexed but the pumps are one indexed.

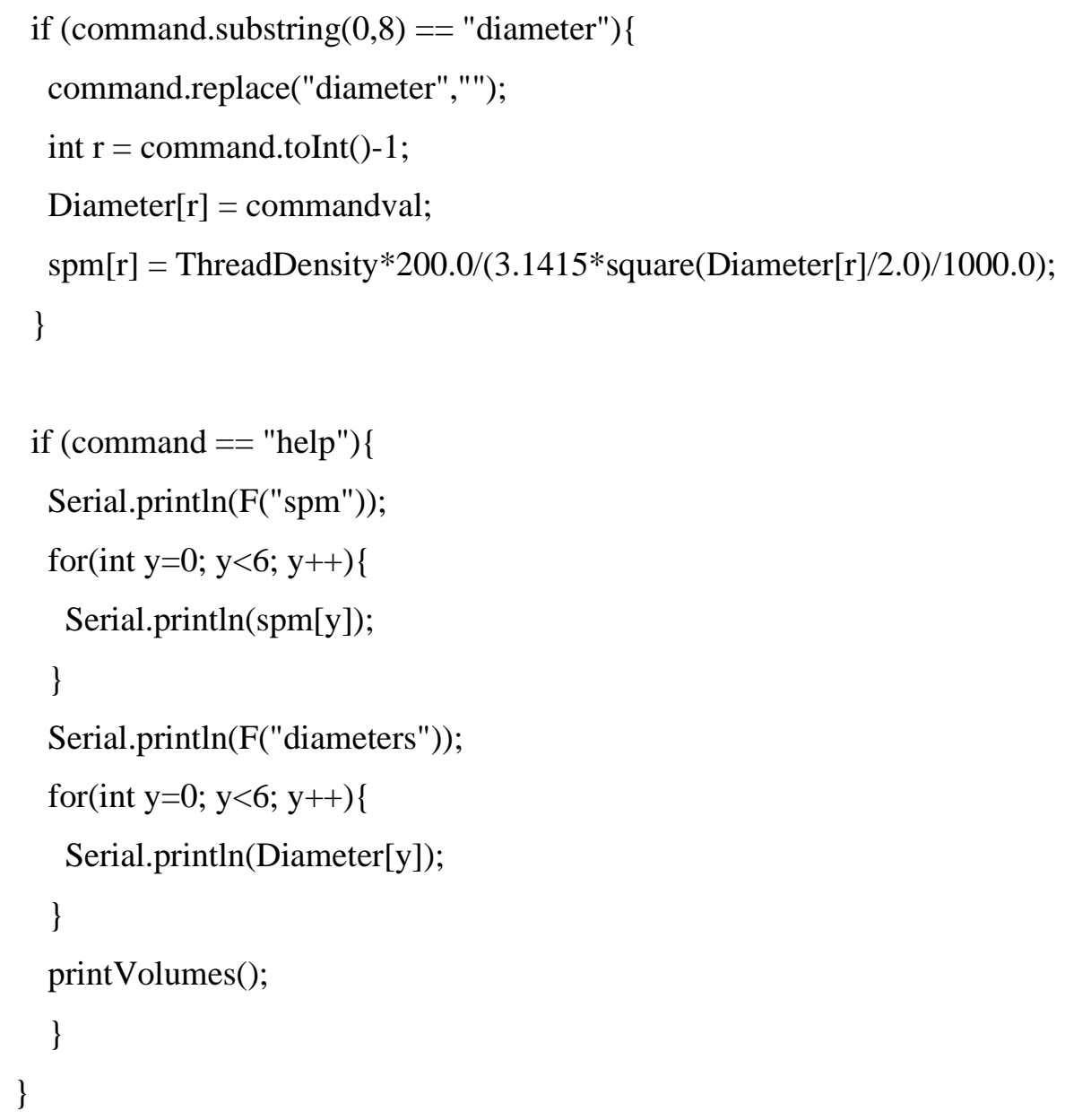

// Now that the serial event has been handled the motors must be polled // This is done using the functions from the AccelStepper Class

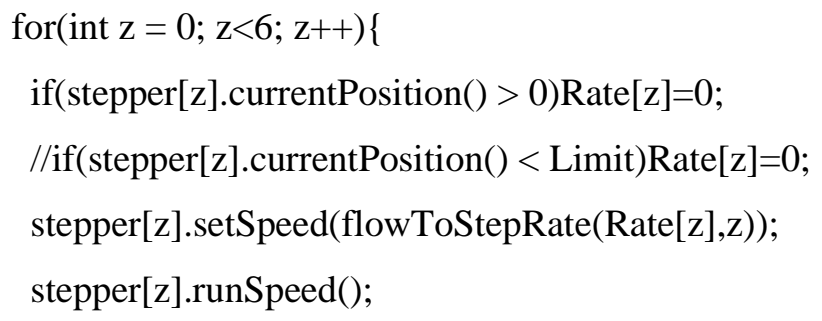




\section{Handling of the Flow Platform}

\subsection{Functions of the Modules}

\subsubsection{Vacuum/Argon Module}

The vacuum/argon module allows switchable connection to either a MFC or a vacuum/argon manifold. The heart of the module is a 4-port-T-valve.

Mode 1: idle

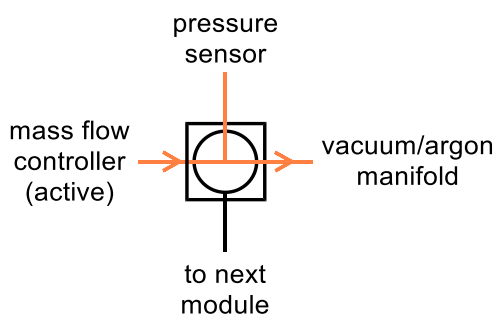

In this mode, the MFC feeds an argon flow to the vacuum/argon manifold, while the next module is disconnected. The pressure is measured by the pressure sensor. This mode is good for the warm-up period of the MFC ( 30 min).

Mode 2: drying/flushing mode ("Schlenk-in-flow" (SiF) mode)

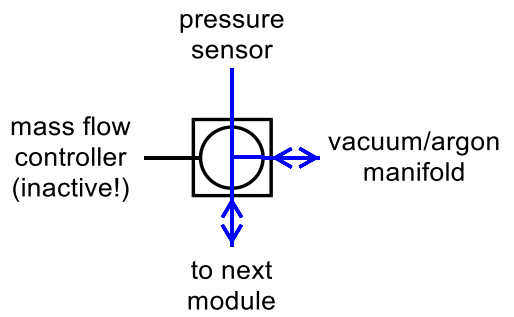

In this mode, the MFC is disconnected and has to be switched to a mass flow of $0 \mathrm{~mL} / \mathrm{min}$ to avoid the build-up of pressure. The pressure sensor, the vacuum/argon manifold, and the next module are connected. By using the vacuum/argon manifold, the next module can be evacuated, solvents can be evaporated or the next module can be flushed with argon. This mode allows the "Schlenk-in-flow" ( $\mathrm{SiF}$ ) techniques. The pressure sensors are quite resistant against most solvents and can be easily replaced as they are relatively inexpensive. 
Mode 3: not recommended!

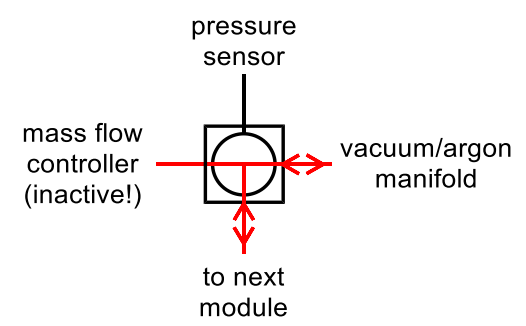

This mode works in the same way as mode 2. In this mode, the MFC has to be switched to a mass flow of $0 \mathrm{~mL} / \mathrm{min}$, to allow a proper vacuum. The build-up of pressure is avoided in this mode, but the MFC is connected to the next module and can be damaged by solvent or reagent vapors.

\section{Mode 4: Reaction mode}

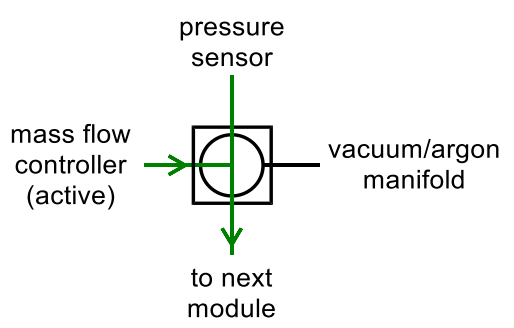

This mode enables the argon-driven flow of reagents. The MFC, the pressure sensor and the next module are connected. The argon stream provided by the MFC is corrected by continuous measurement of the system pressure. The argon stream is directed to the next module, while the vacuum/argon manifold is disconnected. 


\subsubsection{Vacuum/Argon Module Connected to the Reagent Module}

Typically, the vacuum/argon module is connected to the reagent module. The reagent module consists of a HPLC injection valve (6-port-2-ways) and is equipped with a sample loop for storage of reagent solutions.

Mode 1: drying/flushing mode (SiF mode)

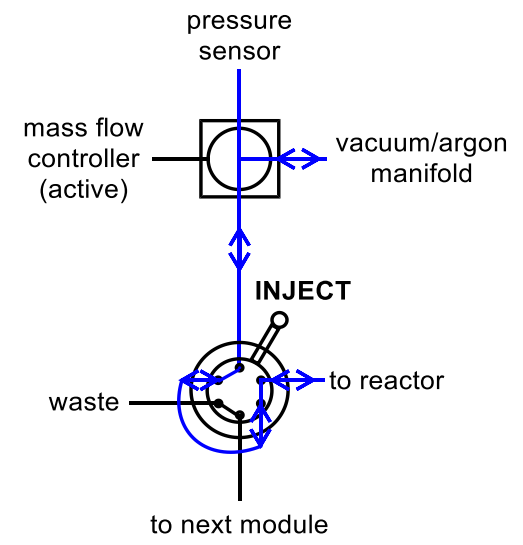

In this mode, the vacuum/argon manifold is connected to the sample loop and the reactor. Thus, the sample loop and the reactor can be dried in vacuum and flushed with argon. To allow evacuation of the reactor, the end of the reactor is either a) sealed with plunger; b) is equipped with a canula and the canula is introduced through a septum of a closed (Schlenk-)flas; or c) is connected with a valve that switches between a plunger and an outlet in a collection flask.

\section{Mode 2: sample loading mode}

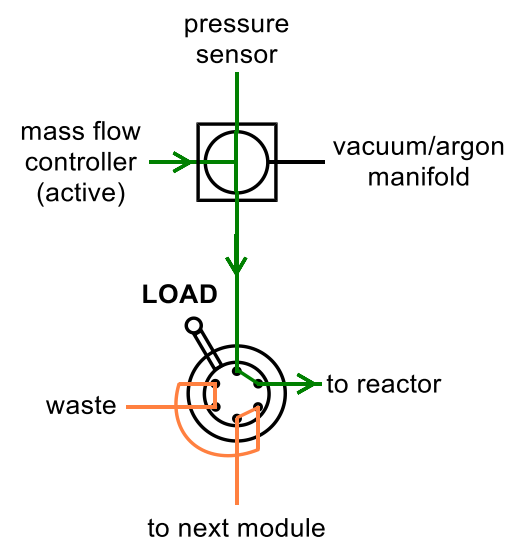

In this mode, the MFC flushes the reactor consistently with argon, while the sample loop can be loaded with a reagent solution. 


\section{Mode 3: reaction mode}

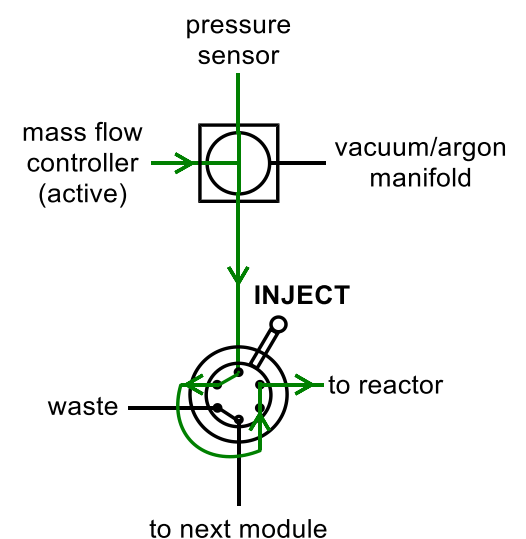

The HPLC injection valve is switched to the injection-position and a liquid slug of the reagent solution is inserted in the argon flow provided by the MFC.

\subsubsection{Inert Sample Loading Module}

This module is important for SiF. It allows to load a reagent solution from a bottle or a Schlenk flask on a syringe. Then, the reagent solution can be loaded on a sample loop. Alternatively, the syringe can be pushed by a syringe pump to pump the reagent solution to another module or a reactor for flow reactions. This module allows also safe quenching or washing procedures.

Mode 1: idle

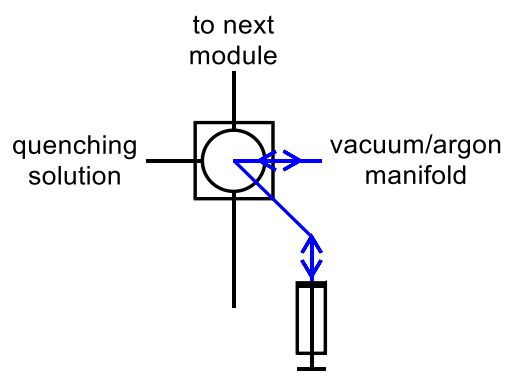

When the valve is switched to this position, the syringe is connected with the vacuum/argon manifold. Thus, the syringe can be evacuated and flushed with argon. In this way, argon can be loaded on the syringe. 


\section{Mode 2: loading}

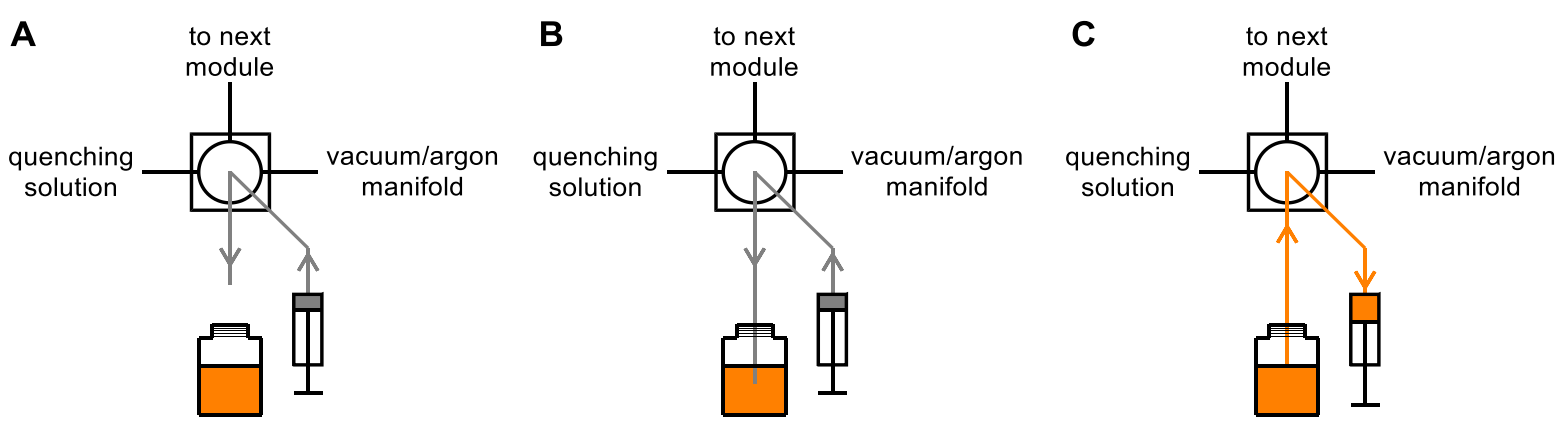

Left: In this position, argon from the syringe can be pushed through the tubes (grey) in order to remove oxygen and moisture from the tubes. Center: Then, the tube is connected to the reagent bottle or Schlenk flask under a flush of argon provided by the syringe. Right: The reagent solution is loaded on the syringe.

\section{Mode 3: injection}

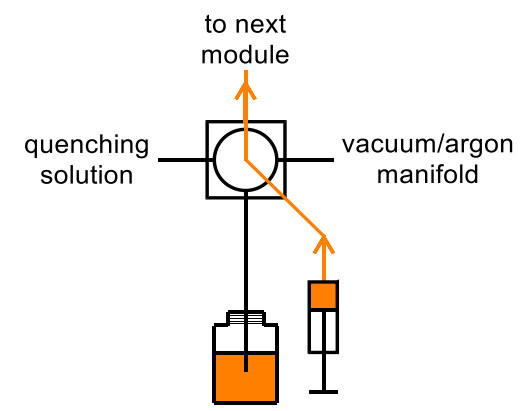

In this position, the reagent solution is injected in the next module.

\section{Mode 4: quenching/washing}

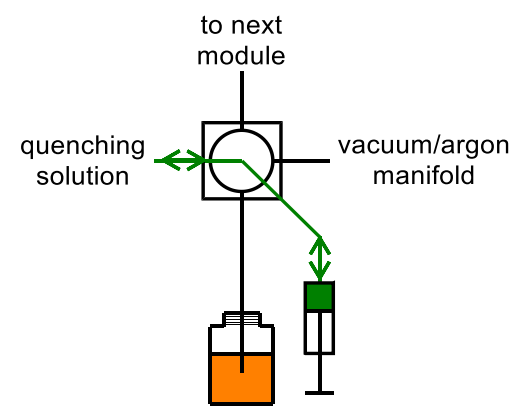

In this position, the syringe and the tubes can be quenched with a quenching solution. Afterwards, the syringe and the tubes can be washed with pure solvents. By removing the tube from the reagent solution bottle and switching to mode 3 , the tube can be washed. 


\subsection{How to Set up a Reaction Using all Modules ("Schlenk in Flow" (SiF) techniques)}

When all three modules are connected to each other, flow reactions can be set up under argon using $\mathrm{SiF}$. For drying of tubes, reactors and valves, they are evacuated in vacuum for $\sim 5$ min and subsequently flushed with argon for at least $30 \mathrm{~s}$. It has to be noted that drying of long tube reactors requires more time. Flushing an evacuated tube with a length of $10 \mathrm{~m}$ (FEP, outer diameter 1/16", inner diameter 1/32") with argon takes several minutes.

\section{Step 1: warm-up period, drying of tubes}

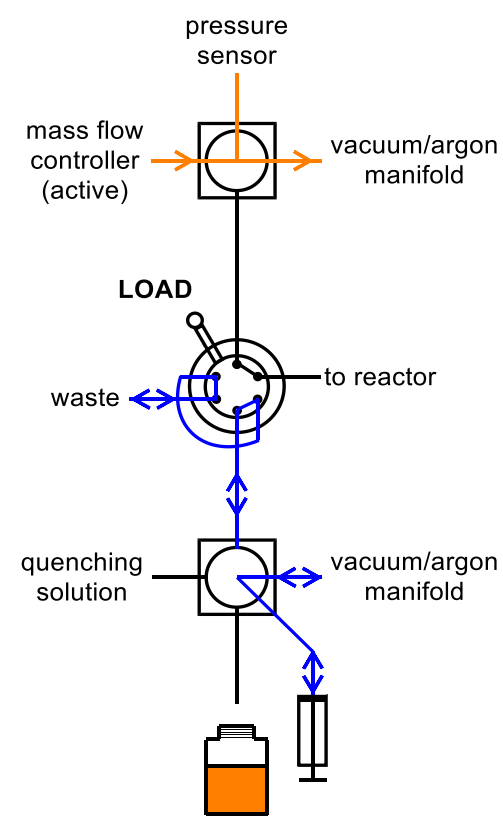

The MFC is warming up feeding argon in the vacuum/argon manifold. The HPLC injection valve is in load position. The sample loop is evacuated and flushed with argon via the connection of the waste with the vacuum/argon manifold. The 4-port selection valve is switched to the vacuum/argon manifold to evacuate and flush the disposable syringe with argon. 


\section{Step 2: warm-up period, drying of tubes}

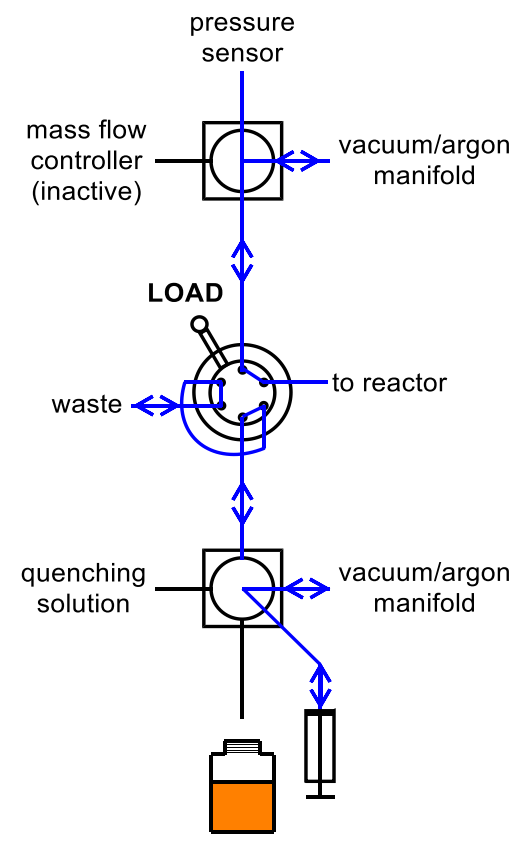

The MFC is switched to a flow rate of $0 \mathrm{~mL} / \mathrm{min}$. The 4-port-T-valve is switched, and the reactor is evacuated and flushed with argon. To do so, the end of the reactor is either sealed with plunger. Alternatively, the end of the reactor tube is equipped with a canula and the canula is introduced through a septum of a closed (Schlenk-)flask. It is also possible to connect the end of the reactor with a valve that switches between a plunger and an outlet in a collection flask.

\section{Step 3: idle mode}

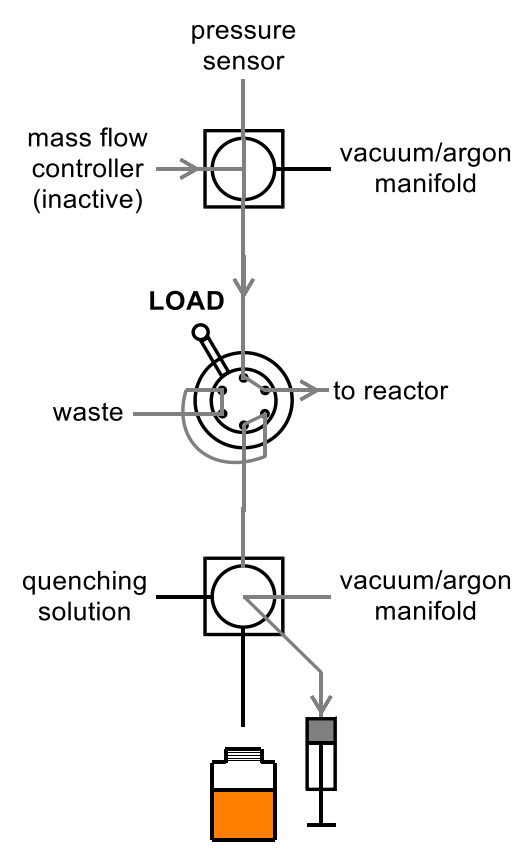

The 4-port-T-valve is switched and the MFC is switched to a flow rate of approximately $5 \mathrm{~mL} / \mathrm{min}$ feeding argon through the reactor. The disposable syringe is loaded with argon. 


\section{Step 4: flushing of the reagent tubes}

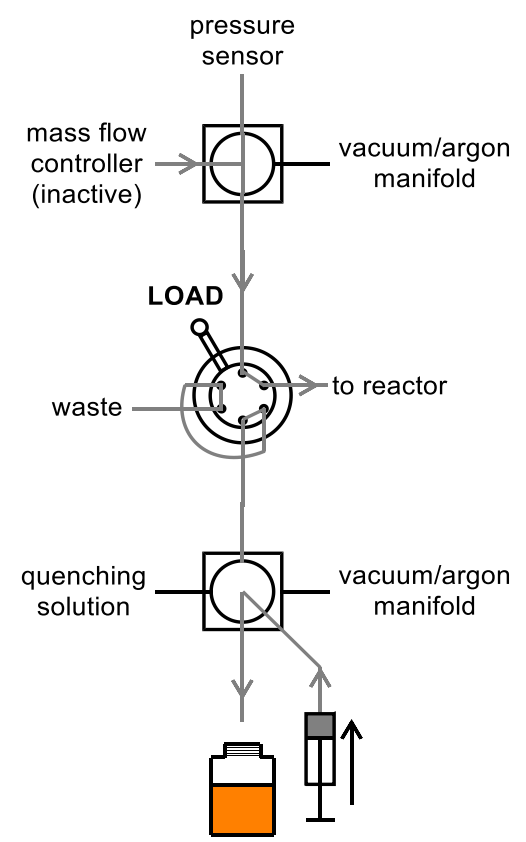

The 4-port selection valve is switched, and the disposable syringe is pushed to flush the argon inside of the syringe through the tube. In this way, the short tube between valve and reagent solution bottle is flushed with argon. Then, the 4-port selection valve is switched to the vacuum/argon manifold, the syringe loaded with argon, the 4-port selection valve is again switched to the reagent position and the argon inside the syringe pushed through the tubes. For very sensitive reagents, this procedure should be repeated an additional $1-3$ times.

\section{Step 5: loading of the reagent solution}

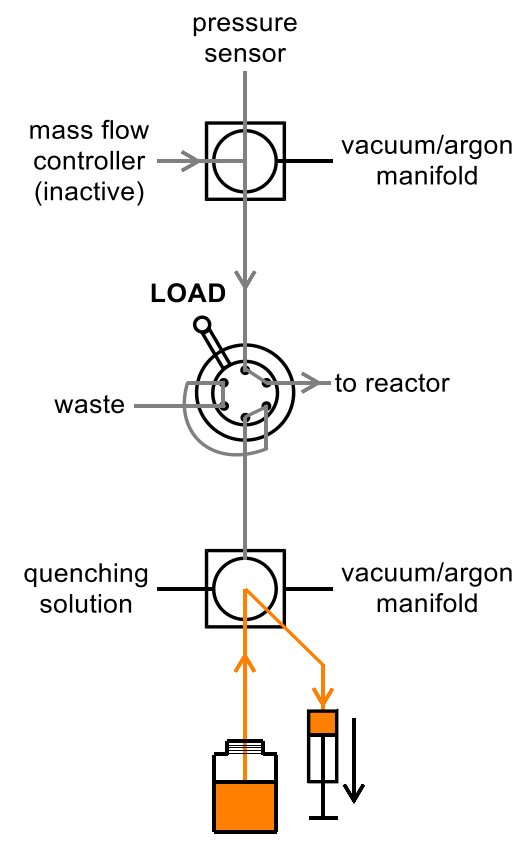

The reagent tube is introduced to the bottle of the reagent solution. The solution is loaded on the syringe. 
Step 6: loading of the reagent solution on the sample loop

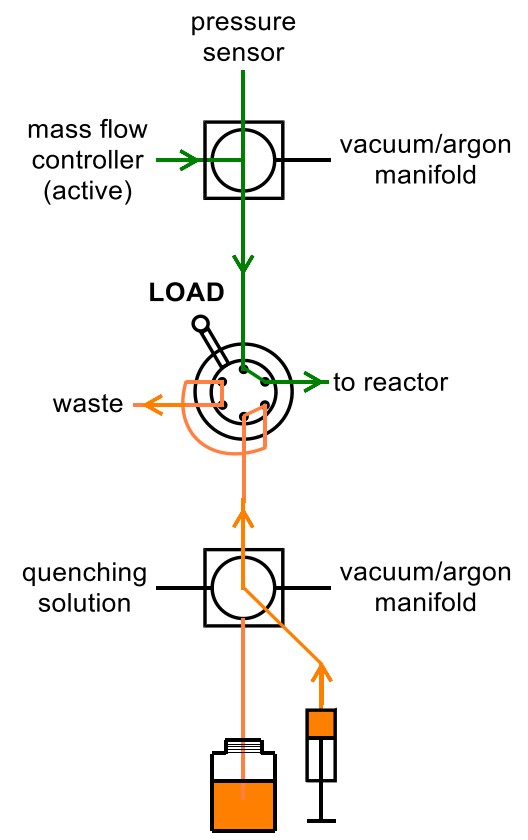

The 4-port selection valve is switched directing the reagent solution to the HPLC injection valve. The reagent solution is loaded on the sample loop by using the syringe.

\section{Step 7: running a reaction}

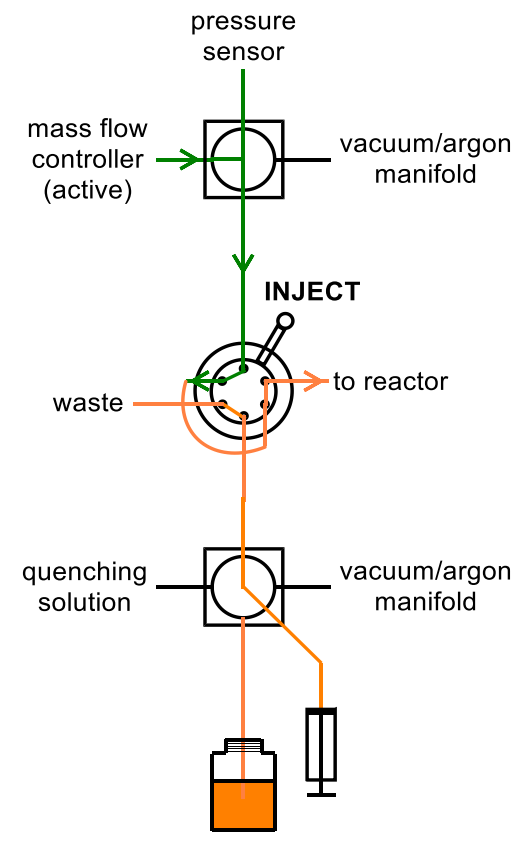

The reaction is started by switching the HPLC injection valve from the LOAD to the INJECTION position. The argon stream provided by the MFC is pumping the reagent solution from the sample loop to the reactor. 


\section{Step 8: removing remaining reagent solution I}

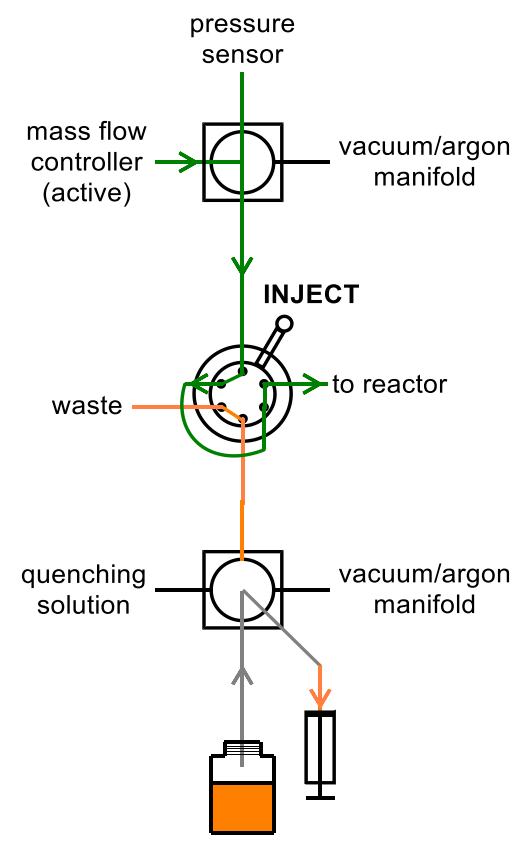

The 4-port selection valve is switched to the reagent solution and the canula reaching in the reagent solution is removed from the solution reaching in the gas space above the solution. The syringe is withdrawn to remove remaining reagent solution from the tubes.

\section{Step 9: removing remaining reagent solution II}

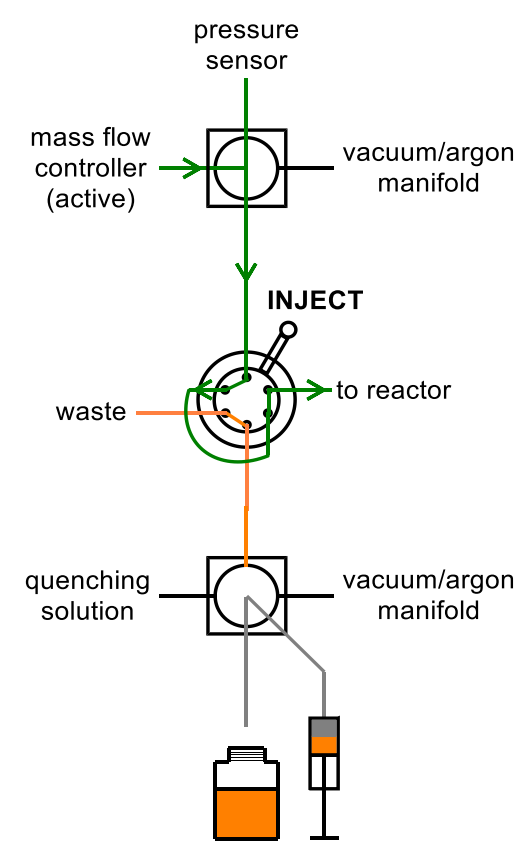

The canula is removed from the reagent solution. 


\section{Step 10: removing remaining reagent solution III}

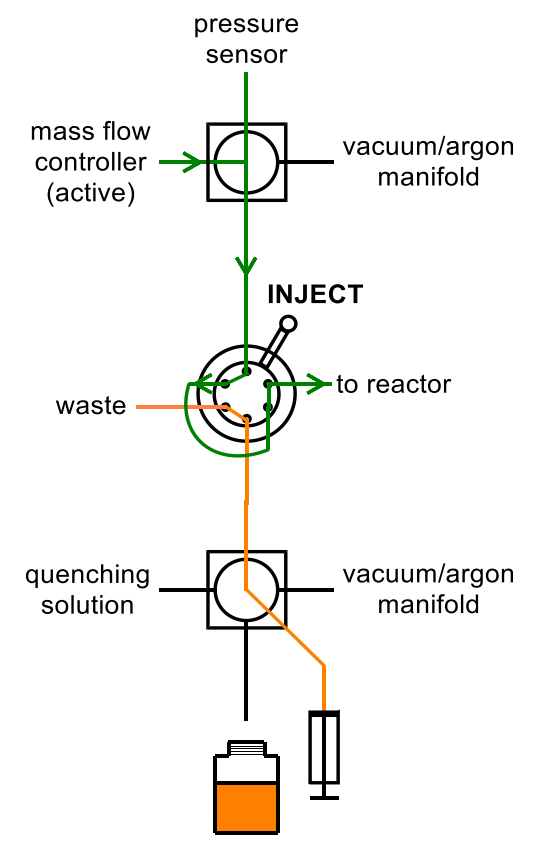

The reagent solution in the syringe is pumped to the waste by pushing the syringe.

\section{Step 11: washing the system I}

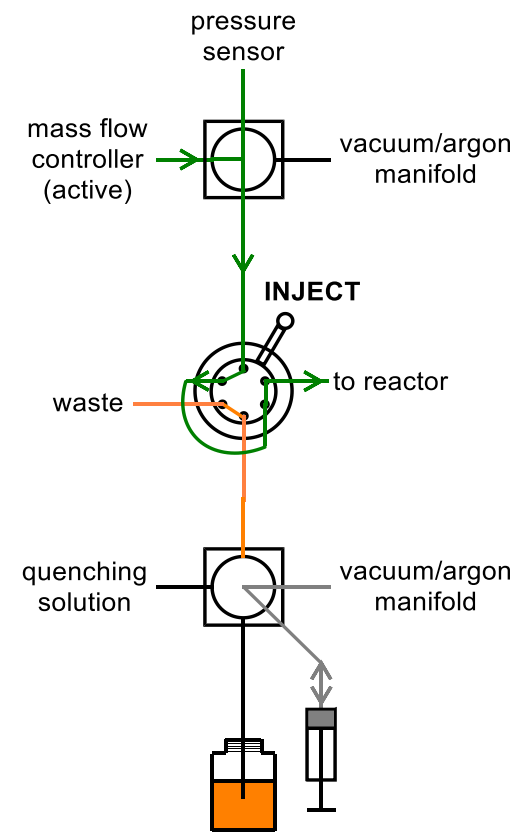

The 4-port selection valve is switched to the vacuum/argon manifold, the syringe loaded with argon, the 4-port selection valve is switched to the injection position and remaining reagent solution in the syringe and the tubes is pushed to the waste. 


\section{Step 12: washing the system II}

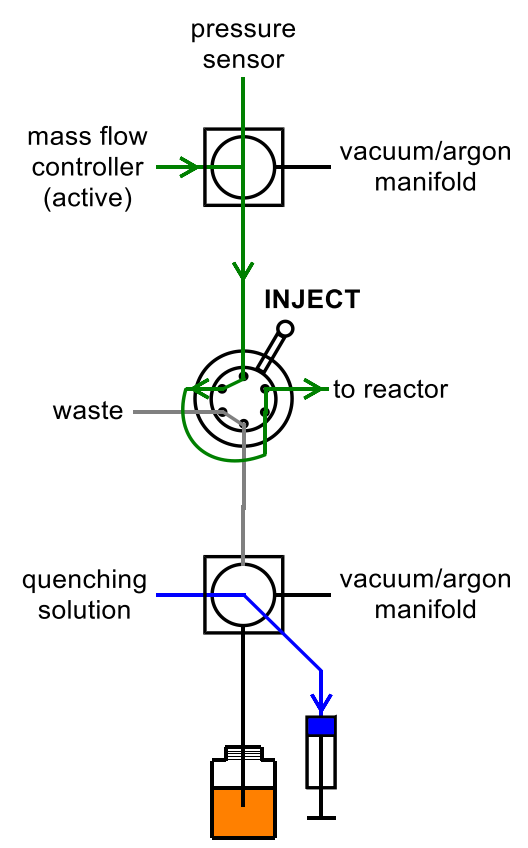

The 4-port selection valve is switched to the quenching solution and the solution is loaded on the syringe. The quenching solution can be e.g. iso-propanol for quenching organometallic reagents, but in most cases, it is recommended to use pure solvent, which should be the same as the one used for the reagent solution. When washing is performed with more "aggressive" solvents such as $\mathrm{CH}_{2} \mathrm{Cl}_{2}$ or tetrahydrofuran, at least one subsequent wash with iso-propanol or acetonitrile should be performed.

\section{Step 13: washing the system III}

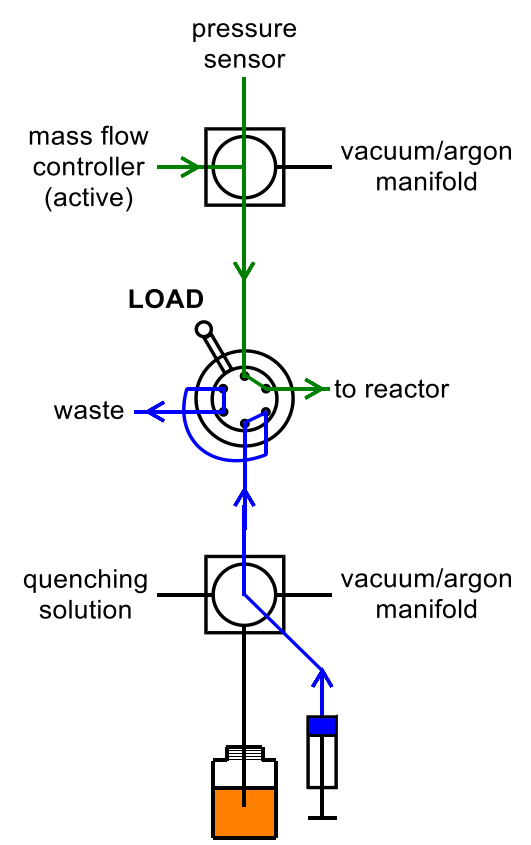

The 4-port selection valve is switched to the quenching solution. The quenching solution is loaded on the syringe. The HPLC injection valve is switched to the LOAD position. The quenching solution is loaded on the sample loop by using the syringe. 
Step 14: washing the system IV

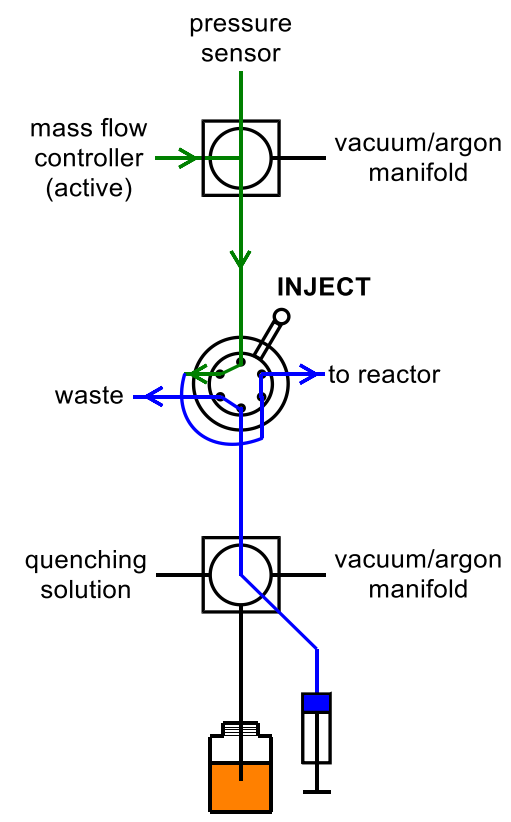

The HPLC injection valve is switched to the inject position and the quenching solution is pumped through the sample loop. Steps 12-14 are repeated at least two times. 


\subsection{Using the LabVIEW Interface}

To control the MFCs and to monitor system pressure and time reading of the HPLC injection valves, a graphical user interface for the LabVIEW software (LabVIEW 2016) was written.

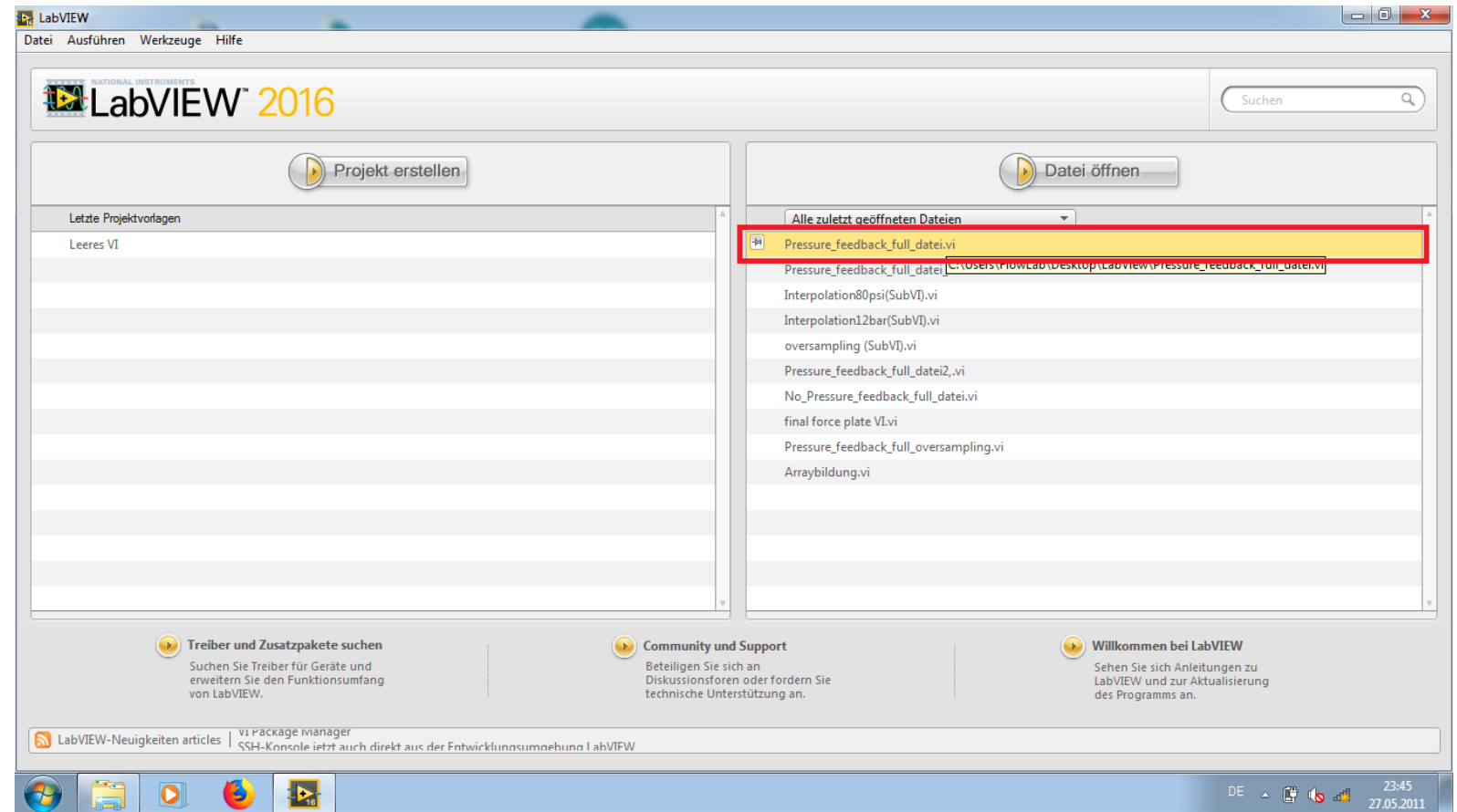

After opening LabVIEW, the script is started.

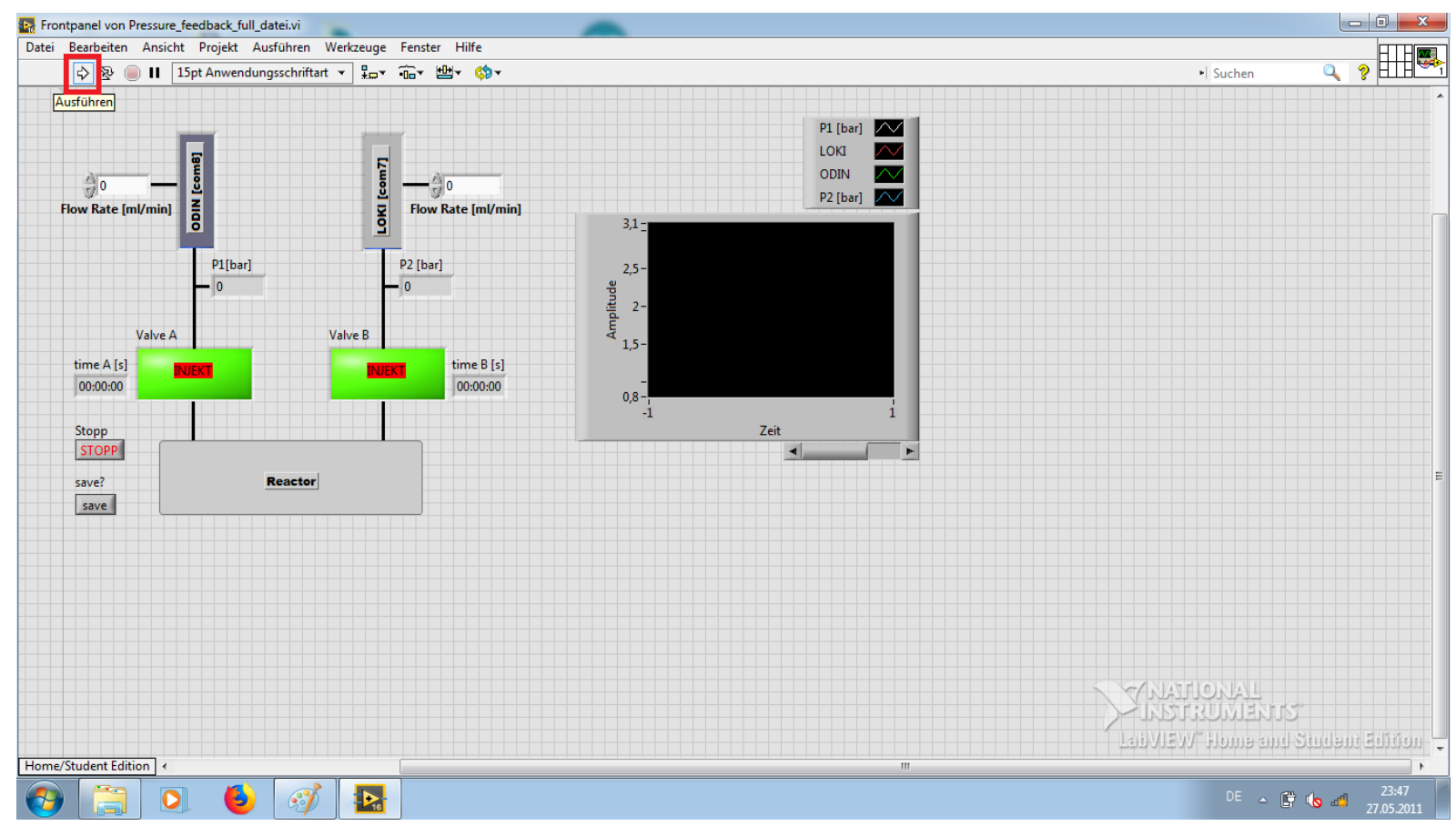

By clicking on the marked button (execute), the script is run. 


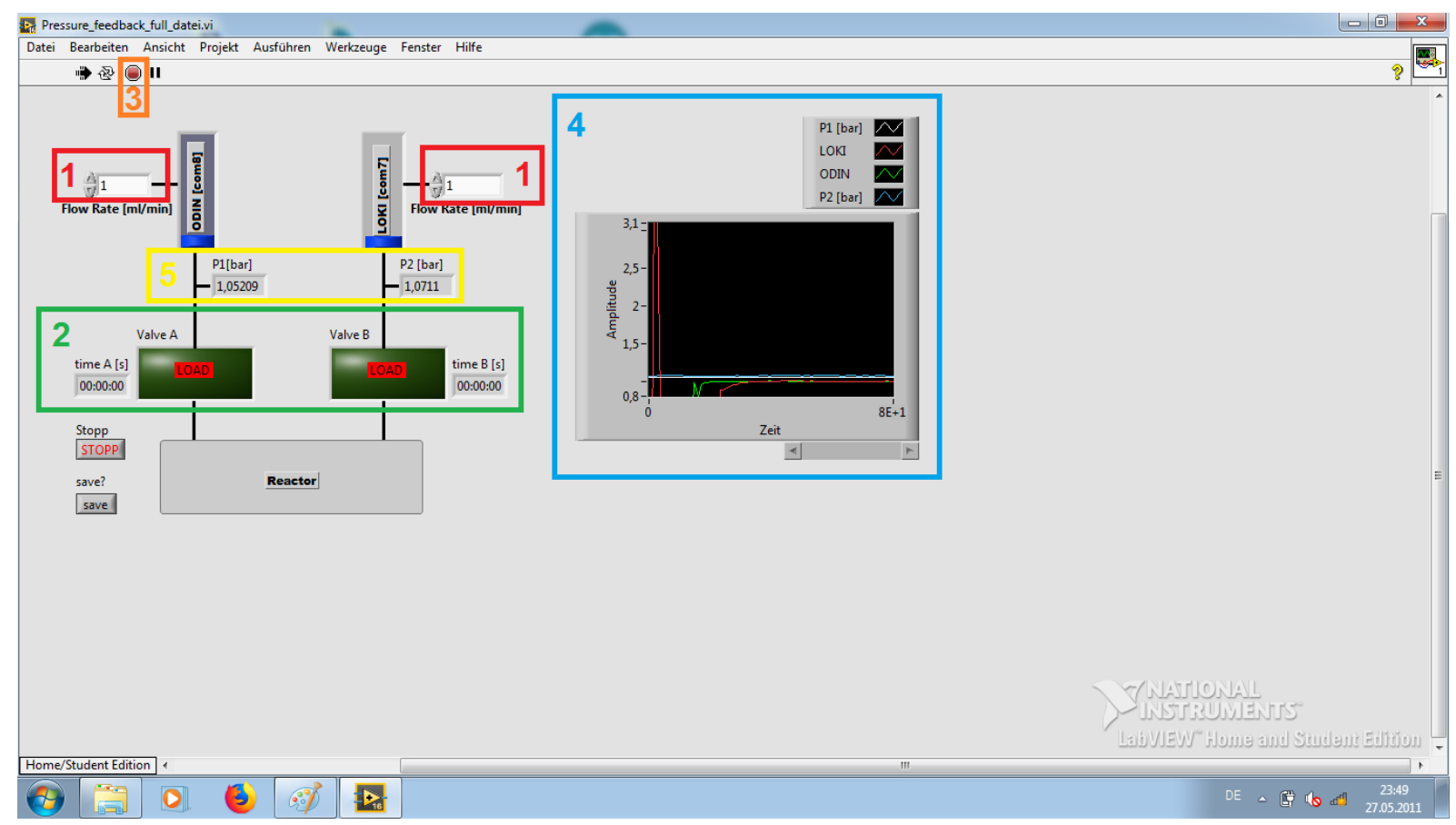

The graphical user interface: 1 . The flow rate is set by using the arrows or by entering the desired flow rate $[\mathrm{x}, \mathrm{y}] .2$. The valve timers are starting when the valve is manually switched from load to inject, which is also displayed in the interface. The timer is reseted by switching the valve back to load. 3 . The LabVIEW Script is stopped by clicking this button. 4. This diagram shows the measured pressure (yaxis) versus the time (x-axis). In addition, the corrected flow rate for both MFCs is showen separately. 5. The current pressure measured on the outlets of both MFCs is displayed separately and updated every second.

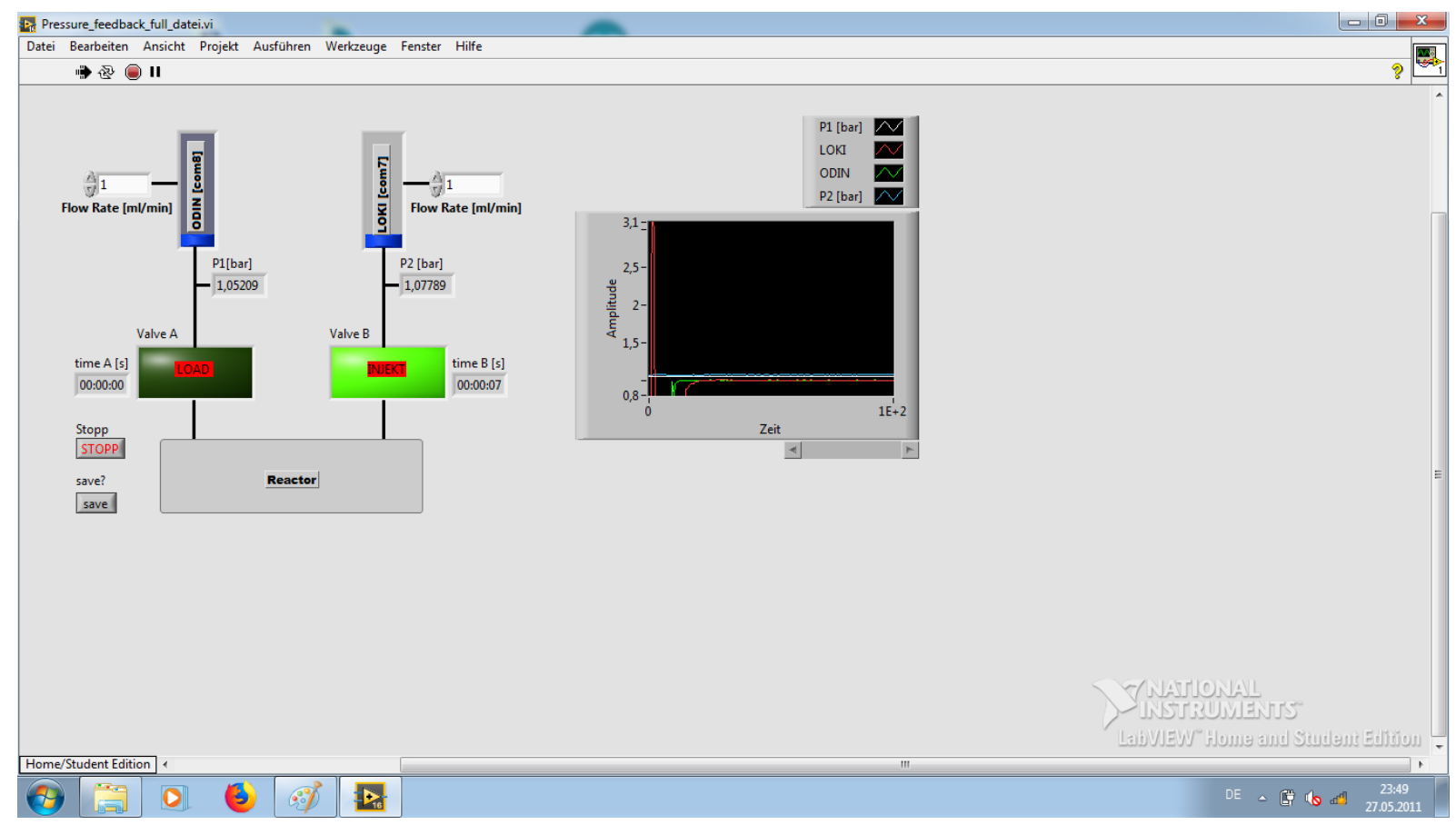

The counter of a HPLC injection valve is started by switching manually the corresponding HPLC valve from load to inject. 


\section{Experimental Procedures}

\subsection{Experiments to Check Oxygen-free Conditions Using SiF}

To investigate the efficiency of $\mathrm{SiF}$, the oxygen content of solutions in the flow system was monitored employing a commonly used titanium(III) metallocene complex as colorimetric indicator. ${ }^{[9]}$

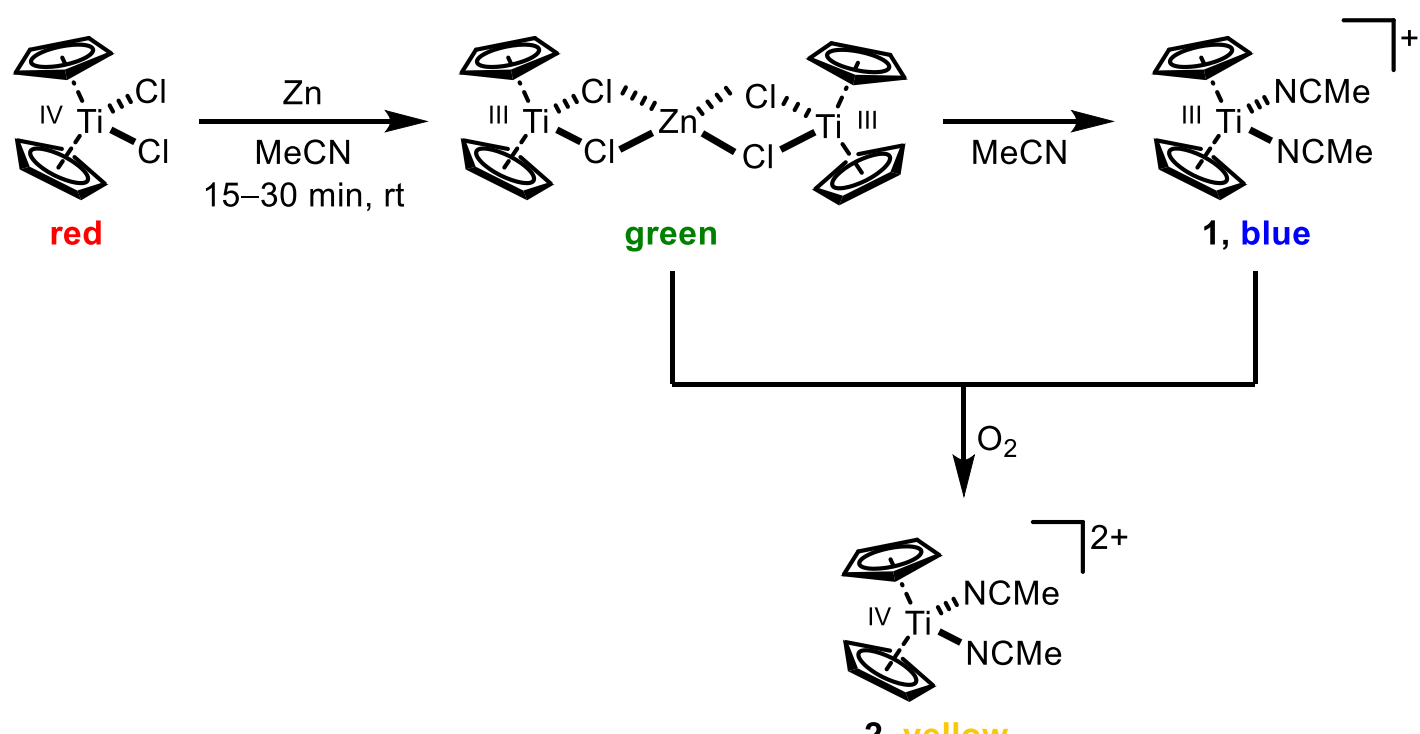

Scheme S1: Schematic presentation of the titanium(III) and titanium (IV) species formed in the colorimetric oxygen indicator solution. By reduction of titanocene dichloride $\left(\mathrm{TiCp}_{2} \mathrm{Cl}_{2}\right)$ with zinc dust, the green $\mathrm{Cl}$-bridged complex $\mathrm{Cp}_{2} \mathrm{Ti}(\mu-\mathrm{Cl})_{2} \mathrm{TiCp}_{2}$ is formed, which further reacts to blue $\mathrm{Cp}_{2} \mathrm{Ti}(\mathrm{III})(\mathrm{NCMe})_{2}(\mathbf{1})$. Both $\mathrm{Cp}_{2} \mathrm{Ti}(\mu-\mathrm{Cl})_{2} \mathrm{TiCp}_{2}$ and $\mathrm{Cp}_{2} \mathrm{Ti}(\mathrm{III})(\mathrm{NCMe})_{2}$ are readily oxidized by trace amounts of oxygen to give yellow $\mathrm{Cp}_{2} \mathrm{Ti}(\mathrm{IV})(\mathrm{NCMe})_{2}(\mathbf{2}) \cdot{ }^{[9,10]}$

Procedure for preparing and using of the indicator solution:

A Schlenk tube was charged with MeCN (20 mL, HPLC grade) and the solvent was purged with argon for $5 \mathrm{~min}$. Then, titanocene (II) dichloride (80-100 mg) and zinc dust (4-5 g) were added in an argon flush. The resulting red suspension was stirred with a large magnetic stirring bar until the suspension turned dark blue. The stirring was stopped to allow the solids to settle. The supernatant blue solution was loaded via syringe on a sample loop $(\mathrm{V}=2.2 \mathrm{~mL}$; FEP tube, outer diameter 1/16", inner diameter $1 / 32 ")$. 


\section{Experiment 1: Loading of a sample loop with $\mathrm{SiF}$}
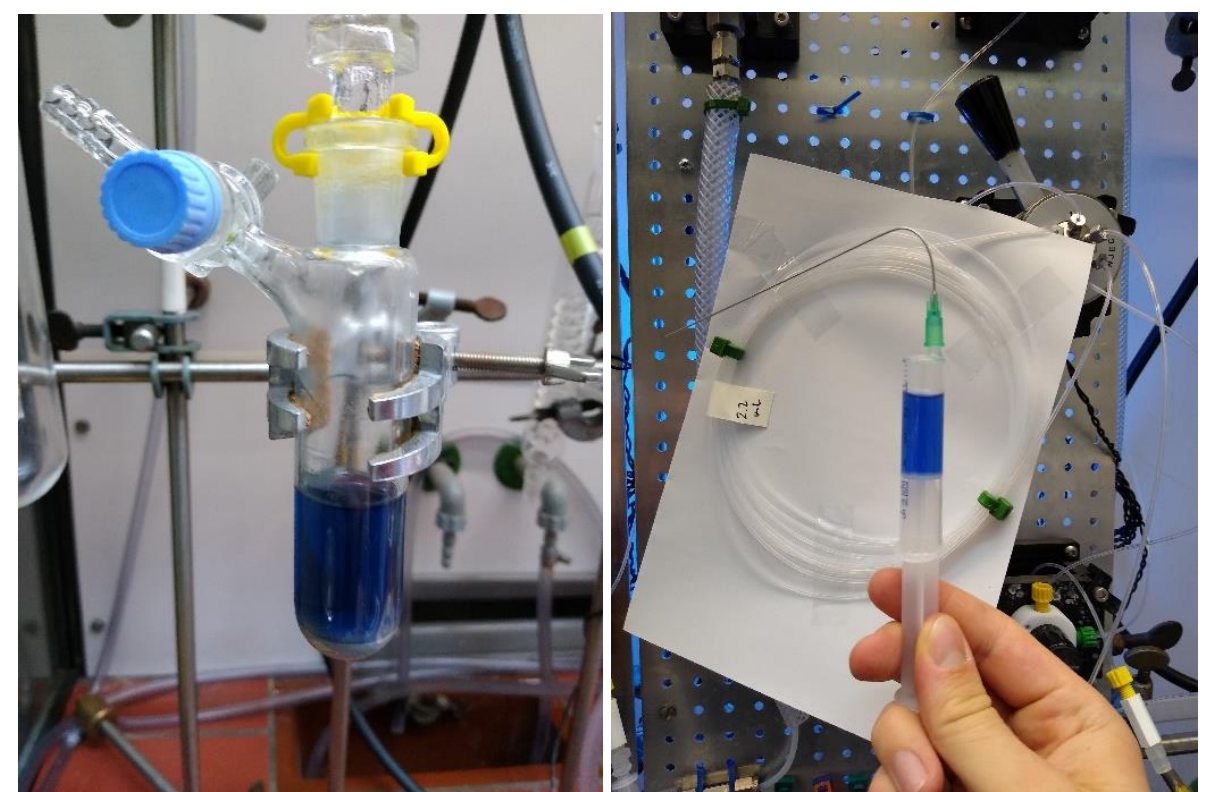

Left: The colorimetric indicator solution in a Schlenk tube. Right: The indicator solution loaded on a syringe.

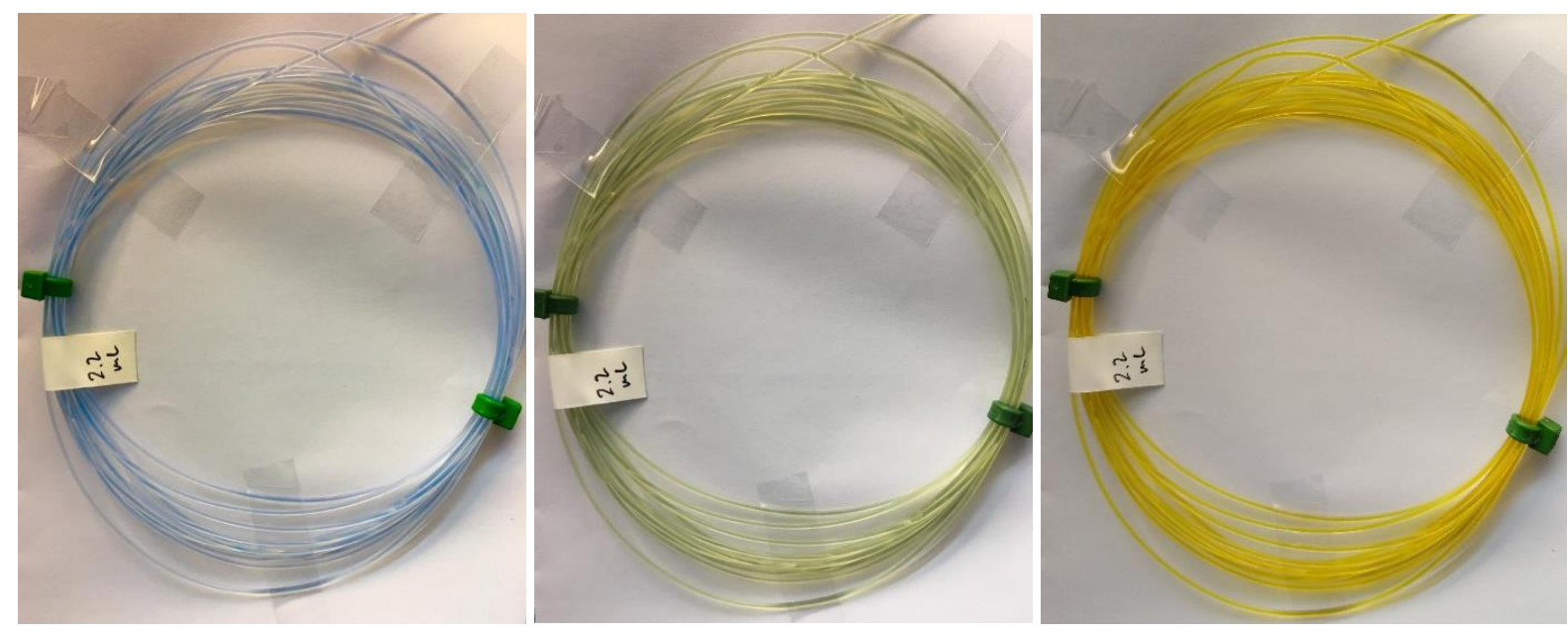

Left: The indicators solution $\sim 30$ seconds after loading on the sample loop. Center: After 30 min.

Right: After 60 min.

This experiment indicates that the indicator solution can be loaded under exclusion of air and moisture on the sample load enabled by SiF. However, completely anaerobic conditions cannot be maintained over a longer period of time very probably due to the oxygen permeability of the tubes consisting of fluorinated polymers. ${ }^{[1]}$ Therefore, very oxygen-sensitive reactions should be set up and realized within minutes or by using tubes made from stainless steel $316 \mathrm{~L}$ or comparable materials. 
Experiment 2: Loading of a sample loop without SiF

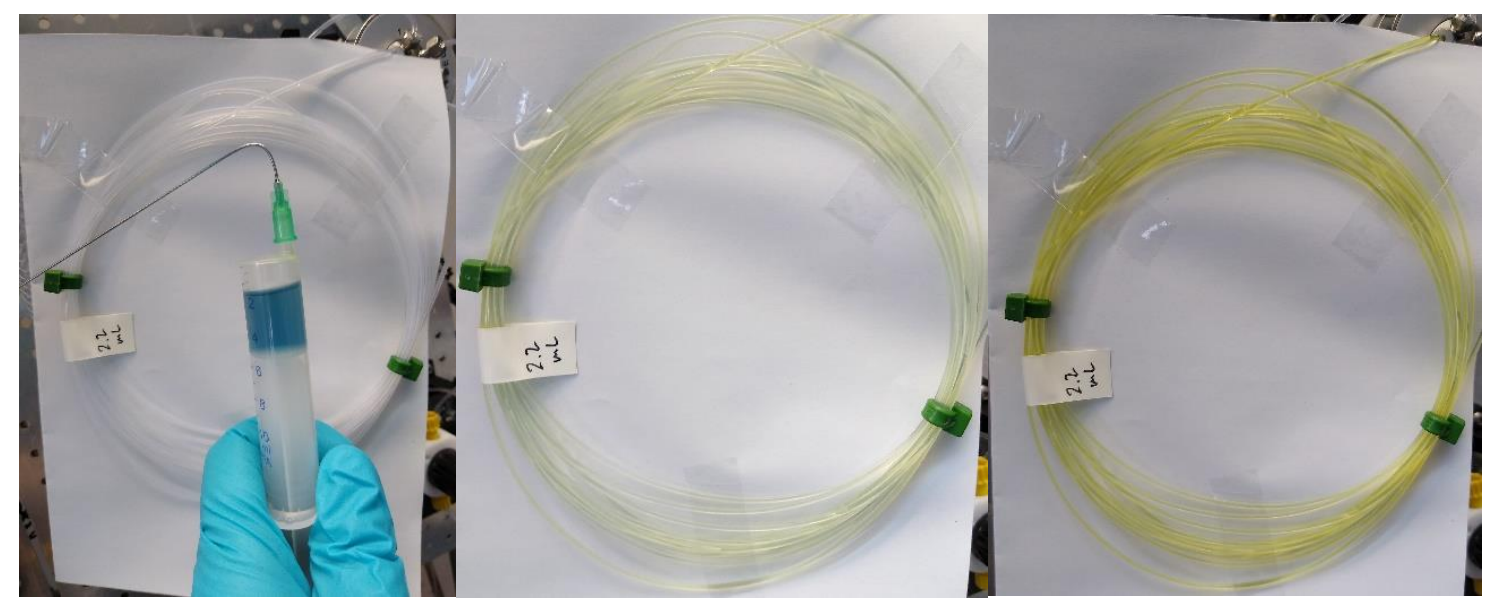

Left: The indicator solution loaded on a syringe. Center: The indicator solution $\sim 30$ seconds after loading on the sample loop. Right: After $10 \mathrm{~min}$.

Experiment 3: Loading of a sample loop without $\mathrm{SiF}$, flushing the tubes with argon for 5 min $\left(\mathrm{v}_{\text {flow }}=5 \mathrm{~mL} / \mathrm{min}\right)$
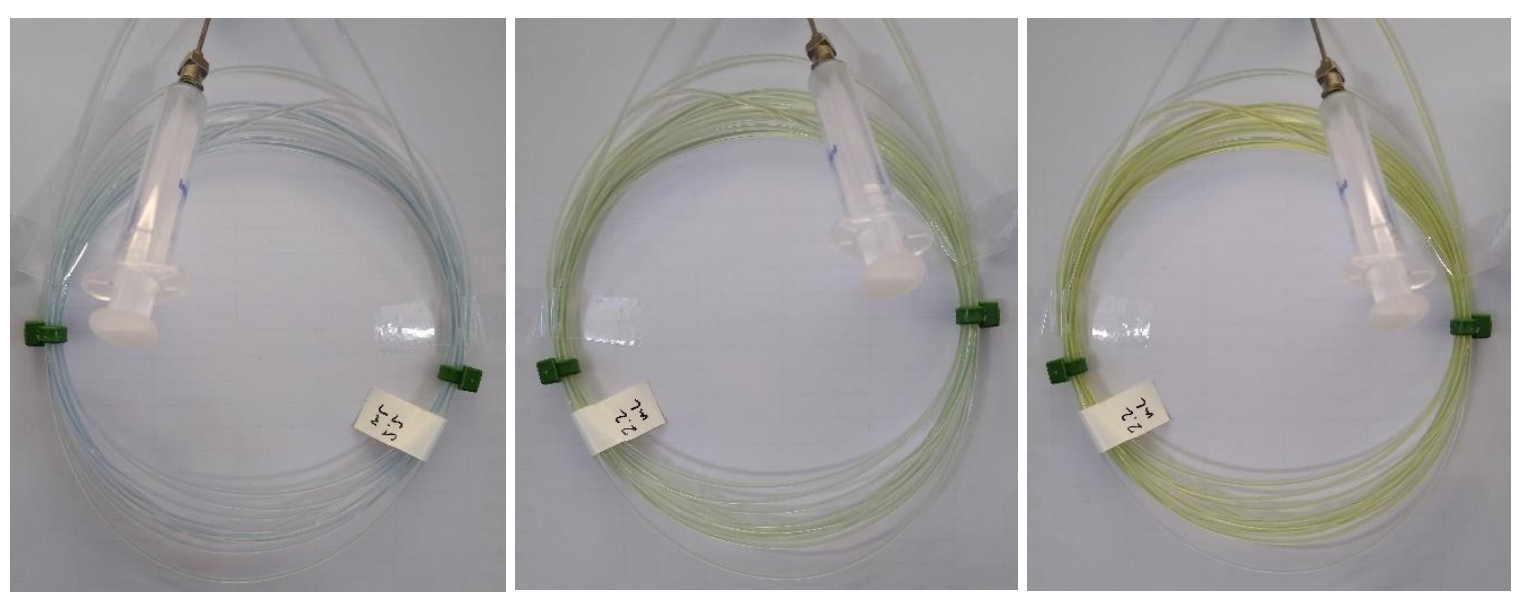

Left: The indicator solution $\sim 30$ seconds after loading on the sample loop. Center: After 10 min. Right: After 30 min.

\section{Experiment 4: Passing a solution of indicator complex 1 through a $10 \mathrm{~mL}$ reactor using $\mathrm{SiF}$}

In another experiment, the indicator solution was loaded on the sample loop and pumped using a MFC $\left(\mathrm{v}_{\text {flow }}=1 \mathrm{~mL} / \mathrm{min}\right)$ through a $10 \mathrm{~mL}$ tube reactor (FEP tube, outer diameter 1/16", inner diameter 1/32", $20 \mathrm{~m}$ length), which was previously deoxygenated using SiF. 

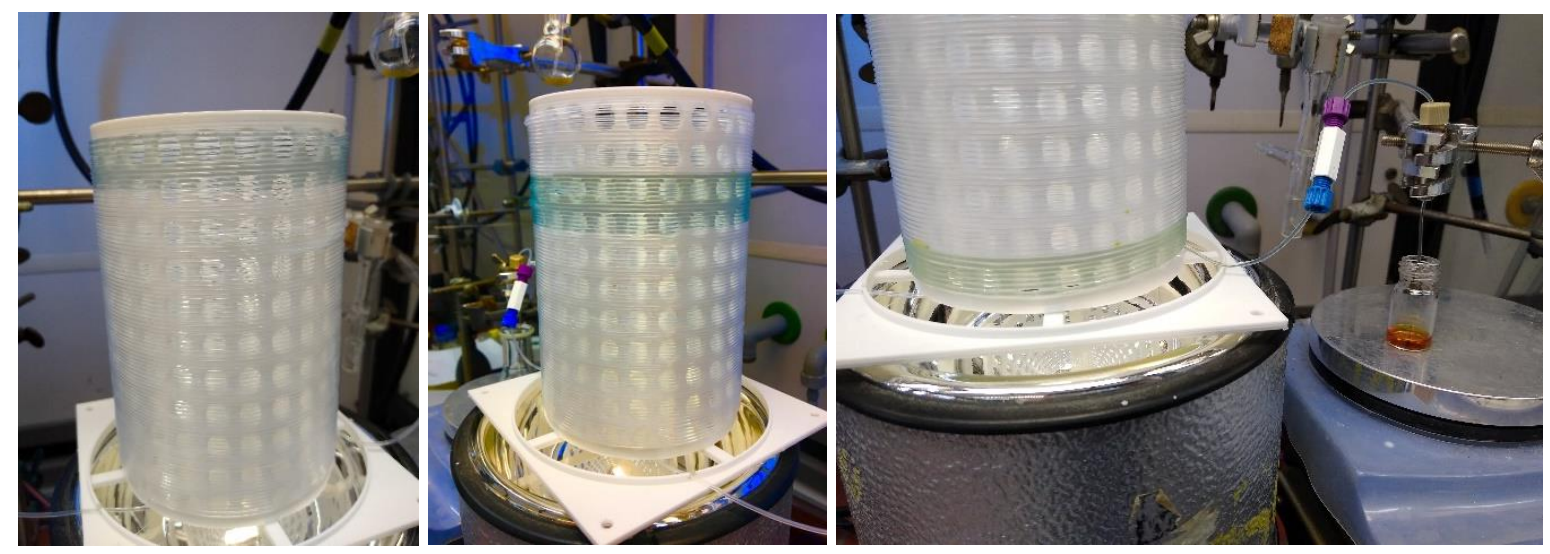

Left: The indicators solution directly after entering the reactor. Center: After a residence time $\mathrm{t}_{\mathrm{r}} \approx 2$ min. Right: After a residence time $\mathrm{t}_{\mathrm{r}} \approx 10 \mathrm{~min}$, the reaction mixture is still green-blue while the solution leaving the reactor immediately colors orange. 


\subsection{Karl Fischer Titration Experiments}

\section{Experiments to investigate the efficiency of established anhydrous conditions}

General procedure (GP01) for determining the drying efficiency of SiF:

Anhydrous THF ( $<5$ ppm residual water) was obtained by distillation from sodium/benzophenone followed by storing over activated MS $3 \AA$ for at least $72 \mathrm{~h}$ before use. ${ }^{[12]}$ Anhydrous THF was loaded on a sample loop ( $\mathrm{V}=5.0 \mathrm{~mL}$; FEP tube, outer diameter 1/16", inner diameter 1/32"), using SiF. The sample loop was not washed with anhydrous THF prior use, as this could dry the sample loop. Then, the loaded THF was driven by an argon flow using MFCs with a flow rate of $\mathrm{v}_{\text {flow }}=1 \mathrm{~mL} / \mathrm{min}$ through a tube reactor ( $\mathrm{V}=4.0 \mathrm{~mL}$, PTFE tube, outer diameter $1.6 \mathrm{~mm}$, inner diameter $1 \mathrm{~mm})$. At the end of the reactor, the THF was collected in a dry Schlenk tube. The collected THF was then directly analyzed by Karl Fischer titration. All experiments were performed twice, the collected THF was analyzed six times.

Table S1: Results of the Karl Fischer titration experiments.

\begin{tabular}{|c|c|c|}
\hline Entry & Abbreviations from the general procedure GP01: & Residual water \\
\hline 1 & none & $12-15 \mathrm{ppm}$ \\
\hline 2 & Without $\mathrm{SiF}$, tubes flushed with $\operatorname{argon}^{[\mathrm{a}]}$ & $35-45 \mathrm{ppm}$ \\
\hline 3 & Without $\mathrm{SiF}$, tubes flushed with $\operatorname{argon}^{[\mathrm{b}]}$ & 19-24 ppm \\
\hline 4 & $\begin{array}{l}\text { After flushing the tubes with } i \mathrm{PrOH} \text {, without } \mathrm{SiF} \text {, tubes dried with THF } \\
\qquad(1 \mathrm{x} 5 \mathrm{~mL})\end{array}$ & $44-48 \mathrm{ppm}$ \\
\hline 5 & $\begin{array}{l}\text { After flushing the tubes with } i \mathrm{PrOH} \text {, without } \mathrm{SiF} \text {, tubes dried with THF } \\
\qquad(2 \times 5 \mathrm{~mL})\end{array}$ & $18-20 \mathrm{ppm}$ \\
\hline 6 & After flushing the tubes with $i \mathrm{PrOH}$, then $\mathrm{SiF}$ & $16-18 \mathrm{ppm}$ \\
\hline 7 & After flushing the tubes with $i \mathrm{PrOH}$, then flushing with argon ${ }^{[\mathrm{a}]}$ & 68-101 ppm \\
\hline 8 & After flushing the tubes with $\mathrm{H}_{2} \mathrm{O}$, then $\mathrm{SiF}$ & $14-18 \mathrm{ppm}$ \\
\hline 9 & After flushing the tubes with $\mathrm{H}_{2} \mathrm{O}$, then flushing with argon ${ }^{[\mathrm{a}]}$ & $>2000 \mathrm{ppm}$ \\
\hline
\end{tabular}

[a] Flushing with argon was performed for $5 \mathrm{~min}$ using a flow rate of $\mathrm{v}_{\text {flow }}=5 \mathrm{~mL} / \mathrm{min}$. [b] Flushing with argon was performed for $15 \mathrm{~min}$ using a flow rate of $\mathrm{v}_{\text {flow }}=5 \mathrm{~mL} / \mathrm{min}$.

\section{Control experiment 01}

Anhydrous THF $(5 \mathrm{~mL})$ were placed in a dry Schlenk tube. The THF was transferred via a FEP tube $(\mathrm{V}=5.0 \mathrm{~mL}$ ) in another dry Schlenk tube using a positive pressure of argon. Prior transferring the THF, the tube was flushed with argon for $5 \mathrm{~min}$.

Residual water: $12-13$ ppm. 


\section{Control experiment 02}

Anhydrous THF ( $5 \mathrm{~mL}$ ) was loaded on a disposable $6 \mathrm{~mL}$ syringe. The THF was stored on the syringe for $1 \mathrm{~min}$, then transferred in a dry Schlenk tube and analyzed.

Residual water: 90-106 ppm.

\section{Control experiment 03}

Anhydrous THF $(5 \mathrm{~mL})$ was loaded on a disposable $6 \mathrm{~mL}$ syringe. The THF was stored on the syringe for $1 \mathrm{~min}$, then pushed through a tube FEP tube $(\mathrm{V}=1.0 \mathrm{~mL})$ and the outcoming THF $(4 \mathrm{~mL})$ was collected in a dry Schlenk tube and analyzed.

Residual water: 118-136 ppm.

\section{Control experiment 04}

A disposable $6 \mathrm{~mL}$ syringe was dried by pulling argon on the syringe and pushing it out for 3 times, as it is commonly done before using the syringe for moisture-sensitive applications. The THF was stored on the syringe for $1 \mathrm{~min}$, then pushed through a tube FEP tube $(\mathrm{V}=1.0 \mathrm{~mL})$, which was prior flushed with argon for $5 \mathrm{~min}$. The outcoming THF (4 mL) was collected in a dry Schlenk tube and analyzed. Residual water: 16-20 ppm.

These experiments lead us to the following conclusions:

- The use of disposable syringes and FEP tubes for transfer processes lead to a slight increase of the residual water content (control experiments 01-04).

- Using SiF, sufficient anhydrous conditions can be realized (table S1, entries 1, 3, and 5).

- Even without using SiF, the residual water in the tubes is relatively small (table S1, entry 2). This is probably because the tubes are in any case flushed with argon by the MFCs (for comparison, see control experiments 03 and 04).

- When the tubes were wetted with $i \mathrm{PrOH}$, the $\mathrm{SiF}$ provides better drying of the tubes (table $\mathrm{S} 1$, entry 3) compared to only flushing the tubes with argon (entry 4).

- When the tubes were wetted with $\mathrm{H}_{2} \mathrm{O}, \mathrm{SiF}$ still provides anhydrous conditions (table S1, entry 5), while flushing the tubes with argon fails in doing so (entry 6).

In summary, $\mathrm{SiF}$ provides anhydrous conditions reliably in the flow reactor and should be used when exclusion of moisture is important for the success of the reaction or when the tubes were previously washed with solvents such as $i \mathrm{PrOH}$ or $\mathrm{H}_{2} \mathrm{O}$. 


\subsection{Synthesis of Amides from Isocyanates and Grignard Reagents to Check Air- and Moisture Free Conditions}

To prove that air- and moisture sensitive reactions can be performed in flow using SiF without wasting large amounts of solvents or reagents, a water-sensitive reaction involving a Grignard reagent was used as reference. For comparison, the reaction was performed one time according to the literature with a classical setup using syringe pumps. Drying and equilibration of the reactor is reached by discarding a prerun of three residence times, as it is typically done in flow chemistry. ${ }^{[6]}$ Then, the reaction was performed using our flow platform and SiF. With the syringe pump setup a yield of $72 \%$ (lit.: $76 \%)^{[6]}$ was obtained, while using our flow platform gave a comparable yield of $68 \%$.

Using a syringe pump setup, a total amount of at least $8.85 \mathrm{~mL}$ anhydrous THF is used to dry the reactor. For the preparation of $1 \mathrm{mmol}$ of product (based on a yield of 100\%), in total $1.76 \mathrm{mmol}$ of product are discarded due to prerun (equilibration period) and postrun (compensation of dead volume of the reactor) of the reaction. This means, that only $36 \%$ of the theoretically formed product is collected in this way. Based on the total amount of reagents that are employed in the flow reaction using a syringe pump setup, the corrected yield is only $28 \%$.

Although the yield of product is slightly lower (68\%) using our flow platform and SiF, the corrected yield involving all employed material is significantly higher (62\% compared to $28 \%$ ) as only small amounts of reagents are lost due to dead volume of tubes, connectors, valves etc.

It has to be noted, that the loss of reagents is only significant for small scale reactions, which are, however, quite important for natural product synthesis and late-stage applications. On multi-gram scale, the amount of reagents that are lost in drying and equilibration processes is comparably small and can sometimes be even neglected (see e.g. the multi-gram experiment in ref. 6).

\section{Amide synthesis with a syringe pump setup}<smiles>O=C=NCc1ccccc1</smiles>

$\mathbf{S 1}$ (1.0 equiv) in THF

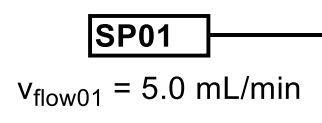

$1.77 \mathrm{~mL}$ tube<smiles>CC(C)C(C)Cl</smiles>

S2 (1.0 equiv) in THF

\section{SP02}

$\mathrm{v}_{\text {flow02 }}=5.0 \mathrm{~mL} / \mathrm{min}$ reactor

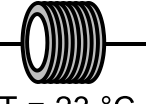

$\mathrm{T}=23^{\circ} \mathrm{C}$

$\mathrm{t}_{\mathrm{r}}=10.6 \mathrm{~s}$

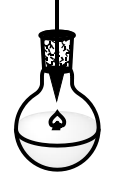

collection flask sat. aq. $\mathrm{NH}_{4} \mathrm{Cl}$

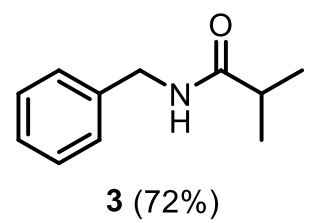

$3(72 \%)$ 
This procedure was performed according to the literature. ${ }^{[6]}$

Directly prior use, the $\mathbf{1 . 7 7} \mathbf{~ m L}$ tube reactor was flushed with anhydrous THF (5 residence time, $8.9 \mathrm{~mL})$.

In a dry Schlenk tube, anhydrous $\mathrm{CuBr}_{2}(11.2 \mathrm{mg}, 50.0 \mu \mathrm{mol})$ was placed and the tube was evacuated and backfilled with argon (3x). Then, benzyl isocyanate $\mathbf{S 1}(666 \mathrm{mg}, 5.00 \mathrm{mmol})$ and anhydrous THF were added to prepare $10 \mathrm{~mL}$ of a $0.5 \mathrm{M}$ solution in THF. This solution was sonicated for $2 \mathrm{~min}$, and then loaded on a gas tight syringe and placed on syringe pump 01 (SP01).

In another dry Schlenk tube, $i \mathrm{PrMgCl} \mathbf{S 2}(2.50 \mathrm{~mL}, 5.00 \mathrm{mmol} ; 2.0 \mathrm{M}$ in THF) was placed and diluted with anhydrous THF $(7.5 \mathrm{~mL})$ to give $10 \mathrm{~mL}$ of a $0.5 \mathrm{M}$ solution in THF. This solution was loaded on a gas tight syringe and placed on syringe pump 02 (SP02). Then, both solutions were mixed at $23{ }^{\circ} \mathrm{C}$ with a flow rate of $\mathrm{v}_{\text {flow } 01}=\mathrm{v}_{\text {flow } 02}=5.0 \mathrm{~mL} / \mathrm{min}$ in a $\mathrm{T}$-piece and pumped through the $\mathbf{1 . 7 7} \mathbf{~ m L}$ tube reactor (FEP tube, outer diameter 1/16", inner diameter 1/32") with a residence time $t_{r}=10.6 \mathrm{~s}$. A prerun of three residence times $(30 \mathrm{~s}, 5 \mathrm{~mL})$ was discarded to allow drying and equilibration of the system. Then, a sample $(24 \mathrm{~s}, 4 \mathrm{~mL})$ of the reaction mixture was collected in a collection flask containing $\mathrm{NH}_{4} \mathrm{Cl}$ (sat. aq., $10 \mathrm{~mL}$ ). The mixture was diluted with EtOAc $(10 \mathrm{~mL})$ and $\mathrm{NaCl}$ (sat. aq., $10 \mathrm{~mL}$ ) and the aqueous layer was separated and extracted with EtOAc $(2 \times 20 \mathrm{~mL})$. The combined organic layers were dried $\left(\mathrm{MgSO}_{4}\right)$, filtered, and concentrated under reduced pressure. MPLC (cyclohexane/EtOAc 2:1) gave amide $\mathbf{S 0 3}$ (128 mg, $722 \mu \mathrm{mol}, 72 \%$ [lit.: 76\% ${ }^{[6]}$ ) as a colorless solid.

The yield is based on the actual reacted reagent solutions: solution $1(1.0 \mathrm{~mL}$; benzyl isocyanate $\mathbf{S 0 1}$ (134 mg, $1.00 \mathrm{mmol}, 1.0$ equiv) and $\left.\mathrm{CuBr}_{2}(2.2 \mathrm{mg}, 0.10 \mu \mathrm{mol}, 1 \mathrm{~mol} \%)\right)$ and solution $2(1.0 \mathrm{~mL}$; $i \mathrm{PrMgCl}$ (1.00 mmol, 1.0 equiv)).

\section{Calculation of solvent and product waste based on the reported procedure ${ }^{[6]}$}

Tube reactor with a reactor volume $V_{R}=1.77 \mathrm{~mL}$; flow rates $v_{1}=v_{2}=5.0 \mathrm{~mL} / \mathrm{min}$. Residence time $t_{r}=\frac{V_{R}}{\left(v_{1}+v_{2}\right)}=\frac{1.77 \mathrm{~mL}}{10 \mathrm{~mL} / \mathrm{min}}=0.177 \mathrm{~min} \triangleq 10.62 \mathrm{~s}$.

"Prior to performing Grignard reactions, the system was flushed with dry THF, for at least 5 residence times."

Thus, the amount of anhydrous THF used to flush the reactor can be calculated as:

$$
5 \times V_{R}=(5 \times 1.77) \mathrm{mL}=8.85 \mathrm{~mL}
$$

"An equilibration period of 3 residence times was allowed, then samples of $1 \mathrm{mmol}$ ( $4 \mathrm{~mL}$ combined flow volume) were collected." 
This means that $1 \mathrm{mmol}$ of product corresponds to a reaction volume of $4 \mathrm{~mL}$ (based on a theoretical yield of 100\%). Therefore, in an equilibration period of 3 residence times, the theoretical amount of wasted product can be calculated as:

$$
\begin{gathered}
4 \mathrm{~mL} \stackrel{\bumpeq}{=} \mathrm{mmol} \text { product } \\
3 \times V_{R}=(3 \times 1.77) \mathrm{mL}=5.31 \mathrm{~mL} \bumpeq 1.32 \mathrm{mmol} \text { product }
\end{gathered}
$$

As the reagents are not driven by gas or by pure solvent and the reactor has a dead volume of $1.77 \mathrm{~mL}$, in addition a reaction mixture of at least $1.77 \mathrm{ml}$ (corresponding to $\approx 0.44 \mathrm{mmol}$ product) remains in the tube reactor (the dead volume of the mixing unit, syringes etc. was neglected). Therefore, the total loss of product is:

$$
(1.32+0.44) \mathrm{mmol}=1.76 \mathrm{mmol}
$$

As according to the procedure $1 \mathrm{mmol}$ of product is collected, the amount of collected product from the total amount of theoretically formed product, including equilibration period and dead volume, is:

$$
\frac{1.00 \mathrm{mmol}}{(1.76+1.00) \mathrm{mmol}}=\frac{1.00}{2.76} \approx 36 \%
$$

In conclusion, $8.85 \mathrm{~mL}$ of anhydrous THF and $1.76 \mathrm{mmol}$ of product for the preparation of $1 \mathrm{mmol}$ product are wasted, meaning that only $36 \%$ of the theoretically formed product can be isolated. The example reaction proceeds with a reported yield of $76 \%$. Based on the amount of reagents that are actually employed in the reaction, the corrected yield can be calculated as:

$$
0.36 \times 0.76 \approx 0.28 \bumpeq 28 \%
$$

Thus, according to the reported procedure and based on the amount of reagents that are actually employed on a $1 \mathrm{mmol}$ scale, the corrected yield is $28 \%$.

The loss of reagents and solvents due to the dead volume of syringes, the mixing unit and connectors was neglected as it ranges typically below $<0.5 \mathrm{~mL}$ (combined). Also, the waste of washing solutions and solvents that are used to clean the reactor, the mixing unit and the connectors were neglected. 


\section{Amide synthesis using the flow platform}

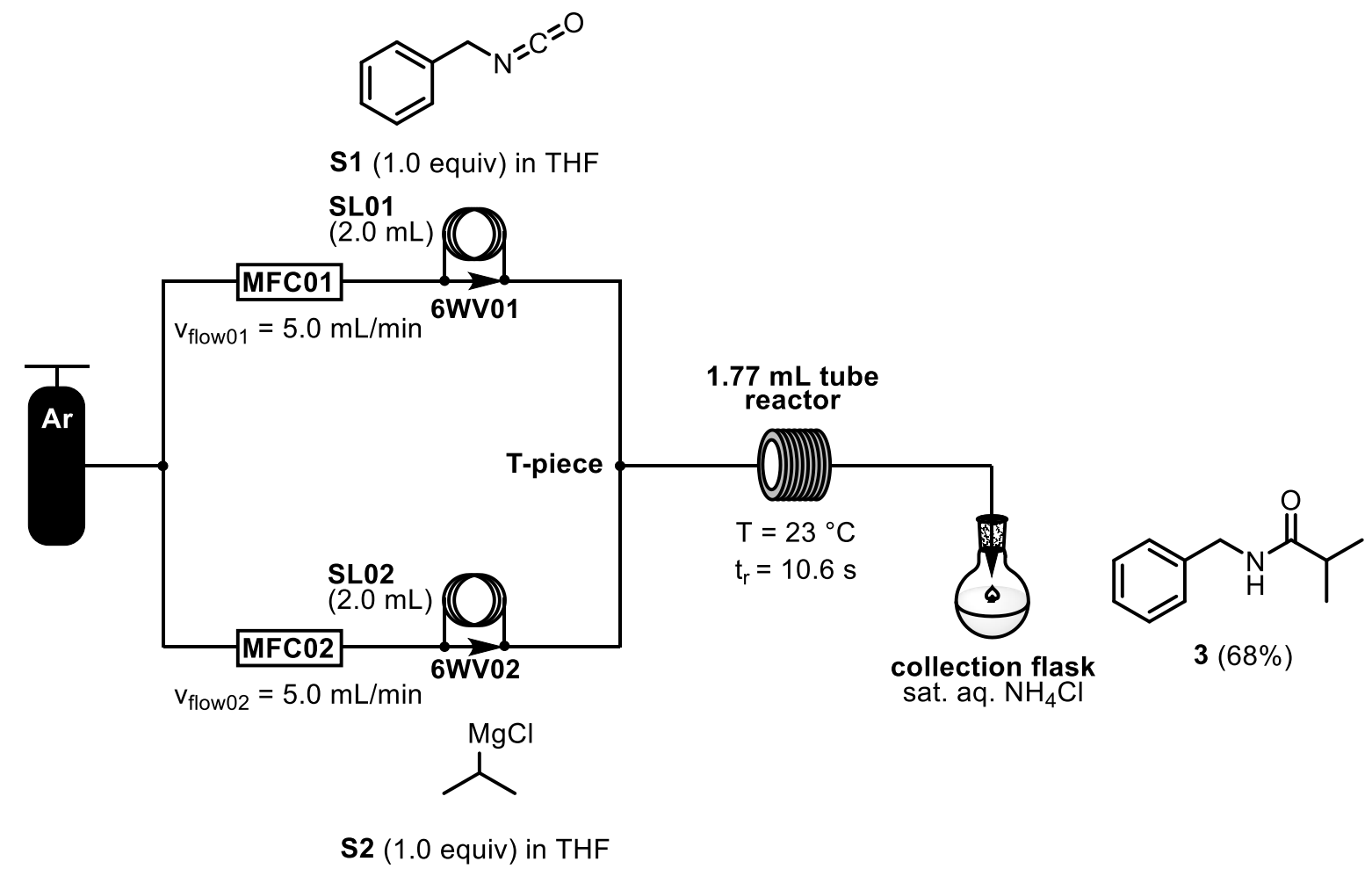

In a dry Schlenk tube, anhydrous $\mathrm{CuBr}_{2}(11.2 \mathrm{mg}, 50.0 \mu \mathrm{mol})$ was placed and the tube was evacuated and backfilled with argon (3x). Then, benzyl isocyanate $\mathbf{S 1}(666 \mathrm{mg}, 5.00 \mathrm{mmol})$ and anhydrous THF were added to prepare a total of $10 \mathrm{~mL}$ of a $0.5 \mathrm{M}$ solution in THF. This solution was sonicated for $2 \mathrm{~min}$, and then loaded on sample loop 01 SL01 (V = $2.0 \mathrm{~mL}$, FEP tube, outer diameter 1/16", inner diameter 1/32").

In another dry Schlenk tube, $i \mathrm{PrMgCl} \mathbf{S 2}(2.50 \mathrm{~mL}, 5.00 \mathrm{mmol}$; $2.0 \mathrm{M}$ in THF) was placed and diluted with anhydrous THF $(7.5 \mathrm{~mL})$ to give $10 \mathrm{~mL}$ of a $0.5 \mathrm{M}$ solution in THF. This solution was loaded on sample loop 02 SL02 (V = $2.0 \mathrm{~mL}$, FEP tube, outer diameter 1/16", inner diameter 1/32"). Then, both solutions were mixed at $23{ }^{\circ} \mathrm{C}$ with a flow rate of $\mathrm{v}_{\text {flow } 01}=\mathrm{v}_{\text {flow } 02}=5.0 \mathrm{~mL} / \mathrm{min}$ in a $\mathrm{T}$-piece and pumped through the $1.77 \mathrm{~mL}$ tube reactor (FEP tube, outer diameter 1/16", inner diameter 1/32") with a residence time $t_{r}=10.6 \mathrm{~s}$. The end of the reactor is equipped with a small canula and the reaction mixture was collected in a collection flask containing $\mathrm{NH}_{4} \mathrm{Cl}$ (sat. aq., $10 \mathrm{~mL}$ ). The mixture was diluted with EtOAc $(10 \mathrm{~mL})$ and $\mathrm{NaCl}$ (sat. aq., $10 \mathrm{~mL}$ ) and the aqueous layer was separated and extracted with EtOAc $(2 \times 20 \mathrm{~mL})$. The combined organic layers were dried $\left(\mathrm{MgSO}_{4}\right)$, filtered, and concentrated under reduced pressure. MPLC (cyclohexane/EtOAc 2:1) gave amide S3 (121 mg, $683 \mu \mathrm{mol}, 68 \%$ ) as a colorless solid.

The yield is based on the actual reacted reagent solutions: solution $1(2.0 \mathrm{~mL}$; benzyl isocyanate $\mathbf{S 0 1}$ (134 mg, $1.00 \mathrm{mmol}, 1.0$ equiv) and $\left.\mathrm{CuBr}_{2}(2.2 \mathrm{mg}, 0.10 \mu \mathrm{mol}, 1 \mathrm{~mol} \%)\right)$ and solution $2(2.0 \mathrm{~mL}$; $i \mathrm{PrMgCl}$ (1.00 mmol, 1.0 equiv)). 
$R_{\mathrm{f}}=0.28($ cyclohexane/EtOAc $2: 1)$

${ }^{1} \mathrm{H}$ NMR $\left(700 \mathrm{MHz}\right.$, DMSO-d $\left.{ }_{6}\right) \delta[\mathrm{ppm}]=8.23(\mathrm{t}, J=6.1 \mathrm{~Hz}, 1 \mathrm{H}), 7.33-7.30(\mathrm{~m}, 2 \mathrm{H}), 7.24-7.21(\mathrm{~m}$, $3 \mathrm{H}), 4.25(\mathrm{~d}, J=6.0 \mathrm{~Hz}, 2 \mathrm{H}), 2.42$ (hept, $J=6.8 \mathrm{~Hz}, 1 \mathrm{H}), 1.03(\mathrm{~d}, J=6.9 \mathrm{~Hz}, 6 \mathrm{H})$.

${ }^{13} \mathrm{C}$ NMR $\left(176 \mathrm{MHz}, \mathrm{DMSO}-\mathrm{d}_{6}\right) \delta[\mathrm{ppm}]=176.0,139.8,128.2,127.0,126.6,41.8,34.0,19.6$.

The spectroscopic data are consistent with those reported previously in the literature. ${ }^{[6]}$

\section{Calculation of solvent and product waste using our flow platform and SiF}

No solvents are used to dry the reactor and neither a pre- nor a postrun are discarded. The tubes, connectors and syringes that are used to load a reagent solution on the sample loop have a dead volume of $\sim 0.2 \mathrm{~mL}$. Thus, for each reagent solution, $2.2 \mathrm{~mL}$ are employed from which $2.0 \mathrm{ml}$ are actually reacted. So, for the preparation of $1 \mathrm{mmol}$ product (corresponding to a combined volume of $4.0 \mathrm{~mL}$ ), in total, $4.4 \mathrm{~mL}$ of reagent solutions are employed, which can be expressed as:

$$
\frac{4.0 \mathrm{~mL}}{4.4 \mathrm{~mL}} \approx 0.91 \triangleq 91 \%
$$

As described above, the corrected yield for the amount of reagents that are actually employed is:

$$
0.91 \times 0.68 \approx 0.62 \bumpeq 62 \%
$$

The amount of consumed argon (typically a few hundred milliliters for each experiment) and the waste of washing solutions and solvents that are used to clean the reactor, the mixing unit etc. were neglected. 


\subsection{Aldol Reaction of the Key Intermediates Aldehyde 4 and Ester 5 of (+)- Darwinolide in Flow}

Preliminary Screening of reaction conditions for the aldol reaction of deprotonated ester $\mathbf{5}$ and aldehyde 4

In preliminary studies, ester $\mathbf{5}$ was deprotonated in batch. The deprotonated species and aldehyde $\mathbf{4}$ were then mixed in a flow reactor. It was found that when sodium bis(trimethylsilyl)amide was employed as base, the subsequent aldol coupling process was relatively slow leading to almost no conversion under the reaction conditions. When freshly prepared $\operatorname{LiN}(i \operatorname{Pr})_{2}$ was used as base, aldol coupling proceeded much faster, providing $\beta$-hydroxy ester 6 in acceptable yields. However, it has to be noted that increasing reaction times did not improve the yield. This is in accordance with our previous observations. ${ }^{[1]}$

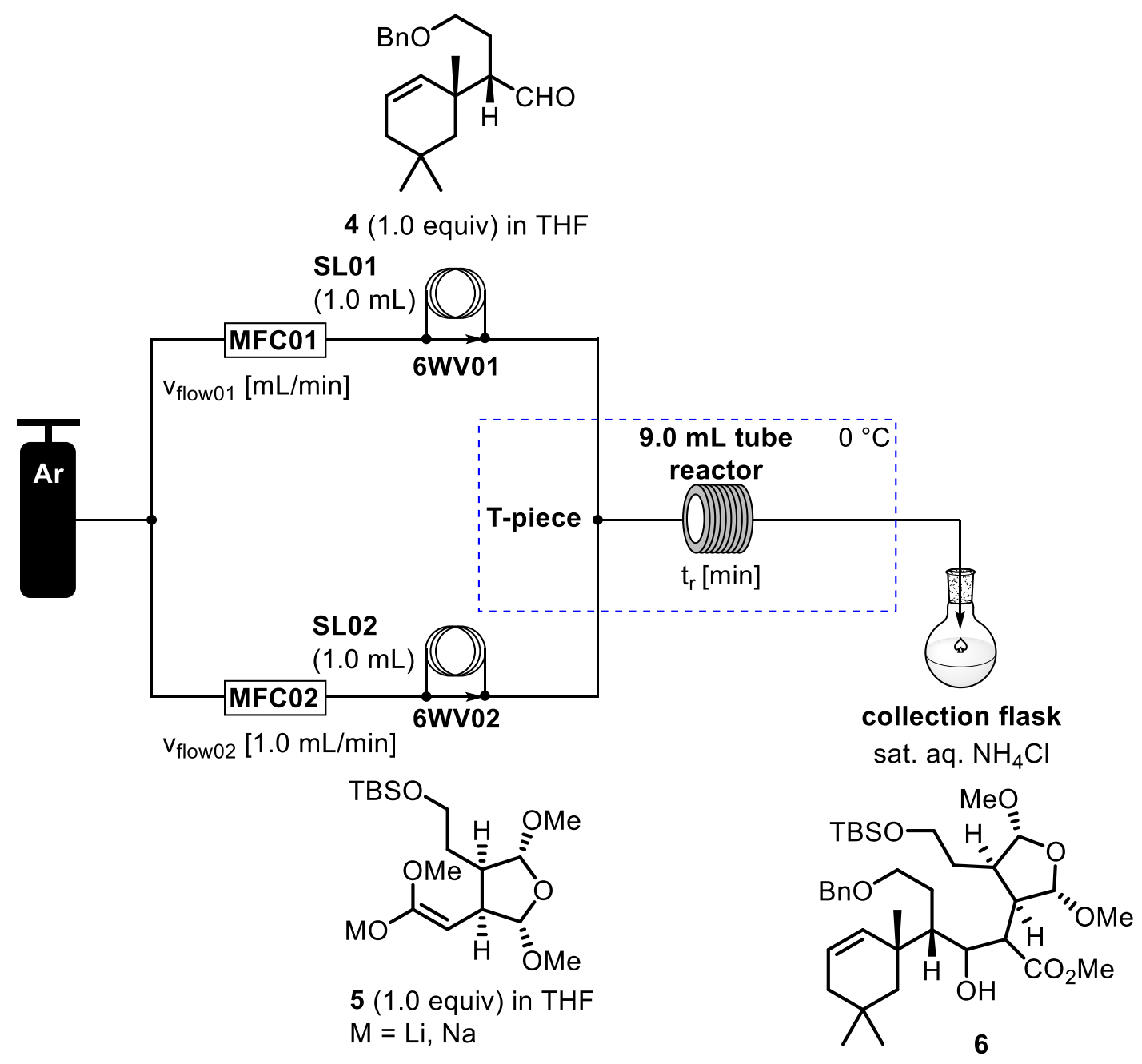


Table S2: Screening of different reaction conditions in flow.

\begin{tabular}{|c|c|c|c|c|}
\hline Entry & Base & $\mathbf{V}_{\text {flow_tot }}[\mathbf{m L} / \mathbf{m i n}]^{[\mathbf{a}]}$ & $\mathbf{t}_{\mathbf{r}}[\mathbf{m i n}]$ & Yield $^{[\mathbf{b}]}$ \\
\hline $\mathbf{1}$ & $\mathrm{NaHMDS}$ & 2 & 4.5 & n.d. $^{[\mathrm{c}]}$ \\
\hline $\mathbf{2}$ & $\operatorname{LiN}(i \mathrm{Pr})_{2}$ & 2 & 4.5 & $42 \%$ \\
\hline $\mathbf{3}$ & $\operatorname{LiN}(i \mathrm{Pr})_{2}$ & 3 & 3 & $41 \%$ \\
\hline $\mathbf{4}$ & $\operatorname{LiN}(i \mathrm{Pr})_{2}$ & 6 & 1.5 & $26 \%$ \\
\hline
\end{tabular}

NaHMDS $=$ sodium bis(trimethylsilyl)amide. $\mathrm{LiN}(i \mathrm{Pr})_{2}$ was freshly prepared from $\mathrm{HN}(i \mathrm{Pr})_{2}$ and $n \mathrm{BuLi}$

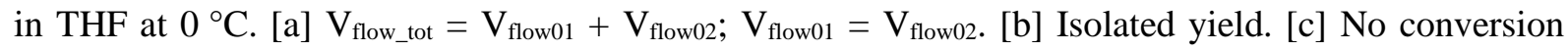
according to TLC.

In a dry Schlenk tube, a solution of ester 5 in THF $(1.2 \mathrm{~mL})$ was treated at $0{ }^{\circ} \mathrm{C}$ with base and stirred at this temperature for $5 \mathrm{~min}$. Then, the reaction mixture was loaded on sample loop 01 (SL01, V = $1.0 \mathrm{~mL}$, FEP tube, outer diameter 1/16", inner diameter 1/32").

In another dry Schlenk tube, $1.2 \mathrm{~mL}$ of a $0.083 \mathrm{M}$ solution of aldehyde $4(29.8 \mu \mathrm{g}, 100 \mu \mathrm{mol})$ was prepared in THF and loaded on sample loop 02 SL02 (V = 1.0 mL, FEP tube, outer diameter 1/16", inner diameter $1 / 32 ")$.

Then, both solutions were driven by an argon flow using MFC01 $\left(\mathrm{v}_{\text {flow01 }}[\mathrm{mL} / \mathrm{min}]\right)$ and MFC02 ( $\mathrm{V}_{\text {flow01 }}$ $[\mathrm{mL} / \mathrm{min}]$ ). Both solutions were passed through a precooling tube (FEP tube, outer diameter 1/16", inner diameter 1/32", $\mathrm{V}=0.2 \mathrm{~mL}$ ), then mixed in a T-piece at $0{ }^{\circ} \mathrm{C}$ and pumped through a cooled $9.0 \mathrm{~mL}$ tube reactor (FEP tube, outer diameter $1 / 16$ ", inner diameter $1 / 32 ")$ at $0{ }^{\circ} \mathrm{C}$ with a residence time $t_{\mathrm{r}}[\mathrm{min}]$. At the end of this reactor, the reaction mixture was collected in a collection flask containing sat. aq. $\mathrm{NH}_{4} \mathrm{Cl}(20 \mathrm{~mL})$. The mixture was diluted with EtOAc $(20 \mathrm{~mL})$, the aqueous layer was separated, and extracted with EtOAc $(2 \times 20 \mathrm{~mL})$. The combined organic layers were dried $\left(\mathrm{MgSO}_{4}\right)$, filtered, and concentrated under reduced pressure. Flash column chromatography $\left(\mathrm{SiO}_{2}, n\right.$ pentane/Et $\left.\mathrm{O}_{2} 3: 1\right)$ gave $\beta$ hydroxy ester $\mathbf{6}$ as a colorless oil. 


\section{Deprotonation of ester 4 and aldol reaction with aldehyde 4 in flow}

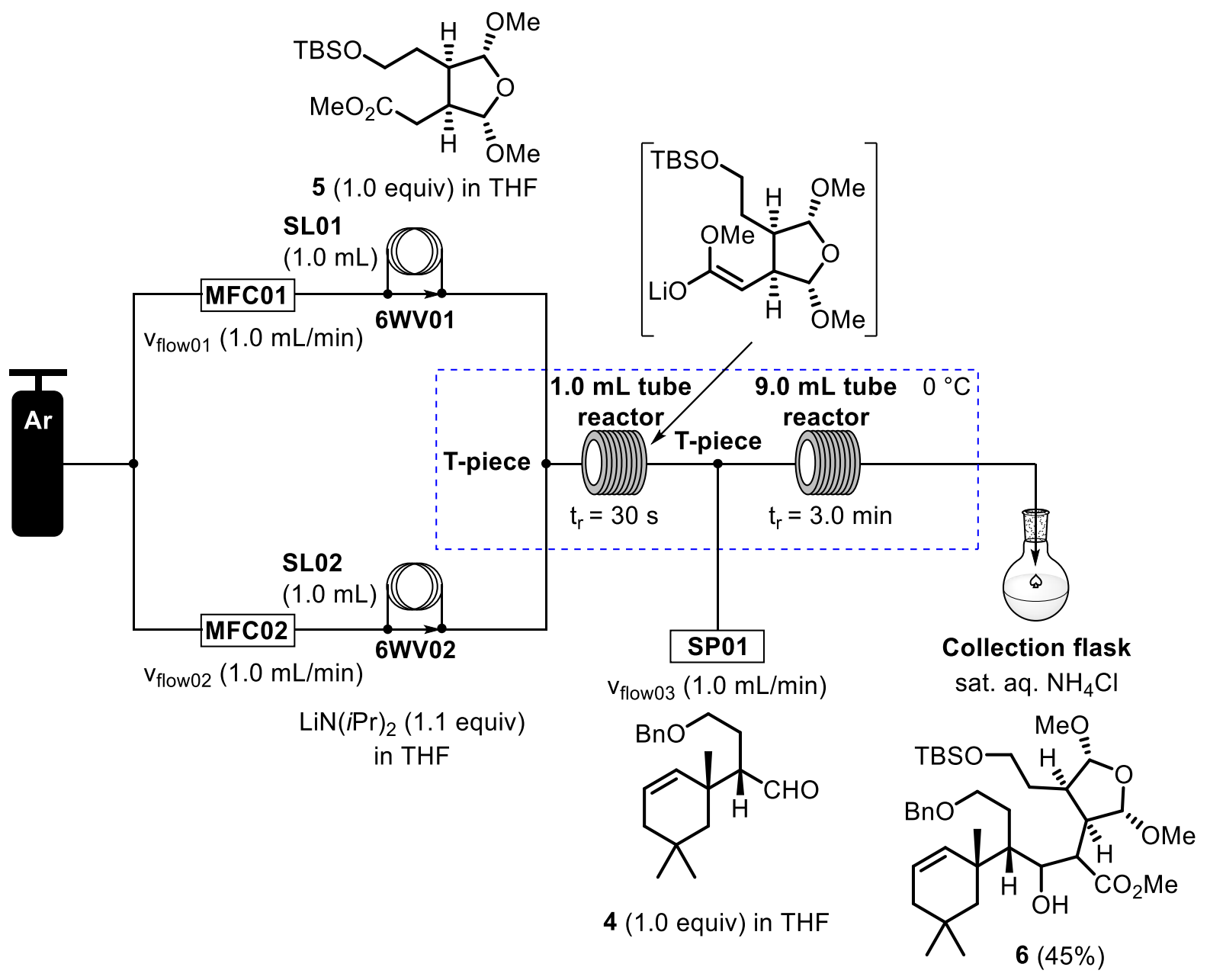

In a dry Schlenk tube, $6 \mathrm{~mL}$ of a $0.09 \mathrm{M}$ solution of $\mathrm{LiN}(i \mathrm{Pr})_{2}$ in THF was prepared by addition of $n \mathrm{BuLi}$ $(220 \mu \mathrm{L}, 546 \mu \mathrm{mol}, 2.5 \mathrm{M}$ in $n$ hexane $)$ to a solution of $\mathrm{HN}(i \operatorname{Pr})_{2}(60.0 \mathrm{mg}, 84.0 \mu \mathrm{L}, 600 \mu \mathrm{mol})$ in anhydrous THF $(5.7 \mathrm{~mL})$ at $0{ }^{\circ} \mathrm{C}$ followed by stirring at this temperature for $5 \mathrm{~min}$. This solution was loaded on sample loop 02 (SL02, V = $1.0 \mathrm{~mL}$, FEP tube, outer diameter 1/16", inner diameter 1/32"). In another dry Schlenk tube, $1.2 \mathrm{~mL}$ of a $0.083 \mathrm{M}$ solution of ester $\mathbf{5}(36.0 \mathrm{mg}, 100 \mu \mathrm{mol})$ was prepared in THF and loaded on sample loop 01 (SL01, V = $1.0 \mathrm{~mL}$, FEP tube, outer diameter 1/16", inner diameter 1/32").

In a third dry Schlenk tube, $1.2 \mathrm{~mL}$ of a $0.083 \mathrm{M}$ solution of aldehyde $4(29.8 \mu \mathrm{g}, 100 \mu \mathrm{mol})$ was prepared in THF and loaded on a gas tight syringe.

Then, both solutions were driven by an argon flow using MFC01 ( $\left.\mathrm{v}_{\text {flow01 }}=1.0 \mathrm{~mL} / \mathrm{min}\right)$ and MFC02 $\left(\mathrm{v}_{\text {flow01 }}=1.0 \mathrm{~mL} / \mathrm{min}\right)$. Both solutions were passed through a precooling tube (FEP tube, outer diameter $1 / 16$ ", inner diameter $1 / 32 ", \mathrm{~V}=0.2 \mathrm{~mL}$ ), then mixed in a T-piece at $0{ }^{\circ} \mathrm{C}$ and pumped through a precooled $1.0 \mathrm{~mL}$ tube reactor (FEP tube, outer diameter $1 / 16$ ”, inner diameter $1 / 32$ ") at $0{ }^{\circ} \mathrm{C}$ with a residence time of $t_{r}=30 \mathrm{~s}$. At the end of this reactor, the reaction stream was mixed with a solution of aldehyde 4 after passing through a precooling tube (FEP tube, outer diameter 1/16", inner diameter $1 / 32$ ", $\mathrm{V}=0.2 \mathrm{~mL}$ ). The combined reaction stream was then pumped through a cooled $\mathbf{9 . 0} \mathbf{~ m L}$ tube 
reactor (FEP tube, outer diameter $1 / 16 "$, inner diameter $1 / 32 "$ ) at $0{ }^{\circ} \mathrm{C}$ with a residence time of $\mathrm{t}_{\mathrm{r}}=3.0 \mathrm{~min}$. At the end of this reactor, the reaction mixture was collected in a collection flask containing sat. aq. $\mathrm{NH}_{4} \mathrm{Cl}(20 \mathrm{~mL})$. The mixture was diluted with EtOAc $(20 \mathrm{~mL})$, the aqueous layer was separated, and extracted with EtOAc $(2 \times 20 \mathrm{~mL})$. The combined organic layers were dried $\left(\mathrm{MgSO}_{4}\right)$, filtered, and concentrated under reduced pressure. Flash column chromatography $\left(\mathrm{SiO}_{2}, n\right.$ pentane/Et $\left.\mathrm{O}_{2} \mathrm{O}: 1\right)$ gave $\beta$ hydroxy ester 6 (24.8 mg, $37.4 \mu \mathrm{mol}, 45 \%$ ) as a colorless oil along with reisolated aldehyde 4 (11.9 mg, $39.6 \mu \mathrm{mol}, 48 \%)$ as colorless oil and ester 5 (13.8 mg, $38.1 \mu \mathrm{mol}, 46 \%)$ as colorless oil.

The yield is based on the actual reacted reagent solutions loaded on SL01 (ester 5 (30.0 mg, $83.0 \mu, 1.0$ equiv)), SL02 (1.0 mL; $\operatorname{LiN}(i \operatorname{Pr})_{2} 1.0 \mathrm{~mL}, 91.0 \mu \mathrm{mol}, 1.1$ equiv; $0.09 \mathrm{M}$ in THF) and the solution of aldehyde 4 (24.9 mg, $83.0 \mu \mathrm{mol}, 1.0$ equiv) reaching the reaction stream $(1.0 \mathrm{~mL})$.

$\mathrm{R}_{\mathrm{f}}=0.36\left(n\right.$-pentane/Et $\left.{ }_{2} \mathrm{O} 3: 1\right)$.

${ }^{1} \mathrm{H}$ NMR $\left(700 \mathrm{MHz}, \mathrm{CDCl}_{3}\right) \delta[\mathrm{ppm}]=7.34-7.31(\mathrm{~m}, 5 \mathrm{H}), 5.63(\mathrm{ddd}, J=10.1,6.0,2.2 \mathrm{~Hz}, 1 \mathrm{H}), 5.33$ (ddd, $J=10.1,2.6,1.4 \mathrm{~Hz}, 1 \mathrm{H}), 4.90(\mathrm{~d}, J=6.5 \mathrm{~Hz}, 1 \mathrm{H}), 4.83(\mathrm{~s}, 1 \mathrm{H}), 4.49$ (d, $J=12.1 \mathrm{~Hz}, 1 \mathrm{H}), 4.45$ $(\mathrm{d}, J=12.1 \mathrm{~Hz}, 1 \mathrm{H}), 4.07-4.04(\mathrm{~m}, 1 \mathrm{H}), 3.59(\mathrm{~s}, 3 \mathrm{H}), 3.59-3.56(\mathrm{~m}, 2 \mathrm{H}), 3.48(\mathrm{~s}, 3 \mathrm{H}), 3.47-3.43$ (m, 1H) $3.36(\mathrm{~s}, 3 \mathrm{H}), 3.35-3.34(\mathrm{~m}, 1 \mathrm{H}), 3.07(\mathrm{dt}, J=12.0,6.5 \mathrm{~Hz}, 1 \mathrm{H}), 2.75(\mathrm{~d}, J=6.8 \mathrm{~Hz}, 1 \mathrm{H}), 2.59$ (dd, $J=11.9,3.8 \mathrm{~Hz}, 1 \mathrm{H}), 2.26(\mathrm{ddd}, J=12.0,6.6,2.7 \mathrm{~Hz}, 1 \mathrm{H}), 1.85-1.79(\mathrm{~m}, 1 \mathrm{H}), 1.77$ (dt, $J=16.8$, 2.6, 1H), 1.69 (dddd, $J=16.7,6.0,2.4,0.9 \mathrm{H}, 1 \mathrm{H}), 1.59(\mathrm{~d}, J=5.2 \mathrm{~Hz}, 1 \mathrm{H}), 1.58-1.50(\mathrm{~m}, 2 \mathrm{H}), 1.45$ $(\mathrm{td}, J=5.0,2.8 \mathrm{~Hz}, 1 \mathrm{H}), 1.27-1.25(\mathrm{~m}, 3 \mathrm{H}), 1.19(\mathrm{ddd}, J=14.1,2.6,1.3 \mathrm{~Hz}, 1 \mathrm{H}), 1.07$ (s, 3H), 0.95 (d, $J=1.3 \mathrm{~Hz}, 6 \mathrm{H}), 0.88(\mathrm{~s}, 9 \mathrm{H}), 0.03(\mathrm{~s}, 3 \mathrm{H}), 0.02(\mathrm{~s}, 3 \mathrm{H})$.

${ }^{13} \mathrm{C}\left\{{ }^{1} \mathrm{H}\right\}$ NMR $\left(151 \mathrm{MHz}, \mathrm{CDCl}_{3}\right) \delta[\mathrm{ppm}]=173.1,138.8,134.6,128.4,127.8,127.5,125.3,108.3$, $107.8,72.8,71.6,69.5,61.8,56.0,54.8,51.8,51.1,49.4,45.5,44.9,44.8,40.1$, 38.5, 33.1, 30.1, 29.2, 28.5, 26.7, 26.0, 25.6, 18.4, -5.3, -5.3.

The spectroscopic data are consistent with those reported in the literature. ${ }^{[1]}$ 


\subsection{Ramberg Bäcklund Rearrangement of $\alpha$-Chlorinated Sulfoxide 7 in}

Flow

Screening of different reaction conditions for the Ramberg-Bäcklund rearrangement of $\alpha$ chlorinated sulfoxide 7 in flow

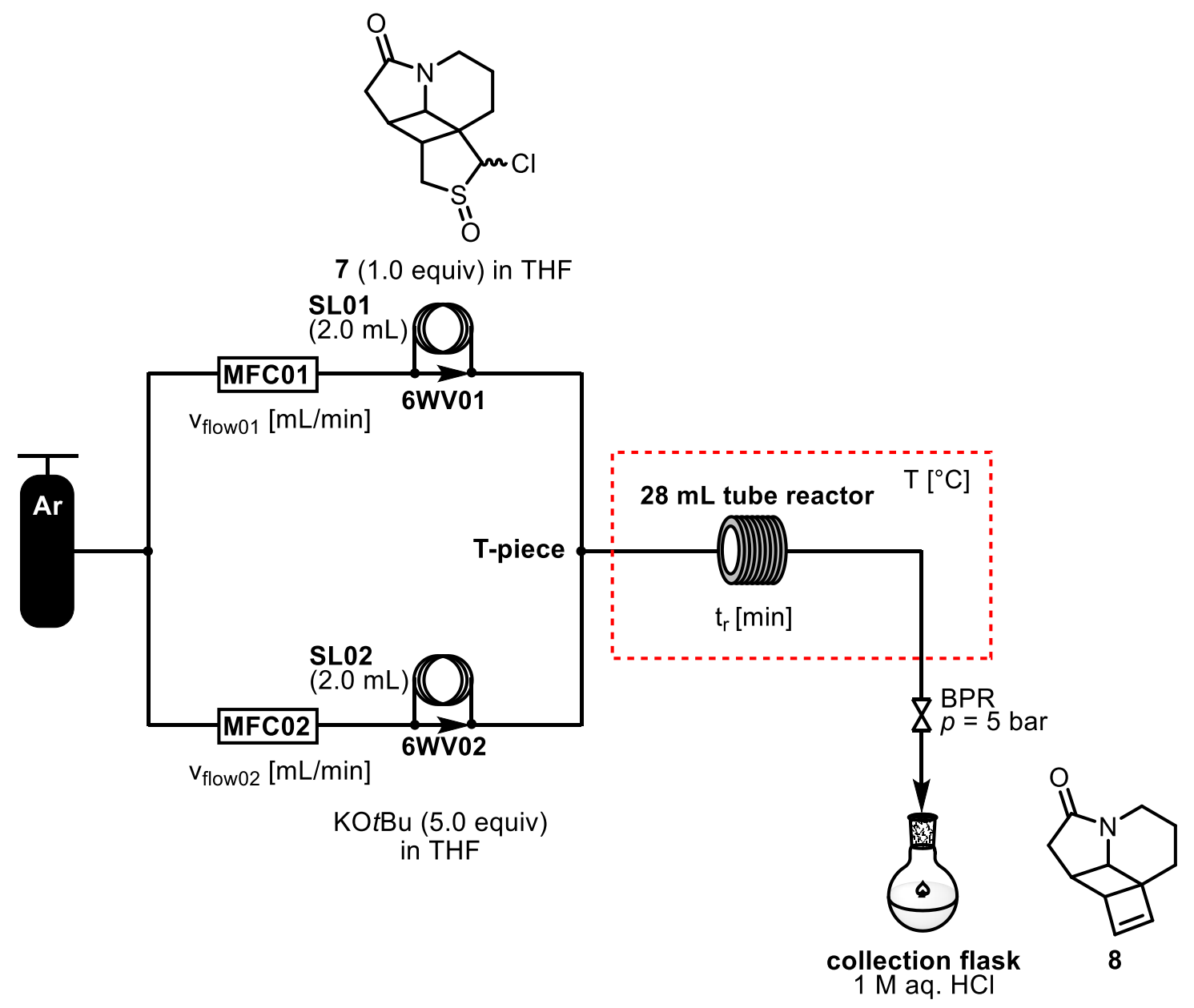

Table S3: Screening of different reaction conditions in flow.

\begin{tabular}{|c|c|c|c|c|}
\hline Entry & $\mathbf{T}\left[{ }^{\circ} \mathbf{C}\right]$ & $\mathbf{t}_{\mathbf{r}}[\mathbf{m i n}]$ & $\mathbf{V}_{\text {flow_tot }}[\mathbf{m L} / \mathbf{m i n}]^{[\mathbf{a}]}$ & Yield [\% $^{[\mathbf{b}]}$ \\
\hline $\mathbf{1}$ & 60 & 30 & 0.6 & 49 \\
\hline $\mathbf{2}$ & 70 & 30 & 0.6 & 42 \\
\hline $\mathbf{3}$ & $\mathbf{5 5}$ & $\mathbf{4 5}$ & $\mathbf{0 . 4}$ & $\mathbf{5 5}$ \\
\hline $\mathbf{4}$ & 50 & 75 & 0.2 & 46 \\
\hline
\end{tabular}

[a] $\mathrm{V}_{\text {flow_tot }}=\mathrm{V}_{\text {flow01 }}+\mathrm{V}_{\text {flow } 02} ; \mathrm{V}_{\text {flow01 }}=\mathrm{V}_{\text {flow02. }}$ [b] Isolated yield.

In a dry Schlenk tube, $\alpha$-chlorinated sulfoxide $7(12.5 \mathrm{mg}, 48.1 \mu \mathrm{mol})$ was placed and the tube was evacuated and backfilled with argon (3x). Then, anhydrous and degassed THF (2.5 mL) was added. The resulting solution was loaded on sample loop SL01 (V = 2.0 mL, FEP tube, outer diameter 1/16", inner diameter 1/32"). In another dry Schlenk tube, $\mathrm{KO} t \mathrm{Bu}(27.0 \mathrm{mg}, 241 \mu \mathrm{mol})$ was placed and the tube was 
evacuated and backfilled with argon (3x). Then, anhydrous and degassed THF ( $2.5 \mathrm{~mL})$ was added. The resulting solution was loaded on sample loop SL02 (V = $2.0 \mathrm{~mL}$, FEP tube, outer diameter 1/16", inner diameter 1/32"). Then, both solutions were driven by an argon flow using MFC01 and MFC02 with the flow rate $\left(\mathrm{v}_{\text {flow }}\right.$ tot $\left.=\mathrm{v}_{\text {flow } 01}+\mathrm{v}_{\text {flow } 02} ; \mathrm{v}_{\text {flow } 01}=\mathrm{v}_{\text {flow } 02}\right)$ indicated. Both solutions were mixed in a T-piece and then pumped through a preheated $28 \mathrm{~mL}$ tube reactor (PTFE tube, outer diameter 1/8", inner diameter 1/16") at the temperature indicated. At the end of the reactor, the reaction mixture was pressurized using a ZAIPUT back pressure regulator BPR (set to $p=5 \mathrm{bar}$ ) and then collected in a $50 \mathrm{~mL}$ collection flask containing a stirred solution of $\mathrm{HCl}(1 \mathrm{M}$, aq., $10 \mathrm{~mL})$. The mixture was diluted with EtOAc $(20 \mathrm{~mL})$. The aqueous layer was separated and extracted with EtOAc $(2 \times 20 \mathrm{~mL})$. The combined organic layers were washed with $\mathrm{NaHCO}_{3}$ (sat. aq., $25 \mathrm{~mL}$ ), $\mathrm{NaCl}$ (sat. aq., $25 \mathrm{~mL}$ ), dried $\left(\mathrm{Na}_{2} \mathrm{SO}_{4}\right)$, filtered, and concentrated under reduced pressure. Flash column chromatography (cyclohexane/EtOAc 1:2) gave cyclobutene $\mathbf{8}$ as a yellow oil.

Yields are based on the actual reacted reagent solutions loaded on SL01 $(2.0 \mathrm{~mL} ; \alpha$-chlorinated sulfoxide 7, $10.0 \mathrm{mg}, 38.0 \mu \mathrm{mol}, 1.0$ equiv) and $\mathbf{S L O 2}$ (2.0 mL; KOtBu, $21.6 \mathrm{mg}, 192 \mu \mathrm{mol}, 5.0$ equiv).

\section{Ramberg Bäcklund rearrangement of $\alpha$-chlorinated sulfoxide 7 under optimized conditions in}

\section{flow}

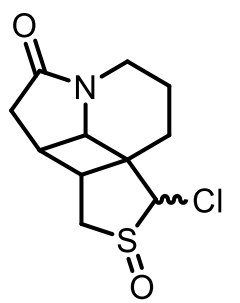

7 (1 equiv) in THF

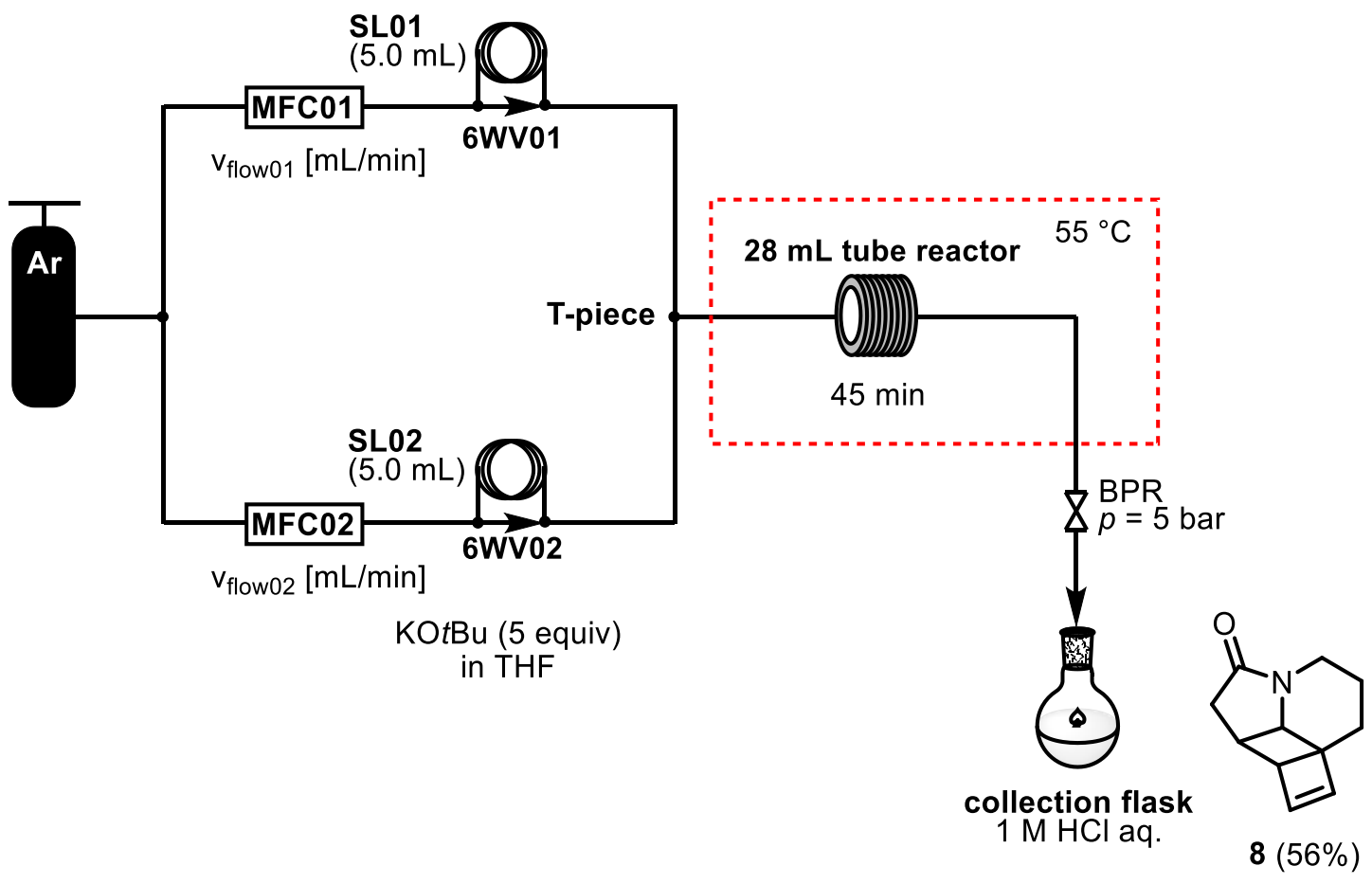


In a dry Schlenk tube, $\alpha$-chlorinated sulfoxide $7(30.0 \mathrm{mg}, 115 \mu \mathrm{mol})$ was placed and the tube was evacuated and backfilled with argon (3x). Then, anhydrous and degassed THF (6.0 mL) was added. The resulting solution was loaded on sample loop SL01 (V = 5.0 mL, FEP tube, outer diameter 1/16", inner diameter 1/32"). In another dry Schlenk tube, $\mathrm{KO} t \mathrm{Bu}(64.8 \mathrm{mg}, 577 \mu \mathrm{mol})$ was placed and the tube was evacuated and backfilled with argon $(3 \mathrm{x})$. Then, anhydrous and degassed THF $(6.0 \mathrm{~mL})$ was added. The resulting solution was loaded on sample loop SL02 (V = 5.0 mL, FEP tube, outer diameter 1/16", inner diameter 1/32"). Then, both solutions were driven by an argon flow using MFC01 ( $\mathrm{v}_{\text {flow01 }}=0.2 \mathrm{~mL} / \mathrm{min}$ ) and MFC02 $\left(\mathrm{v}_{\text {flow01 }}=0.2 \mathrm{~mL} / \mathrm{min}\right)$. Both solutions were mixed in a T-piece and then pumped through a preheated $28 \mathrm{~mL}$ tube reactor (PTFE tube, outer diameter $1 / 8$ ", inner diameter $1 / 16$ ") at $55^{\circ} \mathrm{C}$ for $45 \mathrm{~min}$. At the end of the reactor, the reaction mixture was pressurized using a ZAIPUT back pressure regulator BPR (set to $p=5$ bar) and then collected in a $\mathbf{5 0 ~} \mathbf{~ m L}$ Erlenmeyer flask containing a stirred solution of $\mathrm{HCl}(1 \mathrm{M}$, aq., $10 \mathrm{~mL})$. The mixture was diluted with EtOAc $(20 \mathrm{~mL})$. The aqueous layer was separated and extracted with EtOAc $(2 \times 20 \mathrm{~mL})$. The combined organic layers were washed with $\mathrm{NaHCO}_{3}$ (sat. aq., $25 \mathrm{~mL}$ ), $\mathrm{NaCl}$ (sat. aq., $25 \mathrm{~mL}$ ), dried $\left(\mathrm{Na}_{2} \mathrm{SO}_{4}\right)$, filtered and concentrated under reduced pressure. Flash column chromatography (cyclohexane/EtOAc 1:2) gave cyclobutene 8 (9.50 mg, $54.2 \mu \mathrm{mol}, 56 \%)$ as a yellow oil.

The yield is based on the actual reacted reagent solutions loaded on SL01 $(5.0 \mathrm{~mL} ; \alpha$-chlorinated sulfoxide 7 (25.0 mg, $96.0 \mu \mathrm{mol}, 1.0$ equiv)) and SL02 (5.0 mL; KOtBu (54.0 mg, $481 \mu \mathrm{mol}$, 5.0 equiv)).

$R_{\mathrm{f}}=0.40$ (cyclohexane/EtOAc 1:2).

${ }^{1} \mathrm{H} \mathrm{NMR}\left(600 \mathrm{MHz}, \mathrm{CDCl}_{3}\right) \delta[\mathrm{ppm}]=6.49(\mathrm{~d}, J=2.5 \mathrm{~Hz}, 1 \mathrm{H}), 6.09(\mathrm{t}, J=2.9 \mathrm{~Hz}, 1 \mathrm{H}), 4.09$ (ddt, $J=13.0,4.2,1.8 \mathrm{~Hz}, 1 \mathrm{H}), 3.93(\mathrm{~d}, J=4.6 \mathrm{~Hz}, 1 \mathrm{H}), 2.90(\mathrm{dt}, J=3.5,1.8 \mathrm{~Hz}, 1 \mathrm{H}), 2.71(\mathrm{dd}, J=17.4$, $8.2 \mathrm{~Hz}, 1 \mathrm{H}), 2.60(\mathrm{td}, J=12.4,3.1 \mathrm{~Hz}, 1 \mathrm{H}), 2.49(\mathrm{ddd}, J=7.6,4.7,1.8 \mathrm{~Hz}, 1 \mathrm{H}), 2.27(\mathrm{~d}, J=17.4 \mathrm{~Hz}$, $1 \mathrm{H}), 1.84(\mathrm{ddd}, J=15.0,12.3,5.6 \mathrm{~Hz}, 1 \mathrm{H}), 1.75(\mathrm{ddt}, J=15.0,4.4,1.9 \mathrm{~Hz}, 1 \mathrm{H}), 1.61-1.47(\mathrm{~m}, 2 \mathrm{H})$. ${ }^{13} \mathrm{C}\left\{{ }^{1} \mathrm{H}\right\} \mathrm{NMR}\left(151 \mathrm{MHz}, \mathrm{CDCl}_{3}\right) \delta[\mathrm{ppm}]=175.0,143.8,138.8,59.0,55.9,52.4,39.9,36.5,34.6,27.2$, 23.2 .

The spectroscopic data are consistent with those reported in the literature. ${ }^{[2]}$ 


\subsection{C-H Chlorination of (+)-Sclareolide in Flow}

Screening of different reaction conditions for the $\mathbf{C}-\mathrm{H}$ chlorination of (+)-sclareolide (9)

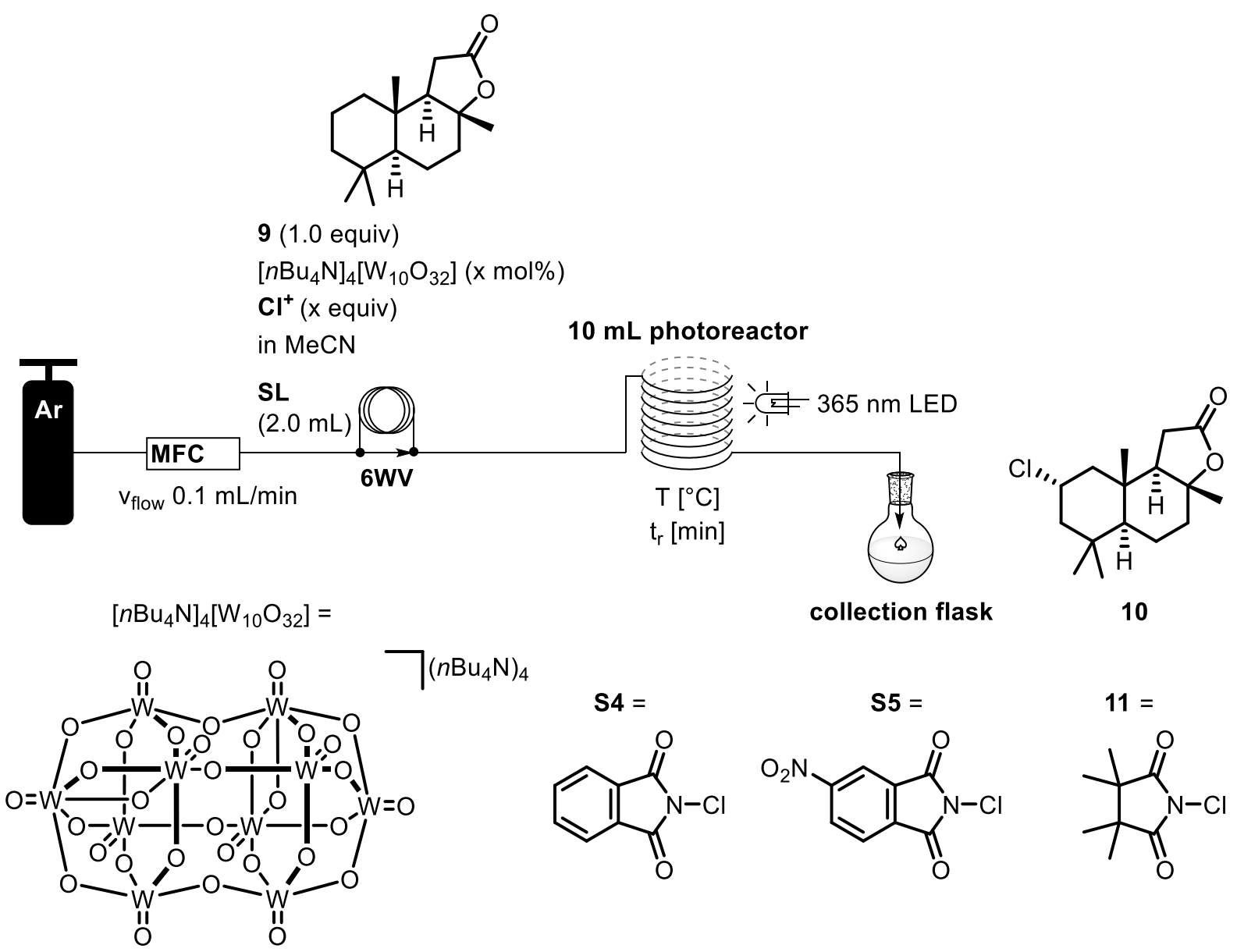

Table S4: Screening of reaction conditions.

\begin{tabular}{|c|c|c|c|c|c|c|c|}
\hline Entry & $\mathbf{C l}^{+}$(equiv) & $\mathbf{m o l} \%$ & conc. $(\mathbf{9})$ & $\mathbf{v}_{\text {flow }}[\mathbf{m i n} / \mathbf{m L}]^{[\mathbf{a}]}$ & $\mathbf{T}\left[{ }^{\circ} \mathbf{C}\right]$ & $\mathbf{t}_{\mathbf{r}}[\mathbf{m i n}]$ & $\mathbf{Y i e l d}^{[\mathbf{b}]}$ \\
\hline $\mathbf{1}$ & NCS (1.2) & 5 & $0.1 \mathrm{M}$ & 0.1 & 30 & 100 & $11 \%$ \\
\hline $\mathbf{2}$ & NCS (1.2) & 5 & $0.2 \mathrm{M}$ & 0.1 & 30 & 100 & $17 \%$ \\
\hline $\mathbf{3}$ & NCS (1.5) & 7 & $0.2 \mathrm{M}$ & 0.1 & 30 & 100 & $24 \%$ \\
\hline $\mathbf{4}$ & $\mathrm{S} 4(1.5)$ & 10 & $0.2 \mathrm{M}$ & 0.1 & 30 & 100 & $19 \%$ \\
\hline $\mathbf{5}$ & $\mathrm{S} 5(1.5)^{[\mathrm{c}]}$ & 10 & $0.2 \mathrm{M}$ & 0.1 & 30 & 100 & $6 \%$ \\
\hline $\mathbf{6}$ & $11(1.5)$ & 10 & $0.2 \mathrm{M}$ & 0.1 & 30 & 100 & $29 \%$ \\
\hline $\mathbf{7}^{[\mathbf{d}]}$ & $11(1.5)$ & 10 & $0.2 \mathrm{M}$ & 0.1 & 30 & 100 & $5 \%$ \\
\hline $\mathbf{8}$ & $11(1.5)$ & 10 & $0.2 \mathrm{M}$ & 0.2 & 30 & 50 & $20 \%$ \\
\hline $\mathbf{9}$ & $\mathbf{1 1}(\mathbf{1 . 5})$ & $\mathbf{1 0}$ & $\mathbf{0 . 2} \mathbf{M}$ & $\mathbf{0 . 1}$ & $\mathbf{1 0}$ & $\mathbf{1 0 0}$ & $\mathbf{4 1 \%}$ \\
\hline
\end{tabular}

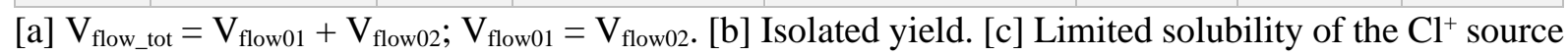
in MeCN. [d] 2-Methyl-2-butene (0.5 equiv) was used as additive. 
In a vial, $2.5 \mathrm{~mL}$ of a solution of (+)-sclareolide (9, 1.0 equiv), $\left[n \mathrm{Bu}_{4} \mathrm{~N}\right]_{4}\left[\mathrm{~W}_{10} \mathrm{O}_{32}\right]$ and the $\mathbf{C l}^{+}$source in MeCN (HPLC grade) were prepared. The solution was swirled, to achieve homogeneity and, if necessary, filtered through a plug of cotton in a Pasteur pipette. Then, the solution was purged with argon for $5 \mathrm{~min}$ and loaded on the sample loop SL (V = 2.0 mL; FEP tube, outer diameter 1/16", inner diameter 1/32"). Then, the solution was driven by an argon flow using the MFC with the flow rate $\mathrm{v}_{\text {flow }}$ indicated through a $\mathbf{1 0} \mathbf{~ m L}$ photoreactor (FEP tube, outer diameter 1/16", inner diameter 1/32") at the temperature indicated. At the end of the reactor, the reaction mixture was collected in a collection flask, diluted with EtOAc $(10 \mathrm{~mL})$ and loaded on Celite ${ }^{\circledR}$. MPLC (cyclohexane/EtOAc 19:1 to 9:1) gave the title compound $\mathbf{1 0}$ as a colorless solid. 


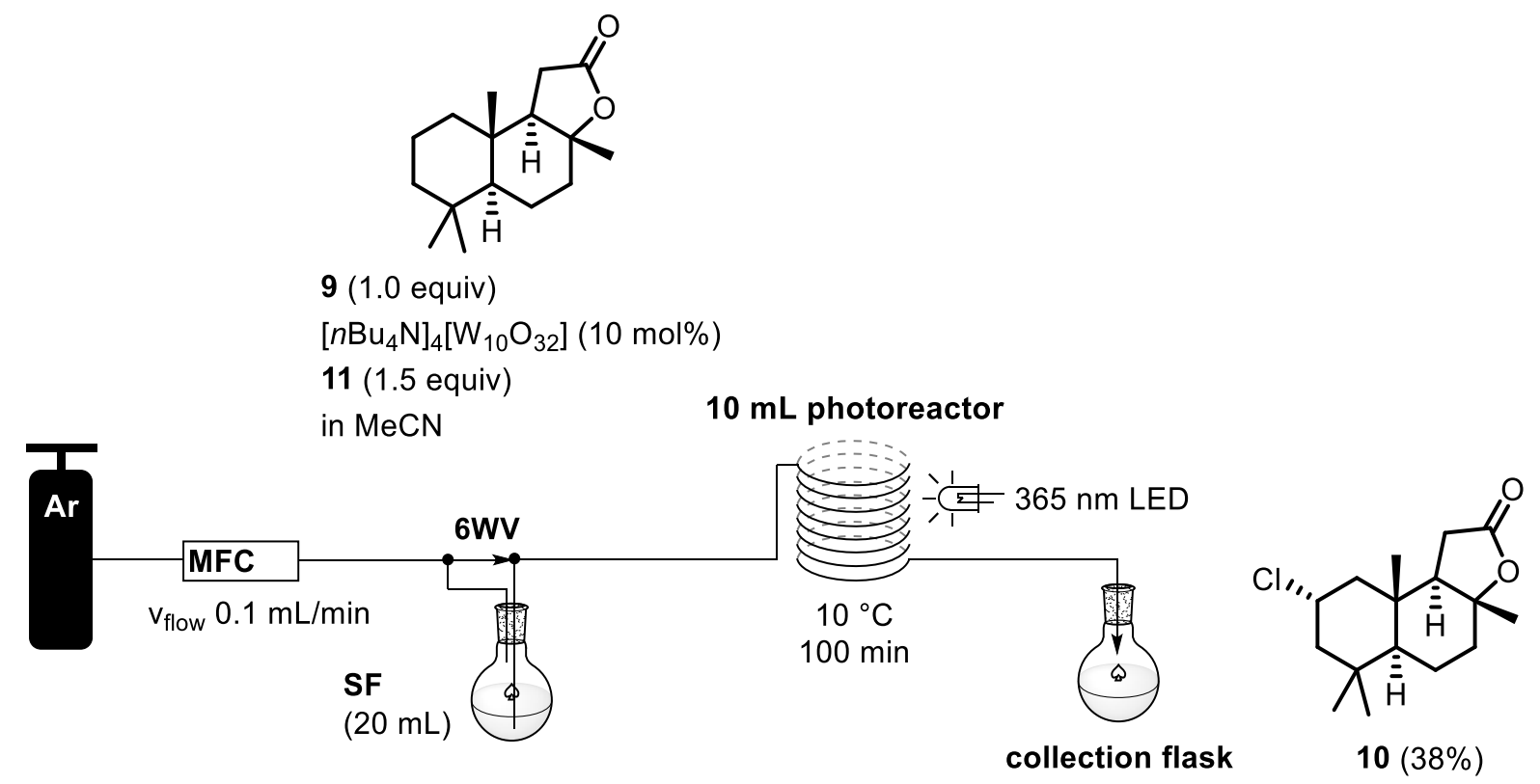

In a vial, $20 \mathrm{~mL}$ of a solution of (+)-sclareolide $\left(9,1.00 \mathrm{~g}, 3.99 \mathrm{mmol}, 1.0\right.$ equiv), $[\mathrm{nBu} 4 \mathrm{~N}]_{4}\left[\mathrm{~W}_{10} \mathrm{O}_{32}\right]$ and 1-chloro-3,3,4,4-tetramethylpyrrolidine-2,5-dione (11, $1.14 \mathrm{~g}, 5.99 \mathrm{mmol}, 1.5$ equiv) in $\mathrm{MeCN}$ (HPLC grade) was prepared. The solution was swirled to achieve homogeneity and filtered through a plug of cotton using a Pasteur pipette in a $25 \mathrm{~mL}$ sample flask $\mathbf{S F}(\mathrm{V}=25 \mathrm{~mL})$. The sample flask $\mathbf{S F}$ was sealed with a rubber septum, purged with argon for $5 \mathrm{~min}$ and connected with the 6-way valve $6 \mathrm{WV}$ using two connection tubes with cannulas. Then, the solution was driven by an argon flow using the MFC ( $\mathrm{v}_{\text {flow }}=0.1 \mathrm{~mL} / \mathrm{min}$ ) through a $\mathbf{1 0} \mathbf{~ m L}$ photoreactor (FEP tube, outer diameter 1/16", inner diameter $1 / 32 ")$ at $10^{\circ} \mathrm{C}$. At the end of the reactor, the reaction mixture was collected in a collection flask, diluted with MeCN (50 mL), and loaded onto Celite ${ }^{\circledR}$. MPLC (cyclohexane/EtOAc 19:1 to 9:1) gave compound $\mathbf{1 0}$ (436 mg, $1.53 \mathrm{mmol}, 38 \%)$ as a colorless solid.

$\mathrm{R}_{\mathrm{f}}=0.30$ (cyclohexane/EtOAc 7:1).

${ }^{1} \mathrm{H}$ NMR $\left(600 \mathrm{MHz}, \mathrm{CDCl}_{3}\right) \delta[\mathrm{ppm}]=4.23(\mathrm{tt}, J=12.2,4.2 \mathrm{~Hz}, 1 \mathrm{H}), 2.43(\mathrm{dd}, J=16.2,14.7 \mathrm{~Hz}, 1 \mathrm{H})$, $2.28(\mathrm{dd}, J=16.2,6.5 \mathrm{~Hz}, 1 \mathrm{H}), 2.10(\mathrm{dt}, J=12.0,3.3 \mathrm{~Hz}, 1 \mathrm{H}), 2.05-1.97(\mathrm{~m}, 3 \mathrm{H}), 1.93-1.87(\mathrm{~m}$, $1 \mathrm{H}), 1.74-1.67(\mathrm{~m}, 1 \mathrm{H}), 1.53(\mathrm{t}, J=12.7 \mathrm{~Hz}, 1 \mathrm{H}), 1.41-1.34(\mathrm{~m}, 2 \mathrm{H}), 1.33(\mathrm{~d}, J=1.0 \mathrm{~Hz}, 3 \mathrm{H}), 0.97$ (s, 3H), 0.96 (s, 3H), 0.89 (s, 3H).

${ }^{13} \mathrm{C} \mathrm{NMR}\left(151 \mathrm{MHz}, \mathrm{CDCl}_{3}\right) \delta[\mathrm{ppm}]=176.3 \mathrm{z}, 86.0,58.7,55.9,54.0,52.5,49.8,38.5,38.3,36.0,33.0$, 28.7, 21.8, 21.5, 20.3, 15.9.

The spectroscopic data are consistent with those reported in the literature. ${ }^{[13]}$ 


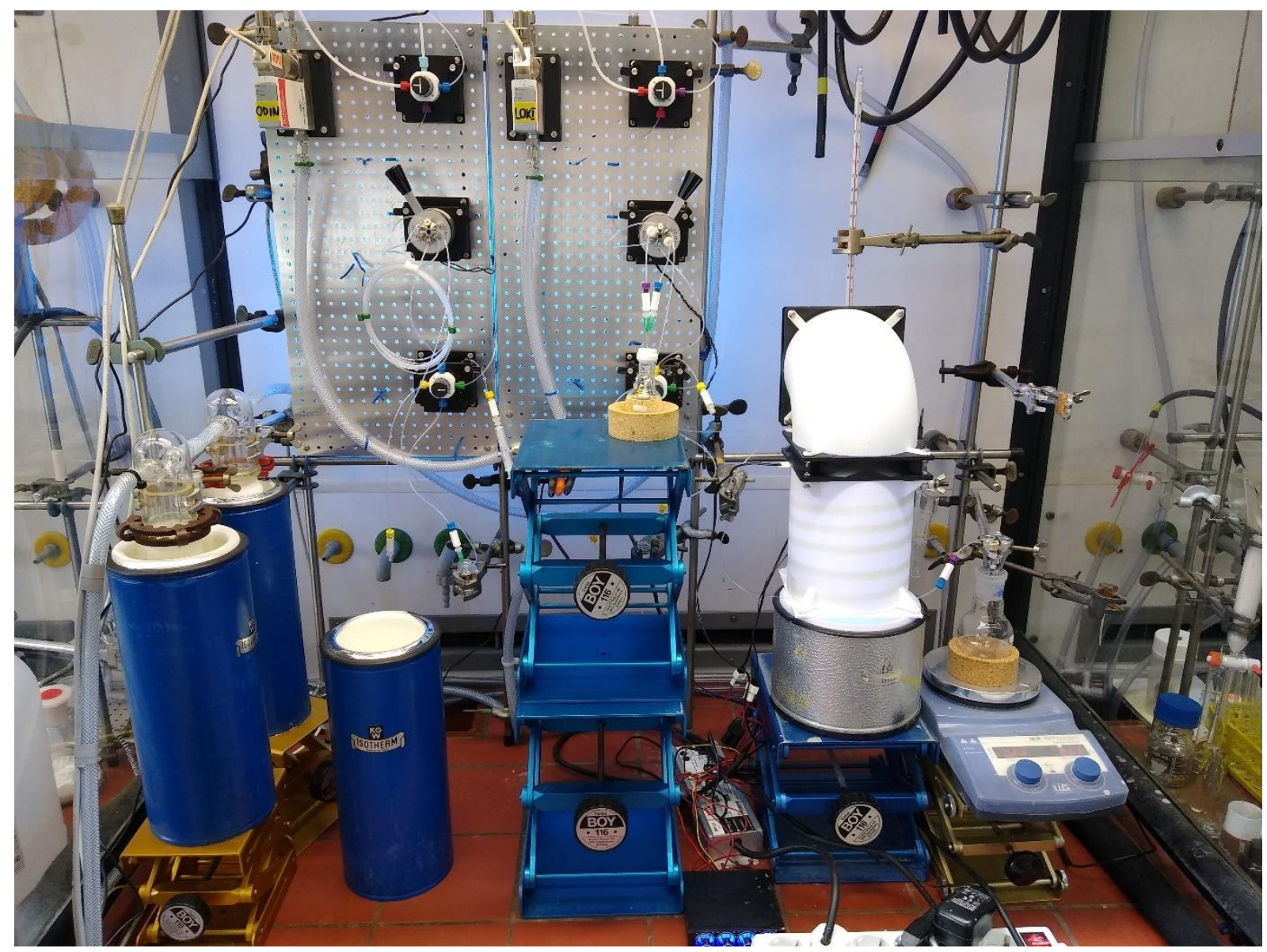

The flow setup for the photochemical gram scale $\mathrm{C}-\mathrm{H}$ chlorination of (+)-sclareolide (9).

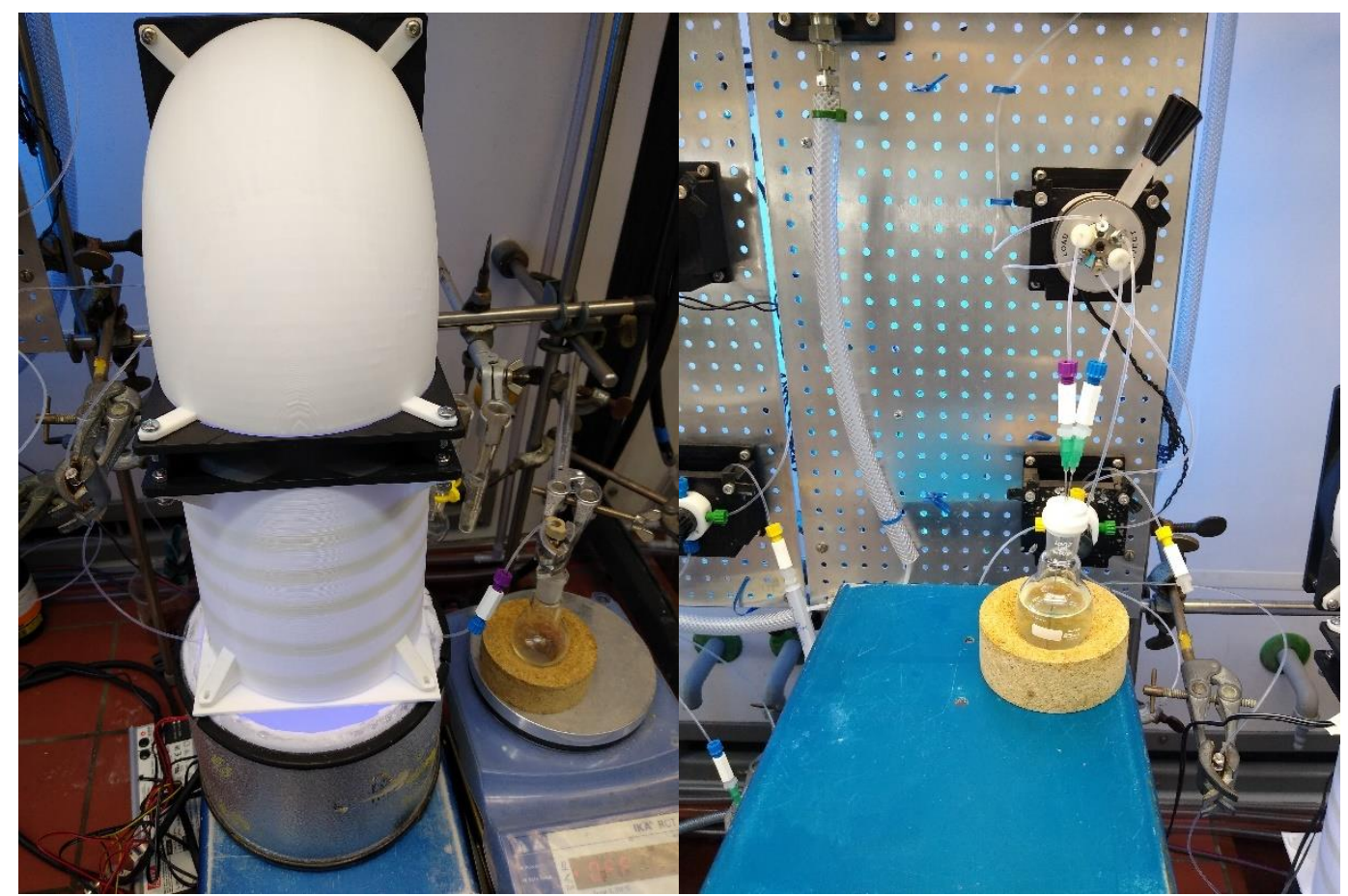

Left: The photoreaction was cooled by placing the photoreactor on a Dewar with liquid nitrogen. The evaporating nitrogen is drawn by two $140 \mathrm{~mm}$ PC fans through the photoreactor. The temperature is measured with a thermometer on the outlet of the photoreactor. By controlling the fan speed of the fans 
with a fan control, the temperature in the photoreactor can be controlled. Right: A $25 \mathrm{~mL}$ round bottom flask is used a sample flask equipped with a septum and canulas to provide a connection between the flask and the HPLC injection valve.

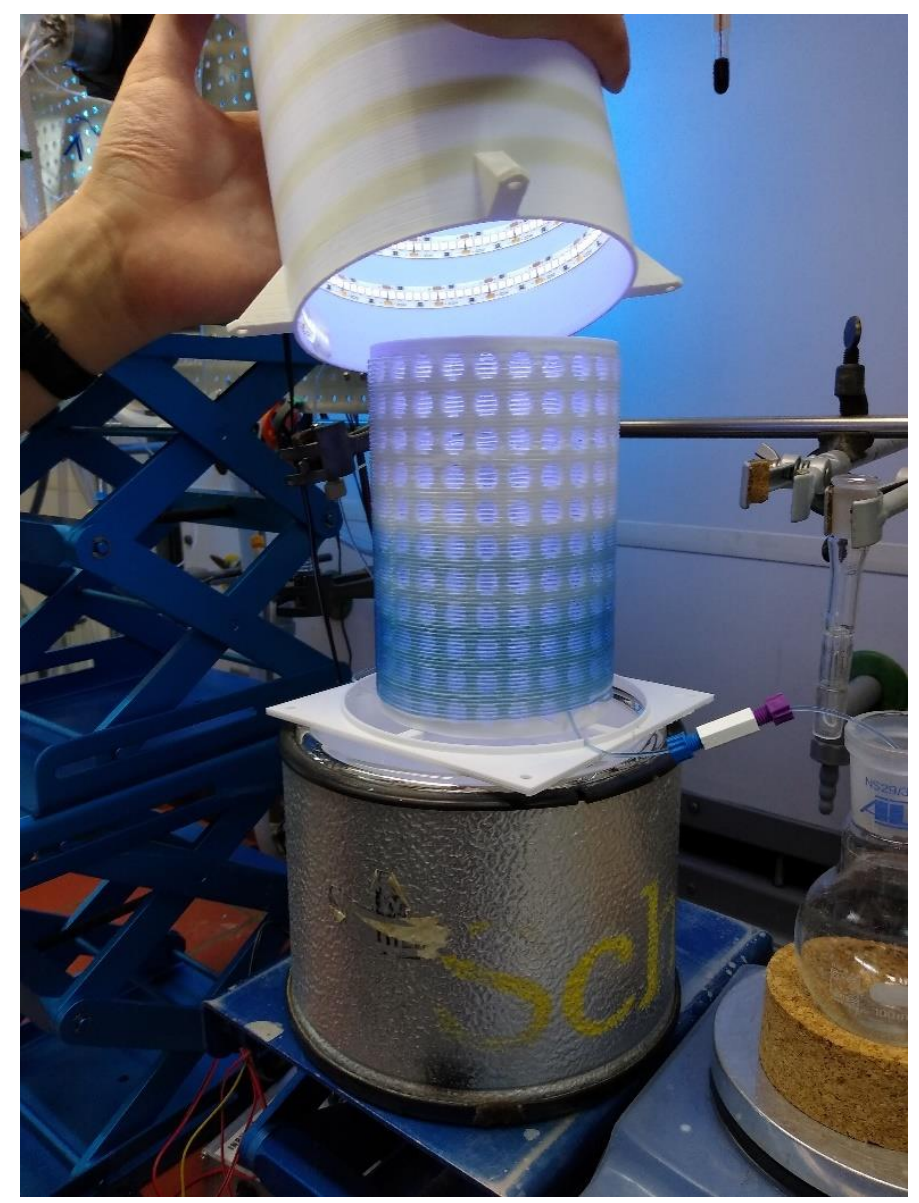

Over the course of the reaction (start on the top of the photoreactor, end on the bottom of the photoreactor), the chlorinating agent is continuously consumed. Thus, at the end of the reaction, the decatungstate deep blue anion $\mathrm{H}^{+}\left[\mathrm{W}_{10} \mathrm{O}_{32}\right]^{5-}$ is not reoxidized to the colorless decatungstate $\left[\mathrm{W}_{10} \mathrm{O}_{32}\right]^{4-}$ anymore, resulting in a blue reaction mixture at the end of the reaction. 


\section{NMR Spectra of Synthesized Compounds}

ํํำ

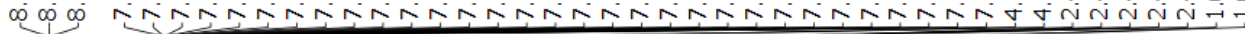<smiles>CC(C)C(=O)NCc1ccccc1</smiles>

3

${ }^{1} \mathrm{H}$ NMR (700 MHz, DMSO-d $\mathrm{d}_{6}$ )

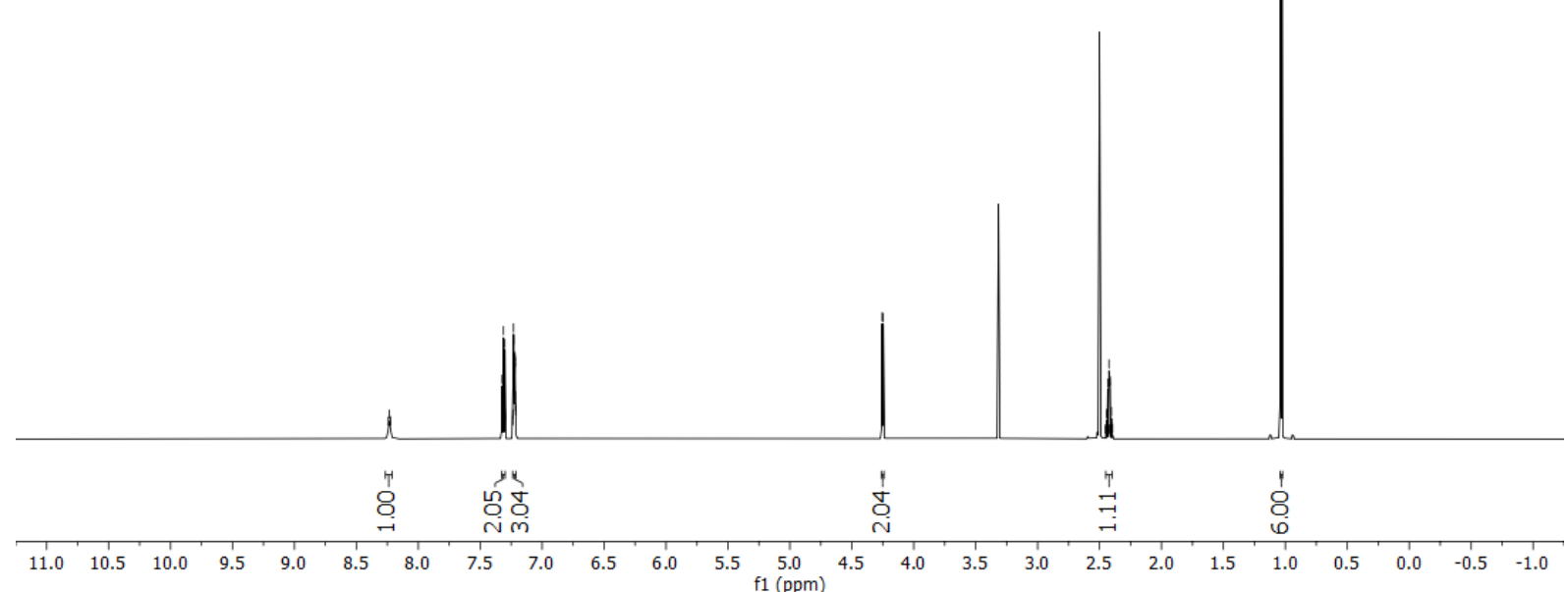<smiles>CC(C)C(=O)NCc1ccccc1</smiles>

3

${ }^{13} \mathrm{C}\left\{{ }^{1} \mathrm{H}\right\}$ NMR (176 MHz, DMSO- $\mathrm{d}_{6}$ )

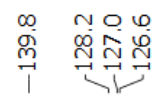

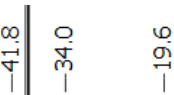

$10 \quad 200 \quad 190$ $\begin{array}{lllll}90 & 180 & 170 & 160 & 1\end{array}$ $50 \quad 140 \quad 130$ 130 $10 \begin{gathered}100 \\ \mathrm{f} 1(\mathrm{ppm})\end{gathered}$ 


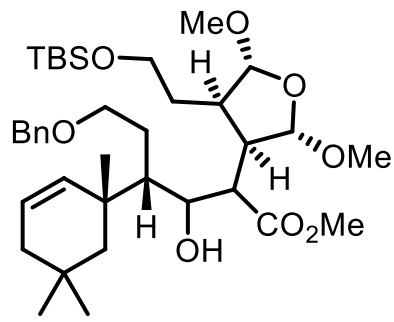

6

${ }^{1} \mathrm{H}$ NMR $\left(700 \mathrm{MHz}, \mathrm{CDCl}_{3}\right)$
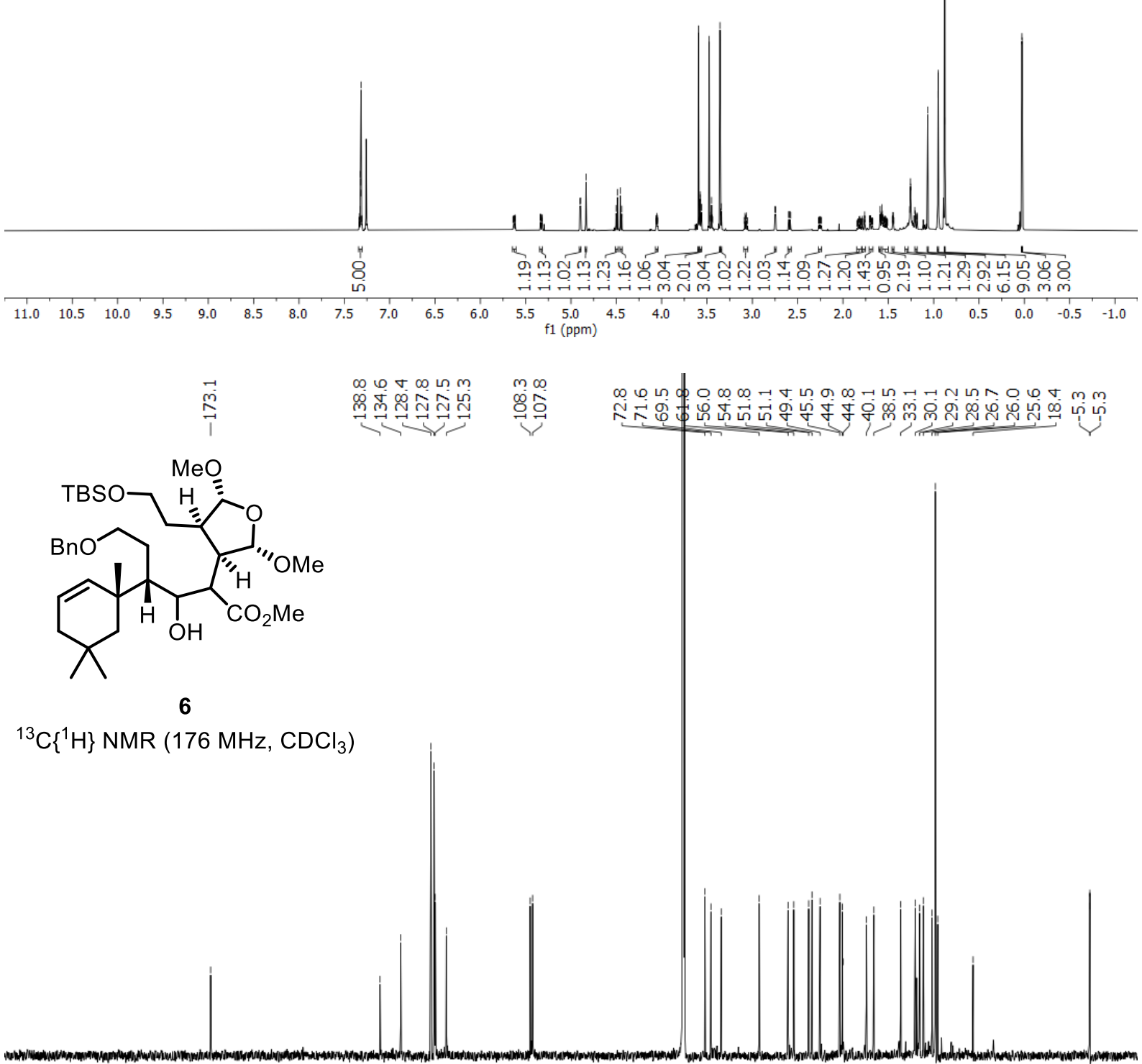

$\begin{array}{lllllllllllllllllllllll}210 & 200 & 190 & 180 & 170 & 160 & 150 & 140 & 130 & 120 & 110 & 100 & 90 & 80 & 70 & 60 & 50 & 40 & 30 & 20 & 10 & 0 & -10\end{array}$ 
<smiles>O=C1CC2C3C=CC4(CCCN1C4)C32</smiles>

8

${ }^{1} \mathrm{H}$ NMR $\left(600 \mathrm{MHz}, \mathrm{CDCl}_{3}\right)$

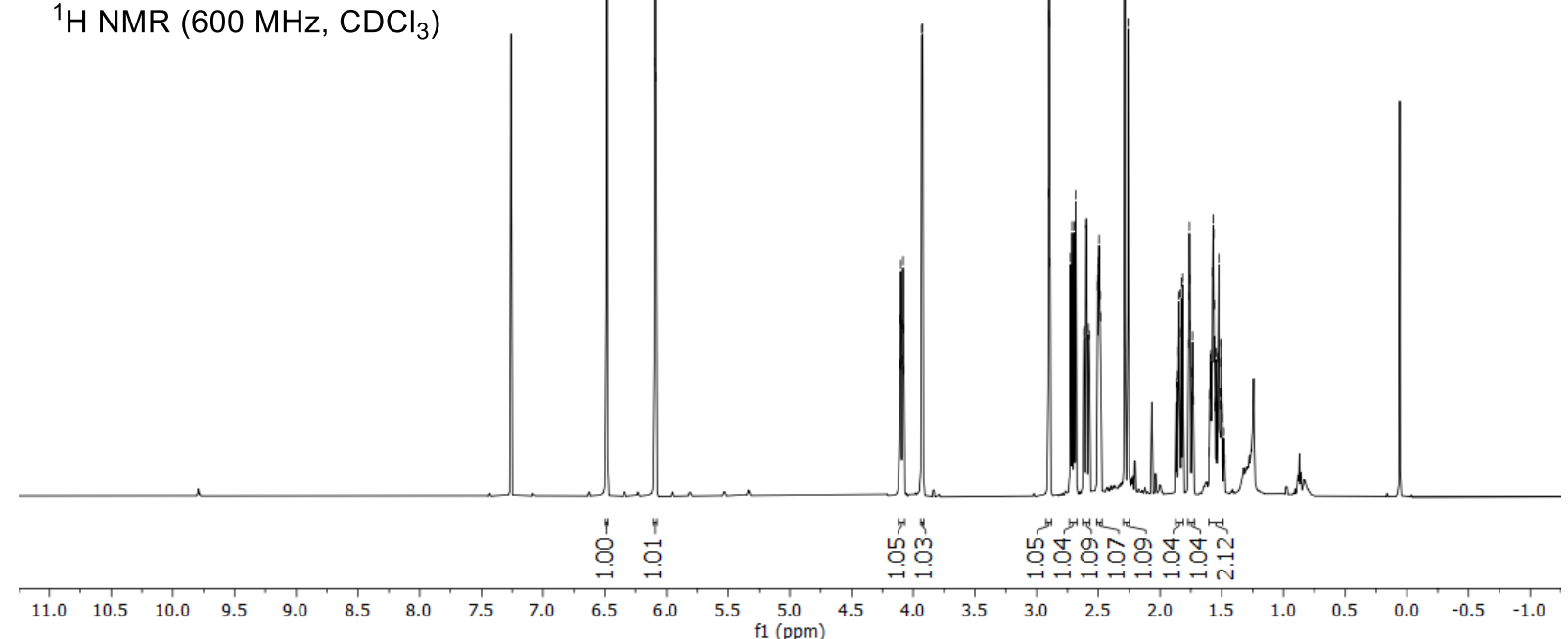

बi்

1. mm<smiles>O=C1CC2C3C=CC4(CCCN1C4)C32</smiles>

8

${ }^{13} \mathrm{C}\left\{{ }^{1} \mathrm{H}\right\}$ NMR

$\left(151 \mathrm{MHz}, \mathrm{CDCl}_{3}\right.$ )

$\begin{array}{llllllllllll}210 & 200 & 190 & 180 & 170 & 160 & 150 & 140 & 130 & 120 & 110 & 100 \\ \mathrm{f} 1(\mathrm{ppm})\end{array}$ 
<smiles>CC1(C)C[C@H](Cl)C[C@]2(C)[C@H]3CC[C@]4(C)OC(=O)C[C@H]4[C@]3(C)[C@H]12</smiles>

10

${ }^{1} \mathrm{H}$ NMR $\left(600 \mathrm{MHz}, \mathrm{CDCl}_{3}\right)$

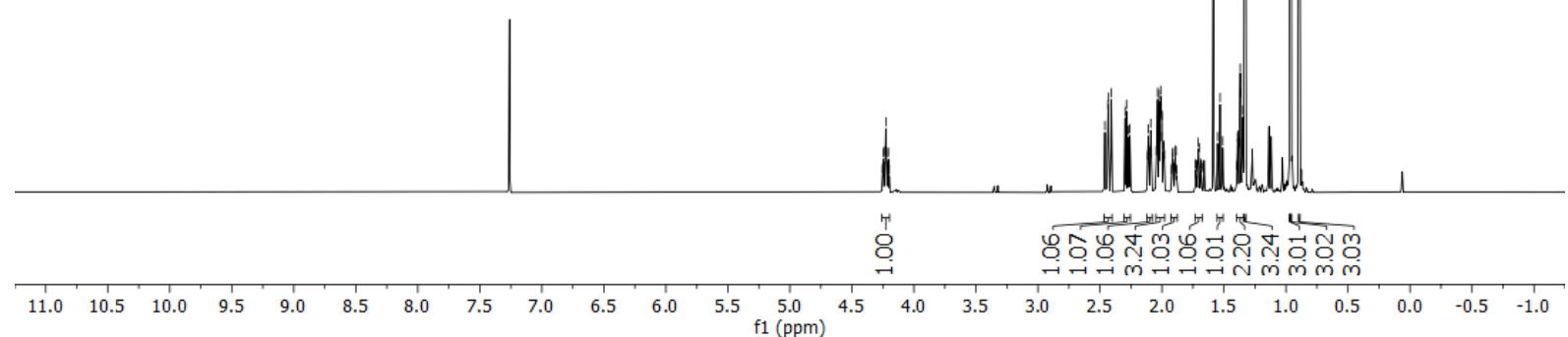

$\stackrel{m}{\stackrel{m}{\circ}}$

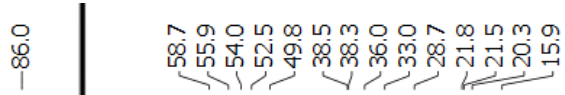<smiles>CC1(C)C[C@H](Cl)C[C@]2(C)[C@H]1CC[C@]1(C)OC(=O)C[C@H]12</smiles>

10

${ }^{13} \mathrm{C}\left\{{ }^{1} \mathrm{H}\right\}$ NMR $\left(151 \mathrm{MHz}, \mathrm{CDCl}_{3}\right)$

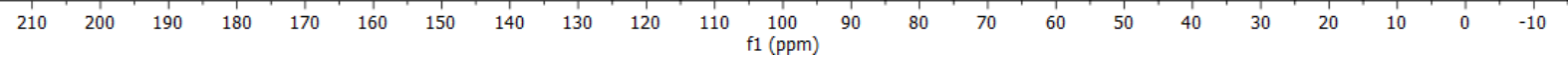
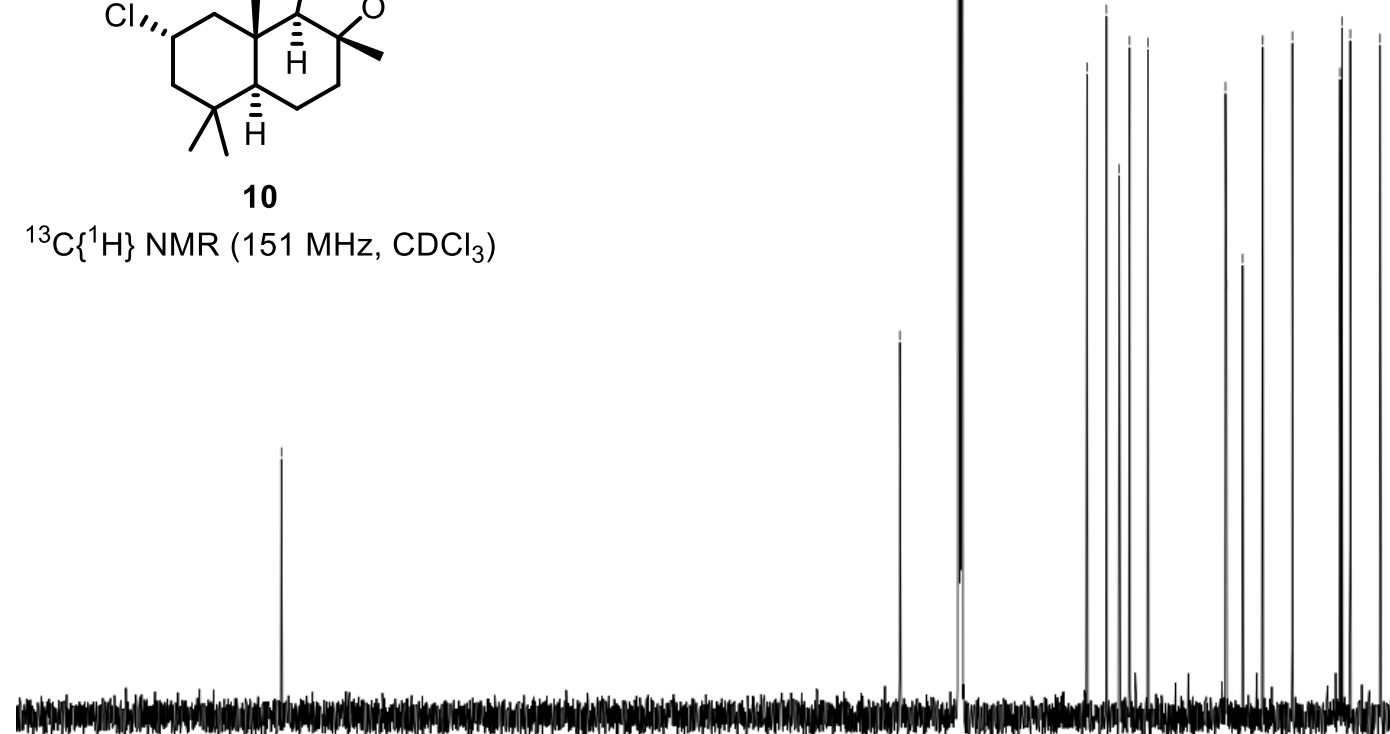


\section{References}

[1] Siemon, T.; Steinhauer, S.; Christmann, M. Synthesis of (+)-Darwinolide, a Biofilm-Penetrating Anti-MRSA Agent. Angew. Chem. Int. Ed. 2019, 58, 1120-1122; Angew. Chem. 2019, 131, 11321134.

[2] Reuß, F.; Heretsch, P. Synthesis of Aspidodispermine via Pericyclic Framework Reconstruction. Org. Lett. 2020, 22, 3956-3959.

[3] Protti, S.; Ravelli, D.; Fagnoni, M.; Albini, A. Solar light-driven photocatalyzed alkylations. Chemistry on the window ledge. Chem. Commun. 2009, 7351-7353.

[4] Ponath, S.; Menger, M.; Grothues, L.; Weber, M.; Lentz, D.; Strohmann, C.; Christmann, M. Mechanistic Studies on the Organocatalytic $\alpha$-Chlorination of Aldehydes: The Role and Nature of OffCycle Intermediates. Angew. Chem. Int. Ed. 2018, 57, 11683-11687; Angew. Chem. 2018, 130, $11857-$ 11861.

[5] Britton, J.; Jamison, T. F. The assembly and use of continuous flow systems for chemical synthesis. Nature Prot. 2017, 12, 2423-2446.

[6] Williams, J. D.; Kerr, W. J.; Leach, S. G.; Lindsay, D. M. A Practical and General Amidation Method from Isocyanates Enabled by Flow Technology. Angew. Chem. Int. Ed. 2018, 57, 12126-12130; Angew. Chem. 2018, 130, 12302-12306.

[7] https://www.buerkert.de/de/content/download/9318/335016/file/DE_Bestaendig_D.pdf (09.11.2020)

[8] Harding, M. J.; Brady, S.; O’Connor, H.; Lopez-Rodriguez, R.; Edwards, M. D.; Tracy, S.;

Dowling, D.; Gibson, G.; Girard, K. P.; Ferguson, S. 3D printing of PEEK reactors for flow chemistry and continuous chemical processing. React. Chem. Eng. 2020, 5, 728-735.

[9] Burgmayer, S. J. N. Use of a titanium metallocene as a colorimetric indicator for learning inert atmosphere techniques. J. Chem. Educ. 1998, 75, 460.

[10] Yeung, D.; Penafiel, J.; Zijlstra, H. S.; McIndoe, J. S. Oxidation of Titanocene(III): The Deceptive Simplicity of a Color Change. Inorg. Chem. 2018, 57, 457-461.

[11] Koros, W. J.; Wang, J.; Felder, R. M. Oxygen Permeation Through FEP Teflon and Kapton Polyimide J. Appl. Polym. Sci. 1981, 26, 2805-2809.

[12] Williams, D. B. G.; Lawton, M. Drying of Organic Solvents: Quantitative Evaluation of the Efficiency of Several Desiccants. J. Org. Chem. 2010, 75, 8351-8354.

[13] Quinn, R. K.; Könst, Z. A.; Michalak, S. E.; Schmidt, Y.; Szklarski, A. R.; Flores, A. R.; Nam, S.; Horne, D. A.; Vanderwal, C. D.; Alexanian, E. J. Site-Selective Aliphatic C-H Chlorination Using $N$ Chloroamides Enables a Synthesis of Chlorolissoclimide. J. Am. Chem. Soc. 2016, 138, 696-702. 